\title{
Cu-Based Electrocatalysts for Carbon Dioxide Conversion to Value-Added Chemicals
}

Qingyang Li

ql0012@mix.wvu.edu

Follow this and additional works at: https://researchrepository.wvu.edu/etd

Part of the Catalysis and Reaction Engineering Commons

\section{Recommended Citation}

Li, Qingyang, "Cu-Based Electrocatalysts for Carbon Dioxide Conversion to Value-Added Chemicals" (2020). Graduate Theses, Dissertations, and Problem Reports. 7744.

https://researchrepository.wvu.edu/etd/7744

This Problem/Project Report is protected by copyright and/or related rights. It has been brought to you by the The Research Repository @ WVU with permission from the rights-holder(s). You are free to use this Problem/Project Report in any way that is permitted by the copyright and related rights legislation that applies to your use. For other uses you must obtain permission from the rights-holder(s) directly, unless additional rights are indicated by a Creative Commons license in the record and/ or on the work itself. This Problem/Project Report has been accepted for inclusion in WVU Graduate Theses, Dissertations, and Problem Reports collection by an authorized administrator of The Research Repository @ WVU. For more information, please contact researchrepository@mail.wvu.edu. 


\title{
Cu-Based Electrocatalysts for Carbon Dioxide Conversion to Value-Added Chemicals
}

\author{
Qingyang Li
}

\author{
Problem Report submitted to \\ the Statler College of Engineering and Mineral Resources \\ at West Virginia University \\ in partial fulfillment of the requirements for the degree of \\ Master of Science \\ in \\ Chemical Engineering
}

Jianli (John) Hu, Ph.D., Committee Chair

Charter Stinespring, Ph.D.

Debangsu Bhattacharyya, Ph.D.

Department of Chemical and Biomedical Engineering

Morgantown, West Virginia

2020

Keywords: Carbon Dioxide; Cu-based Catalyst; Electrocatalysis; $\mathrm{C}_{2}$ Products; Efficiency and Selectivity; Pathway and Mechanism

Copyright 2020 Qingyang Li 


\section{ABSTRACT \\ Cu-Based Electrocatalysts for Carbon Dioxide Conversion to Value-Added Chemicals \\ Qingyang Li}

Massive usage of fossil fuel has being causing considerable emission of $\mathrm{CO}_{2}$, which increases the temperature of the planet and greatly threaten human living environment, such as soil degradation, lower agricultural productivity, desertification, less biodiversity, fresh-water reduction, ocean acidification, ozone sphere destruction, etc. A number of technologies are being developed to reduce the $\mathrm{CO}_{2}$ amount, however, all existing technologies except utilizing $\mathrm{CO}_{2}$ as a feedstock, are hardly to essentially close the anthropogenic carbon loop. Currently, considering the economy and operability, electroreduction of $\mathrm{CO}_{2}$ seems to be the most promising strategy to convert $\mathrm{CO}_{2}$ to high value chemicals.

During the process of $\mathrm{CO}_{2}$ electroreduction, $\mathrm{Cu}$-based catalysts become the most popular because they meet the requirements of activating $\mathrm{CO}_{2}$ and intermediates, suppression of hydrogen formation, and electron transportation. Herein, the factors that affect the $\mathrm{Cu}$-based catalysts' performance, including morphology, particle sizes, presence of atomic-scale defects, surface roughness, residual oxygen atoms, and so on, have been surveyed and discussed. In addition, the most probable reaction pathways to synthesize the desirable $\mathrm{C}_{2}$ products under different situation have been identified, which follow $* \mathrm{CO}+* \mathrm{CO} \rightarrow * \mathrm{COCO},{ }^{*} \mathrm{CO}+{ }^{*} \mathrm{COH} \rightarrow$ $\mathrm{C}_{2},{ }^{*} \mathrm{CO}+{ }^{*} \mathrm{CHO} \rightarrow \mathrm{C}_{2}$ and ${ }^{*} \mathrm{COH} \rightarrow{ }^{*} \mathrm{CH}_{2} \rightarrow \mathrm{C}_{2}$. This report will benefit the design and optimization of $\mathrm{Cu}$-based catalysts for the conversion of $\mathrm{CO}_{2}$ to high value chemicals with high efficiency and selectivity. 


\section{Acknowledgements}

I have been encouraged by many people along the journey of my MS studies over the past three years.

I would like to first express my sincerest gratitude and appreciation to my advisor, Dr. John $\mathrm{Hu}$, for his guidance and encouragement during this work. He is my mentor for both his knowledge and personality.

I also would like to thank Dr. Debangsu Bhattacharyya for his patience and invaluable suggestions on my thesis.

I must especially thank Dr. Charter Stinespring. He taught me three courses and guided me during the MS program.

I am grateful to Dr. John W. Zondlo, Dr. Rakesh K. Gupta, Dr. Richard Turton, Dr. Hanjing Tian, Dr. Xueyan Song, Dr. David J. Klinke, Dr. Jeremy S. Hardinger, Dr. Xinjian He and Dr. Xiaopeng Ning for their teaching and kindness.

I am thankful to all graduate students, especially Ashley Caiola and I-Wen Wang, in the Department of Chemical Engineering for their friendliness, warmth and help that have made my stay in Morgantown pleasant and productive.

Finally, thanks to my family members. Throughout my life, they have supported me with unconditional love and care. They always believe in me and encourage me to be a better person. 


\section{Table of Contents}

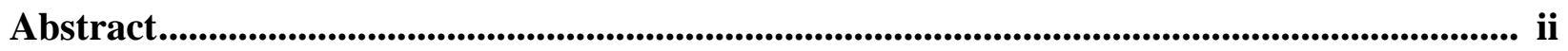

Acknowledgements ...................................................................................................................................... iii

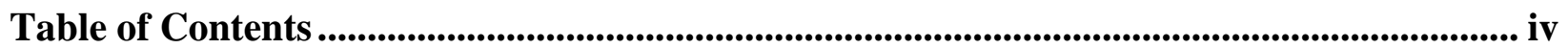

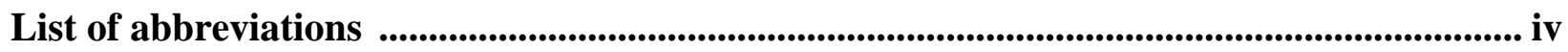

List of figures, tables and schemes ......................................................................................................... vi

Chapter 1. Introduction ....................................................................................................................1

Chapter 2. Current technologies and on-going research for $\mathrm{CO}_{2}$ treatment ...........................5

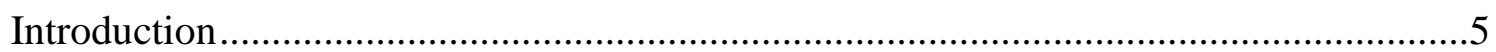

$2.1 \mathrm{CO}_{2}$ capturing

$2.2 \mathrm{CO}_{2}$ sequestration and storage ……...................................................................

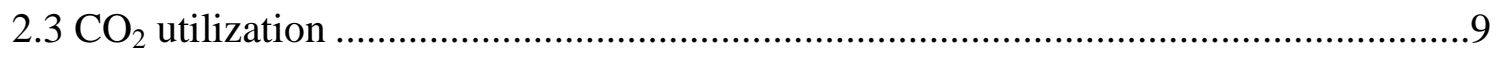

Chapter 3. Recent advances in $\mathrm{CO}_{2}$ reduction on copper-based electrocatalysts...................19

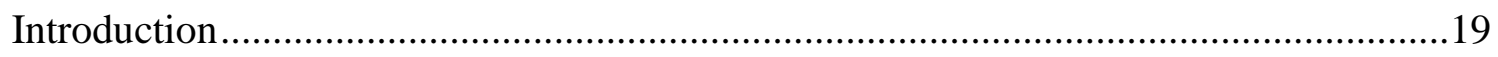

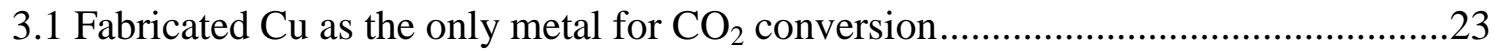

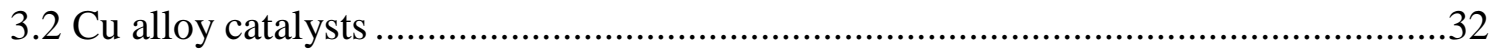

3.3 Organic $\mathrm{Cu}$ as catalyst ........................................................................................

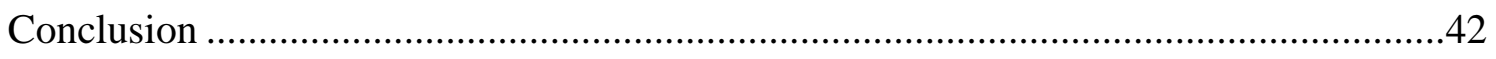

Chapter 4. Performance and mechanism of $\mathrm{Cu}$-based catalysts .................................................5 50 Introduction

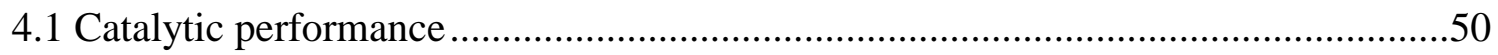

4.2 Mechanism and pathways for $\mathrm{CO}_{2}$ conversion to $\mathrm{C}_{2}$ products ................................54

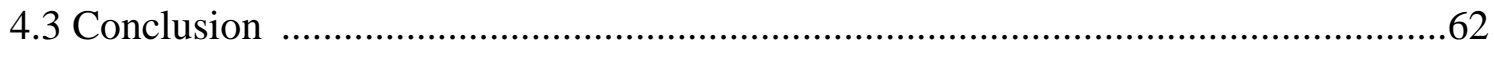




\section{List of abbreviations (Alphabetical):}

\begin{tabular}{|l|l|}
\hline Abbreviation & Full Name \\
\hline ADF & Annular dark-field \\
\hline DAT & 3,5-diamino-1,2,4-triazole \\
\hline DFT & Density functional theory \\
\hline EDS/ EDX & Energy dispersive X-ray spectroscopy \\
\hline EEL & Electron energy loss \\
\hline FE & Faradaic efficiency \\
\hline FT & Fischer-Tropsch \\
\hline GCP & Global Carbon Project \\
\hline HER & Hydrogen evolution reaction \\
\hline Hupd & Hydrogen underpotential deposition \\
\hline NA & Nanoalloys \\
\hline NC & Nanocubes \\
\hline NP & Nanoparticles \\
\hline NPS & National Park Service \\
\hline NS & Nanosheets \\
\hline NW & Nanowires \\
\hline OLEMS & Online electrochemical mass spectrometry \\
\hline PorCu & Copper-porphyrin \\
\hline RDS & Rate-determining steps \\
\hline RHE & Reversible hydrogen electrode \\
\hline SEM & Scanning electron microscope \\
\hline SHE & Standard hydrogen electrode \\
\hline STEM & Scanning transmission electron microscope \\
\hline TEM & Transmission electron microscope \\
\hline TPD-MS & Temperature Programmed Desorption Mass Spectrometry \\
\hline TPR & Temperature programmed reduction \\
\hline XPS & X-ray photoelectron spectroscopy \\
\hline XRD & X-ray diffraction \\
\hline & \\
\hline
\end{tabular}




\section{List of figures, tables and schemes:}

Figure 1.1. Greater concentrations of greenhouse gases mean more solar radiation is trapped within the Earth's atmosphere, making temperatures rise. Source: W. Elder, NPS.

Figure 1.2. Global average land-sea temperature anomaly relative to the 1961-1990 average temperature in degrees Celsius $\left({ }^{\circ} \mathrm{C}\right)$. Source: Hadley Center (Had CRUT4).

Figure 2.1. Summary of $\mathrm{CO}_{2}$ capture technologies from large combustion system.

Figure 2.2. $\mathrm{CO}_{2}$ sequestration underground and in sea. Source: Reagan Smith Energy Solutions, INC.

Figure 2.3. World energy consumption tendency. Source: U.S. Energy Information Administration, International Energy Outlook 2017.

Figure 2.4. Usage pattern of US fossil fuel. Source: U.S. Energy Information Administration, Monthly Energy Review.

Figure 2.5. Proposed timeline of $\mathrm{CO}_{2}$ utilization methods.

Figure 3.1. The binding energies of the intermediates, $\Delta E_{C O *}$ and $\Delta E_{H *}$.

Figure 3.2. Current efficiency for each product as a function of potential (left) and Tafel plot of the partial current going to each product (right), respectively.

Figure 3.3. a) Total geometric current density; b) current density for $\mathrm{CO}_{2}$ reduction;

c) faradaic efficiency (FE) of methane on $\mathrm{Cu}-10$ and $\mathrm{CuO}-1$; d) faradaic efficiency of ethylene and ethanol on $\mathrm{CuO}-1, \mathrm{CuO}-10$, and $\mathrm{CuO}-60$ catalysts; and e) faradaic efficiency of carbon monoxide and formate on $\mathrm{CuO}-60$ catalyst.

Figure 3.4. SEM images of $\mathrm{Cu}$ hollow fibres: a) outer surface, $50 \mathrm{~mm}$; b) outer surface, $2 \mathrm{~mm}$; c) cross-sectional of a perpendicularly broken, $100 \mathrm{~mm}$; d) outer surface and cross-section in the parallel direction to the length, $50 \mathrm{~mm}$, e) crosssectional image of the $\mathrm{Cu}$ hollow fibre, $500 \mu \mathrm{m}$; and f) $\mathrm{Cu}$ hollow fibre employed as an electrode at $20 \mathrm{~mL} \cdot \mathrm{min}^{-1}$ gas flow.

Figure 3.5. Comparison of the performance of different electrodes on the basis of the partial current density with $\mathrm{CO}$ at variable potentials.

Figure 3.6. a) Schematic illustration of the diffusion of electrolytes into $\mathrm{Cu}$ nanowire arrays; $b$ and c) Faradaic efficiency of various products at 8.1- $\mu$ m-length $\mathrm{Cu}$ NW arrays and 3- $\mu \mathrm{m}$-length $\mathrm{Cu} \mathrm{NW}$ arrays, respectively.

Figure 3.7. a) Linear sweep voltammetry and; b) composition of gaseous products of $\mathrm{CO}_{2}$ reduction on $\mathrm{Cu} \mathrm{NP}$ with different size. 
Figure 3.8. a) Cyclic voltammogram of an oxidation-reduction cycle of $\mathrm{Cu}$ in $0.1 \mathrm{M}$ $\mathrm{KHCO}_{3}$ and $4 \mathrm{mM} \mathrm{KCl}$; b and c) Online electrochemical mass spectrometry results of $\mathrm{CO}_{2}$ reduction with polycrystalline $\mathrm{Cu}(\mathrm{b})$ and $\mathrm{Cu}$ after an oxidation-reduction cycle (c).

Figure 3.9. Catalyst design and structural characterization. a) Schematic illustration of $\mathrm{Cu}_{2} \mathrm{~S}-\mathrm{Cu}-\mathrm{V}$ electrocatalyst design; b) TEM and c) EDS mapping of the original $\mathrm{V}$ $\mathrm{Cu}_{2} \mathrm{~S}$ nanoparticles; d) EDS mapping; e) high-resolution TEM; f) EDS line scan and g) the ratio of $\mathrm{Cu} / \mathrm{S}$ concentration of the reduced $\mathrm{Cu}_{2} \mathrm{~S}-\mathrm{Cu}-\mathrm{V}$ nanocatalysts after electrochemical reduction. $\mathrm{V}-\mathrm{Cu}$ indicates $\mathrm{Cu}$ with surface vacancies.

Figure 3.10. Theoretical calculations of the most stable structures of $\mathrm{Cu}$-doped $\mathrm{CeO}_{2}(110)$ and their effects on $\mathrm{CO}_{2}$ activation .

Figure 3.11. A) TEM image of the $\mathrm{Cu} / \mathrm{Ni}(\mathrm{OH})_{2}$ nanosheets after being stored in air at room temperature for 90 days; B) XRD patterns of the nanosheets after storing in air at room temperature for 7 to 90 days; c) TPD-MS profiles of the $\mathrm{Cu} / \mathrm{Ni}(\mathrm{OH})_{2}$ nanosheets heated in vacuum. Whereas the bottom shows relative ionization intensities of the main decomposition products at different temperatures, the top displays the accumulative ionization intensity ( $\mathrm{m} / \mathrm{z}$, mass/charge ratio); D) FTIR spectrum of the nanosheets and $\mathrm{E}$ ) Adsorption model of formate on $\mathrm{Cu}$. Color codes: cyan, $\mathrm{Cu}$; red, O; gray, C; white, H. F) STEM and G) EDX mapping images of the $\mathrm{Cu} / \mathrm{Ni}(\mathrm{OH})_{2}$ nanosheets.

Figure 3.12. $\mathrm{CO}_{2}$ reduction activity over $\mathrm{PdCu} / \mathrm{C}$ and $\mathrm{Pd} / \mathrm{C}$ catalysts in $\mathrm{CO}_{2}$-saturated $0.1 \mathrm{M} \mathrm{KHCO}_{3}$ solution.

Figure 3.13. a) Illustration of the prepared CuPd nanoalloys with different structures; b) XRD patterns of $\mathrm{CuPd}$ nanoalloys, $\mathrm{Cu}, \mathrm{Pd}$ and $\mathrm{CuPd}$ alloys; c-e) high-resolution TEM images of $\mathrm{Cu}$ (red) and $\mathrm{Pd}$ (green).

Figure 3.14. Faradaic efficiencies for a) $\mathrm{CO}$; b) $\mathrm{CH}_{4}$; c) $\mathrm{C}_{2} \mathrm{H}_{4}$; d) $\mathrm{C}_{2} \mathrm{H}_{5} \mathrm{OH}$ for catalysts with different $\mathrm{Cu}: \mathrm{Pd}$ ratios: $\mathrm{Cu}, \mathrm{Cu}_{3} \mathrm{Pd}, \mathrm{CuPd}, \mathrm{CuPd}_{3}$, and $\mathrm{Pd}$.

Figure 3.15. a) XRD and b) XPS patterns of CuAg-poly (6\% Ag) electrodeposited without DAT, $\mathrm{Cu}$-wire (0\% Ag) electrodeposited with DAT, and $\mathrm{CuAg}$-wire (6\% Ag) electrodeposited with DAT.

Figure 3.16. The illustration of a-b) wettable dendrite electrode and c-d) hydrophobic dendrite electrode for electroreduction.

Figure 3.17. Synthetic routes for copper-porphyrin molecular catalysts.

Figure 4.1. Possible reaction pathways for the electrocatalytic reduction of $\mathrm{CO}_{2}$ to products on transition metals and molecular catalysts. 
Figure 4.2. Proposed reaction paths for electrocatalytic reduction of $\mathrm{CO}_{2}$ on $\mathrm{Cu}$ nanowire arrays.

Figure 4.3. Proposed reaction paths for $\mathrm{CO}_{2}$ electroreduction on $\mathrm{Cu}(111)$.

Figure 4.4. Free energy of $\mathrm{CO}$ electrochemical reduction on $\mathrm{Cu}(111)$ at $\mathrm{pH}=1,7$ and 12 , respectively .

Figure 4.5. Summarized mechanisms for the reduction of $\mathrm{CO}$ to $\mathrm{C}_{2}$ products.

60

Table 1.1. Increase in rates of the amount of carbon dioxide in the atmosphere for the last 1000 years.

Table 2.1. Major commodity chemicals currently synthesized from $\mathrm{CO}_{2}$ on an industrial scale globally.

Table 2.3. Standard electrochemical potentials for $\mathrm{CO}_{2}$ reduction.

Table 3.1. Reported faradaic efficiencies of various reaction products measured for the electroreduction of $\mathrm{CO}_{2}$ in $0.1 \mathrm{M} \mathrm{KHCO}_{3}$.

Table 4.1. Summary of electrocatalytic reduction toward carbon products performance on different catalysts.

Scheme 3.1. Schematic illustration of electrochemical reduction of $\mathrm{CO}_{2}$.

Scheme 3.2. A schematic drawing of the full electrochemical cell including a buffer layer with circulating liquid electrolyte. 


\section{Chapter 1. Introduction}

Greenhouse gases are mainly composed of carbon dioxide $\left(\mathrm{CO}_{2}\right)$, carbon monoxide $(\mathrm{CO})$, nitrogen oxides $(\mathrm{NOx})$, methane $\left(\mathrm{CH}_{4}\right)$ and fluorinated gases, making much contribution to sustain the earth's temperature for the reason that greenhouse gases can absorb thermal radiation from the earth's surface and then re-emits the radiation back to the earth (Figure 1.1). However, continuously increasing greenhouse gases have being dramatically increasing the temperature of our planet due to massive usage of fossil fuel and other industrial activities in which produced considerable emission of $\mathrm{CO}_{2}, \mathrm{NOx}$, hydrocarbons, $\mathrm{CO}$, and so on (Figure 1.2). Rising temperature may cause soil degradation, lower agricultural productivity, desertification, less biodiversity, fresh-water reduction, ozone sphere destruction, etc. Excessive greenhouse gases also have a directly negative effect on human living environment, such as natural disasters, malnutrition, and increased mortality induced by heat wave [1-3].
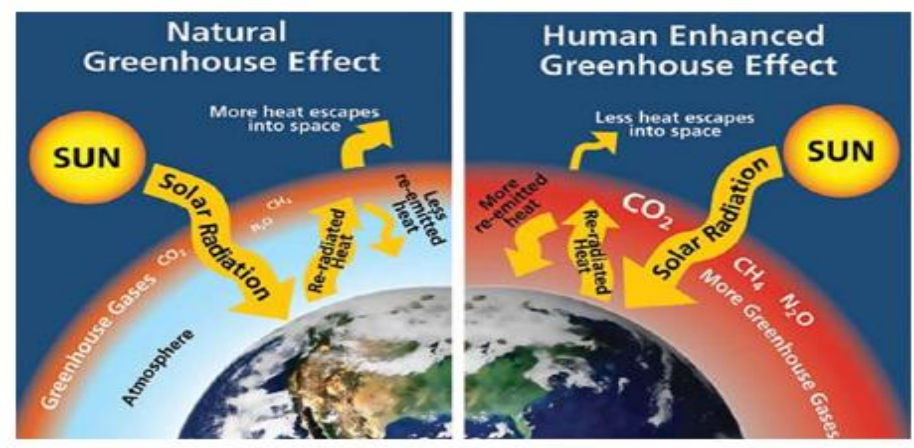

Figure.1.1 Greater concentrations of greenhouse gases mean more solar radiation is trapped within the Earth's atmosphere, making temperatures rise. Source: W. Elder, NPS 


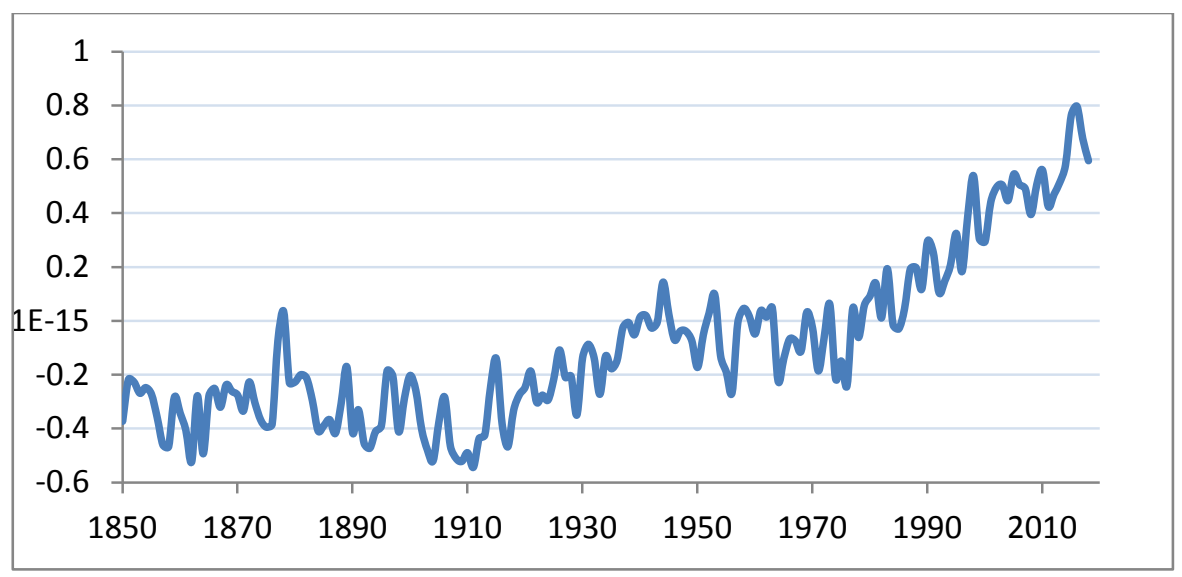

Figure.1.2 Global average land-sea temperature anomaly relative to the 1961-1990 average temperature in degrees celsius $\left({ }^{\circ} \mathrm{C}\right)$. Source: Hadley Center (Had CRUT4).

Notably, $\mathrm{CO}_{2}$, accounting for nearly $77 \%$ of greenhouse gases, has extremely increased after industrial revolution and should be principally responsible for global warming [4,5]. Before industrial revolution, new-produced $\mathrm{CO}_{2}$ can be consumed by plants to keep the concentration of $\mathrm{CO}_{2}$ balanced. In recent years, it is clearly realized that the human-generated $\mathrm{CO}_{2}$ greatly exceeds the threshold of nature's capability (Table1.1). It is reported by Global Carbon Project (GCP) that global $\mathrm{CO}_{2}$ emission from burning fossil fuels, the culprit of $\mathrm{CO}_{2}$ emission, increased by 2.7 percent in 2018, after a 1.6 percent increase in 2017 .

Table 1.1. Increase of carbon dioxide in the atmosphere for the last 1000 years [2,3].

\begin{tabular}{|c|c|c|c|c|}
\hline Year & $\begin{array}{c}\text { Period } \\
(\text { year})\end{array}$ & $\begin{array}{c}\text { Concentration } \\
(\mathrm{ppm})\end{array}$ & $\begin{array}{c}\text { Increase } \\
(\mathrm{ppm})\end{array}$ & $\begin{array}{c}\text { Increase rate } \\
(\mathrm{ppm} / \text { year})\end{array}$ \\
\hline $1000-1800$ & 800 & $270-280$ & 10 & 0.01 \\
\hline $1800-1950$ & 150 & $280-310$ & 30 & 0.2 \\
\hline $1958-1975$ & 17 & $315-330$ & 15 & 0.9 \\
\hline $1975-2002$ & 27 & $330-370$ & 40 & 1.5 (8 billion tons) \\
\hline $2002-2010$ & 8 & $370-388$ & 18 & 2.25 (12 billion tons) \\
\hline $2010-2018$ & 8 & $388-407$ & 19 & 2.38 \\
\hline
\end{tabular}


In the past decades, people gradually realized the significance and urgency of controlling $\mathrm{CO}_{2}$ concentration to prevent the Earth's temperature from continuously increasing. Though relative methods and research are conducted to solve those problems, the effect is limited and the $\mathrm{CO}_{2}$ concentration continues to grow [6,7]. Therefore, many nations, especially those main emission countries, have issued more strict laws and taken more actions to reverse the situation. For example, in 2011, the US Department of Energy (DOE) invested \$106 million in various $\mathrm{CO}_{2}$-utilization projects, and in 2018, DOE invested \$17.6 millions and \$44 millions in Technologies Capable of Reducing $\mathrm{CO}_{2}$ Capture Cost and Energy Penalties, and Advanced Carbon Capture Technologies Projects, respectively. In addition, the European Union has set up a prize worths $€ 1.5$ million for a technology demonstrating viable $\mathrm{CO}_{2}$ utilization in 2020 . China is expected to invest $\$ 4-5$ billion in $\mathrm{CO}_{2}$ recycling from main emission sources, such as coal, steel, cement and paper industries [8-10].

Based on the previous and current supports from society and governments, technologies are being developed and applied to further solve the problems. In the following chapters, these technologies will be discussed in detail. 


\section{Reference}

[1] Rossati, A. (2017). Global warming and its health impact. Int J Occup Environ Med (The IJOEM), 8(1 January), 963-7.

[2] Labonté, R., Mohindra, K., \& Schrecker, T. (2011). The growing impact of globalization for health and public health practice. Annual review of public health, 32.

[3] Solow, A. R. (2013). Global warming: A call for peace on climate and conflict. Nature, 497(7448), 179.

[4] Köne, A. Ç., \& Büke, T. (2010). Forecasting of $\mathrm{CO}_{2}$ emissions from fuel combustion using trend analysis. Renewable and Sustainable Energy Reviews, 14(9), 2906-2915.

[5] Lindsey, R. (2018). Climate change: atmospheric carbon dioxide. National Oceanographic and Atmospheric Administration, News \& Features. August.

[6] Omae, I. (2016). Carbon Dioxide Utilization by the Five-Membered Ring Products of Cyclometalation Reactions. Current organic chemistry, 20(9), 953.

[7] Greenwood, N. N., \& Earnshaw, A. (2012). Chemistry of the Elements. Elsevier.

[8] Carbon Capture and Storage News. https://www.energy.gov/fe/listings/carbon-capture-andstorage-news

[9] Commission launches three Horizon Prizes for energy innovation. https://ec.europa.eu/programmes/horizon2020/en/news/commission-launches-three-horizonprizes-energy-innovation

[10] Lim, X. (2015). How to make the most of carbon dioxide. Nature News, 526(7575), 628. 


\section{Chapter 2. Current technologies and on-going research for $\mathrm{CO}_{2}$ treatment}

\section{Introduction}

$\mathrm{CO}_{2}$ is generated from both nature and human activities. Natural sources are composed of decomposition, ocean release and respiration, while human activities include cements and papers production, deforestation, and burning of fossil fuel, etc. Basically, there are two ways to control and even reduce the $\mathrm{CO}_{2}$ concentration: 1) replacing the traditional fossil fuel, which accounts for 87 percent of all human-produced $\mathrm{CO}_{2}$ emissions, with renewable clean energy, such as solar, wind and bioenergy; 2) capturing, sequestration and utilization of $\mathrm{CO}_{2}[1-3]$. Here, we will focus on the second method. Although the concentration of $\mathrm{CO}_{2}$ has dramatically increased in past decades, its absolute concentration in the air is still low at about $0.04 \%$ [4-6]. Therefore, the first challenge is to capture diluted $\mathrm{CO}_{2}$ in the air. After $\mathrm{CO}_{2}$ is captured, it can be sequestrated or utilized as a feedstock to produce chemicals or fuels.

\subsection{Carbon dioxide capture}

In order to utilize carbon dioxide, the first step is to capture it efficiently. In theory, $\mathrm{CO}_{2}$ even at low concentration can be transported and injected underground, however, energy cost and other associated costs make this approach impractical [7-9]. Therefore, pure $\mathrm{CO}_{2}$ needs to be produced for the purpose of transportation and storage. $\mathrm{CO}_{2}$ capture requires the separation of $\mathrm{CO}_{2}$ from other species contained in industrial gases, such as flue gas, synthetic gas, air, or raw natural gas $[10,11]$. These separation steps can be accomplished by physical or chemical solvents, filtration membranes, solid adsorbents, or cryogenic separation. There are two approaches to 
collect $\mathrm{CO}_{2}$ with high concentration: 1) capture it from the large emission factories, utility plant, steel and cement plants; 2) and collect it directly in the atmosphere [12,13].

\subsubsection{Capture $\mathrm{CO}_{2}$ from industrial sources}

Basically, there are three different technologies that can be used to capture $\mathrm{CO}_{2}$ from the large industrial sources as shown in Figure 2.1, including post-combustion, pre-combustion, and oxyfuel. Post-combustion approach separates $\mathrm{CO}_{2}$ from the flue gas produced by the primary fuel combustion in the air [14-16]. In pre-combustion approach, fuel reacts with steam and air or oxygen first to produce syngas $\left(\mathrm{CO}\right.$ and $\left.\mathrm{H}_{2}\right)$. Then, $\mathrm{CO}$ is converted to $\mathrm{CO}_{2}$ by further reaction with steam via water-gas-shift reaction, and $\mathrm{H}_{2}$ is separated as fuel. In this process, a lot of work needs to be done in the early stage, but the separation is relatively easier in the later stage, and hydrogen can be utilized in many industrial processes. Oxy-fuel system uses oxygen to substitute air for primary combustion, producing flue gases dominated by water vapor and $\mathrm{CO}_{2}$. This process requires the separation of oxygen from the air first. The flue gas produced by this method has a very high concentration of $\mathrm{CO}_{2}$ [17-20]. It is economically feasible to capture $\mathrm{CO}_{2}$ in power plants with post-combustion system under certain conditions. $\mathrm{CO}_{2}$ separation from natural gas is a matured technology. The technology of pre-combustion has been widely used in the fertilizer manufacturing and hydrogen production industries. 


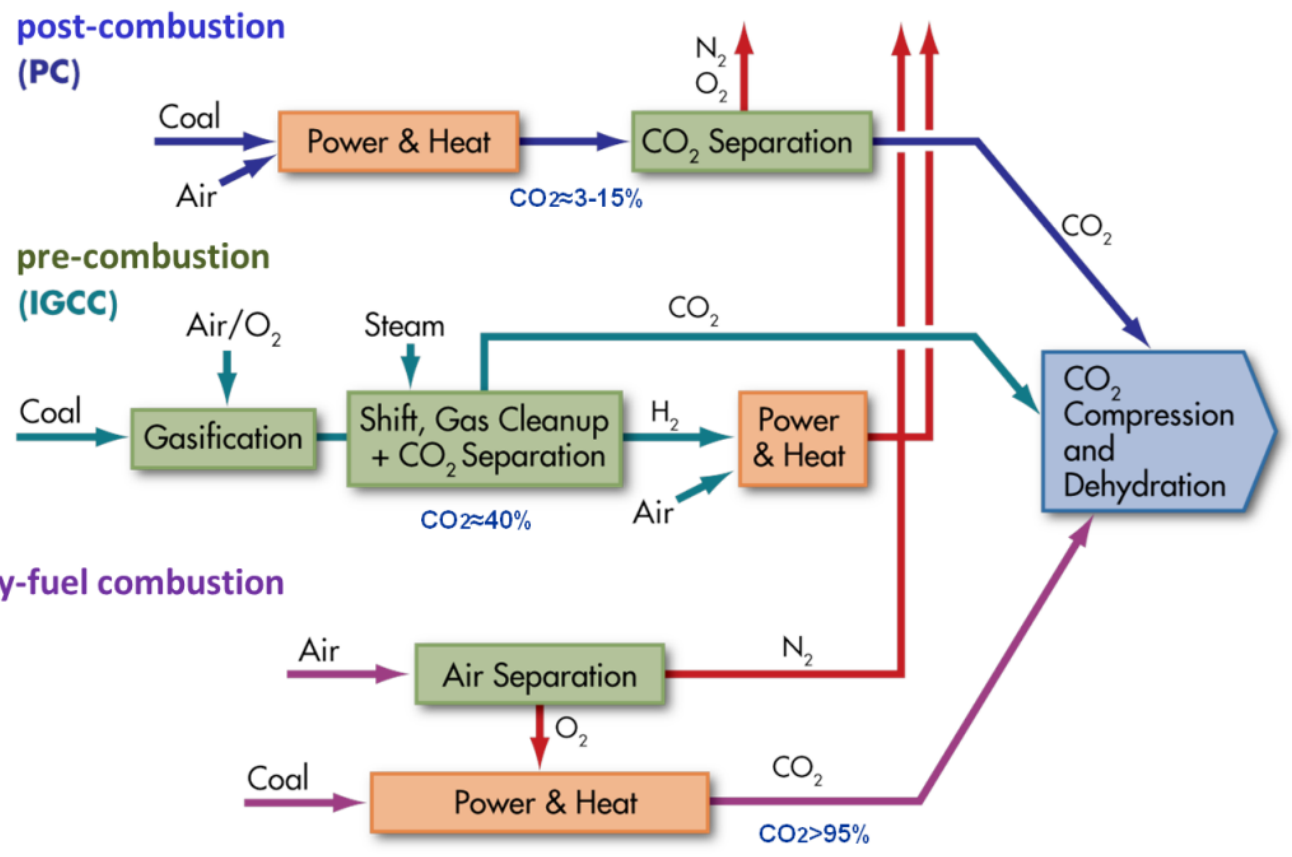

Figure 2.1. Summary of $\mathrm{CO}_{2}$ capture technologies [18].

Organic solvent and membrane are usually used to separate and capture $\mathrm{CO}_{2}$. Normally, organic solvents, such as monoethanolamine (MEA) and ammonia, are considered as the most available and widely used technology. However, it is not reasonable to considered it as a sustainable technology for its high cost and difficulty in regeneration. Membrane technology will be one of the most promising technologies, because it is compact, modular, mobile, low cost and environment-friendly [21-25].

\subsubsection{Capture $\mathrm{CO}_{2}$ from atmosphere}

Chemically scrubbing $\mathrm{CO}_{2}$ directly from the ambient air is another technology for $\mathrm{CO}_{2}$ capture [26]. Though it is costly and energy-intensive, it is still an attractive technology because its potential scale of deployment is enormous [27-29]. 


\section{2. $2 \mathrm{CO}_{2}$ storage and sequestration}

$\mathrm{CO}_{2}$ sequestration is considered as a potential technology for large-scale reduction of $\mathrm{CO}_{2}$ concentration in the air. The idea is to inject compressed $\mathrm{CO}_{2}$ into the ground or ocean to store it there for a long period of time [30-32]. For oceanic fixation, liquid carbon dioxide is injected into the ocean at different depths via ocean pipelines or marine transportation vessels, allowing it to dissolve in water or form stable carbon dioxide lakes. On land, liquid carbon dioxide is injected into the underground formation where it is locked by water dissolution, physical adsorption or chemical reactions (Figure 2.2).

In 2013, the United States Geological Survey (USGS) released the first comprehensive, geologically-based probabilistic assessment for $\mathrm{CO}_{2}$, showing a range of 2,400 to 3,700 metric gigatons of potential $\mathrm{CO}_{2}$ storage in USA. In addition, assessment also proved that carbon dioxide can be successfully injected using today's engineering practices and technologies $[33,34]$. However, Geological and oceanic sequestration have significant disadvantages. For example, when $\mathrm{CO}_{2}$ is injected into the ocean, it may lead to the acidification of seawater, endangering the ecosystem. In addition, there is a risk of leakage that could contaminate groundwater or endanger organisms after it is buried underground. In the past, sequestration of $\mathrm{CO}_{2}$ in the underground was practiced for its convenience and low cost. However, in recent years, the social acceptance becomes lower and lower for the uncertainty and controversy [35,36]. 


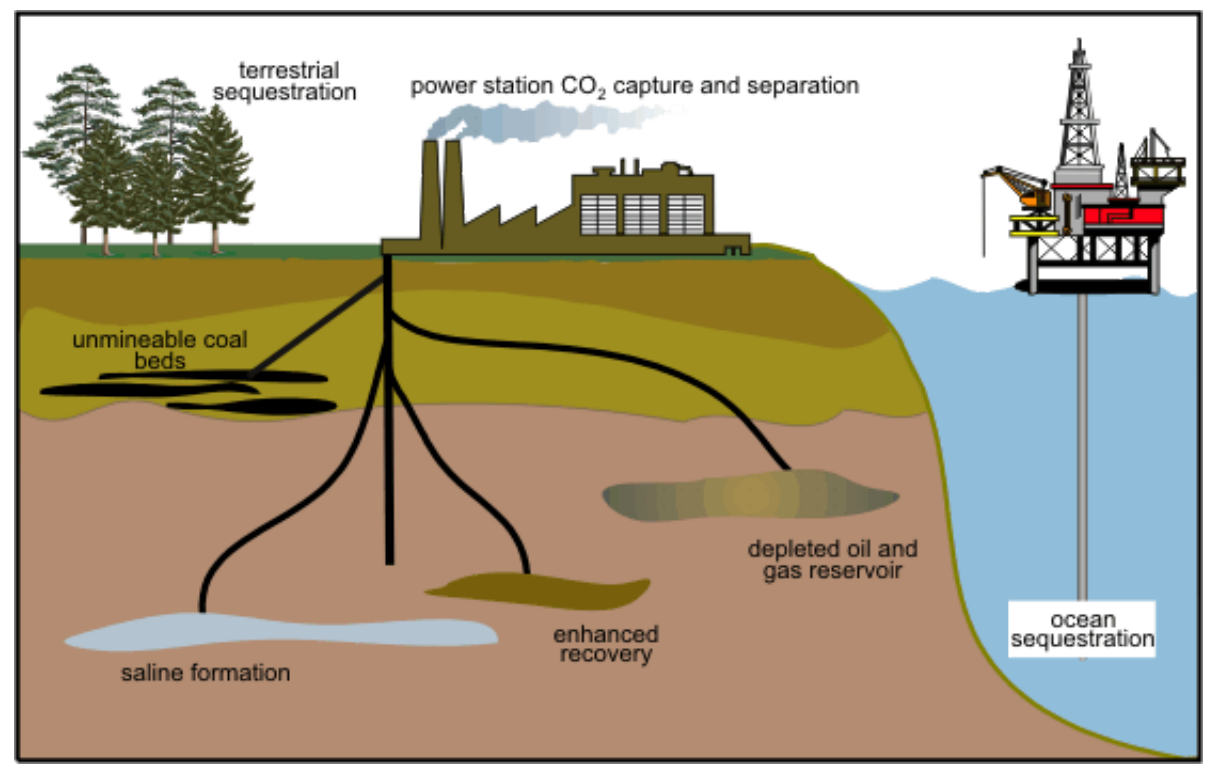

Figure 2.2. $\mathrm{CO}_{2}$ sequestration underground and in sea. Source: Reagan Smith Energy Solutions, INC.

\section{3 $\mathrm{CO}_{2}$ utilization}

According to the report from Energy Information Administration (EIA), in the coming decades, energy consumption will increase continuously and fossil fuel still dominates the energy market, which means $\mathrm{CO}_{2}$ emission will further threaten our lives (Figure 2.3). Closing material cycle is a fundamental principle of industrial ecology. Hence, the best way to avoid sustained $\mathrm{CO}_{2}$ increase in the atmosphere is to keep the carbon balanced in biosphere [37-40]. Obviously, $\mathrm{CO}_{2}$ utilization is more consistent with this principle than $\mathrm{CO}_{2}$ sequestration. Basically, there are two ways to utilize $\mathrm{CO}_{2}:$ 1) use it "as is"; 2) used it as feedstock to synthesize fuels and chemicals. 


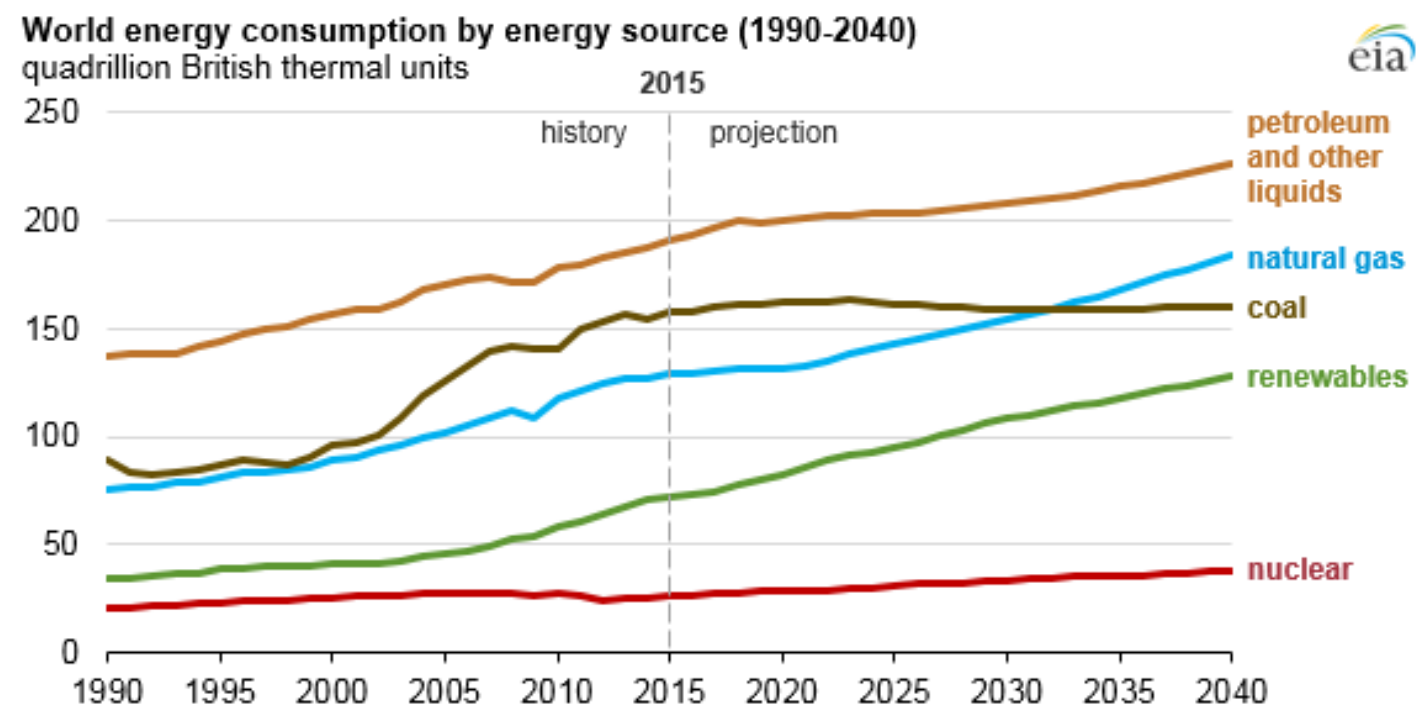

Figure 2.3. World energy consumption tendency. Source: U.S. Energy Information Administration, International Energy Outlook 2017.

\subsubsection{Use $\mathrm{CO}_{2}$ "as is"}

Every year, about 20 million tonnes of $\mathrm{CO}_{2}$ are widely utilized in industries "as is" [41]. For example, it is used as shield gas in manufacturing and construction industries at a large scale. In food industry, people use it to prevent fungal and bacterial growth, carbonate soft drinks, beers and wine, de-caffeinate coffee, keep food fresh, etc $[42,43]$. In oilfield, engineers use $\mathrm{CO}_{2}$ foam to enhance oil recovery. Interestingly, $\mathrm{CO}_{2}$ can be captured to enhance the growth of plants as some studies have shown that increasing the concentration of $\mathrm{CO}_{2}$ appropriately is beneficial to photosynthesis [44]. In addition, it is also used for neutralizing alkaline water, and producing fire extinguishers.

\subsection{2 $\mathrm{CO}_{2}$ is used as feedstock for chemical synthesis}

Statistically, over $90 \%$ of commercially available organic chemicals are produced from crude oil. $\mathrm{CO}_{2}$ conversion to organic chemicals will help reduce the emitted $\mathrm{CO}_{2}$ in air and the consumption of petroleum. In reality, industry has made some progress in utilizing $\mathrm{CO}_{2}$ as raw 
materials to produce chemicals (Table 2.1). Two notable examples are salicylic acid and urea produced from $\mathrm{CO}_{2}$ which account for approximately $60 \%$ of the total worldwide consumption.

Table 2.1. Major commodity chemicals currently synthesized from $\mathrm{CO}_{2}$ on an industrial scale globally. First three groups data are cited from reference [45] and the other data are cited from reference [46].

\begin{tabular}{|c|c|}
\hline Chemical & Production (ton) \\
\hline Cyclic carbonates & 80,000 in 2010 \\
\hline Salicylic acid & 89,800 in 2013 \\
\hline Urea & $164,000,000$ in 2015 \\
\hline Polycarbonate (Asahi Kasei process) & 605,000 \\
\hline Polypropylene carbonate & 76,000 \\
\hline Acetylsalicylic acid & 90,000 \\
\hline Methanol & 4000 \\
\hline
\end{tabular}

Thanks to the advances in technology, more and more methods for $\mathrm{CO}_{2}$ utilization have been developed in recent decades. For example, since 2013, Calera has been using $\mathrm{CO}_{2}$ to produce pure calcium carbonate, which is turned into fiber cement boards $[47,48]$. More research has being conducted to convert $\mathrm{CO}_{2}$ to cyclic carbonates due to its rapid growth in the area of electrolytes for lithium ion batteries [49,50]. Another promising area is the production of polyols, which are used as the raw material for polymers to further produce adhesives, coatings, mattresses, insulation refrigerator, and so on.

\subsection{3 $\mathrm{CO}_{2}$ conversion to fuel}

People have been debating the unmeaning topic for several decades when fossil energy will run out. First, it is hard to predict the amount of fossil fuel because it is subjected to many uncertain factors, such as the development of exploration and exploitation technology, and the 
consumption rate. Second, the environment cannot enduringly tolerate the use of fossil as the main energy source and the energy configuration must be changed because fossil energy will inevitably cause global warming, acid rain, haze, and so on. Therefore, establishing a renewable carbon system will not only reduce $\mathrm{CO}_{2}$ emissions, but also alleviate other pollution caused by fossil processing and transportation. Though tremendous work has been done to convert $\mathrm{CO}_{2}$ to high-value products, it is impossible to essentially close the anthropogenic carbon loop. Because about $70 \%$ fossil fuel is combusted to generate energy while only $7 \%$ is used as chemical products according to the data from EIA (Figure 2.4). Therefore, to prevent continuous carbon accumulation in ecosphere, fossil fuel must be replaced by other energy without carbon emission, such as solar, wind and water.

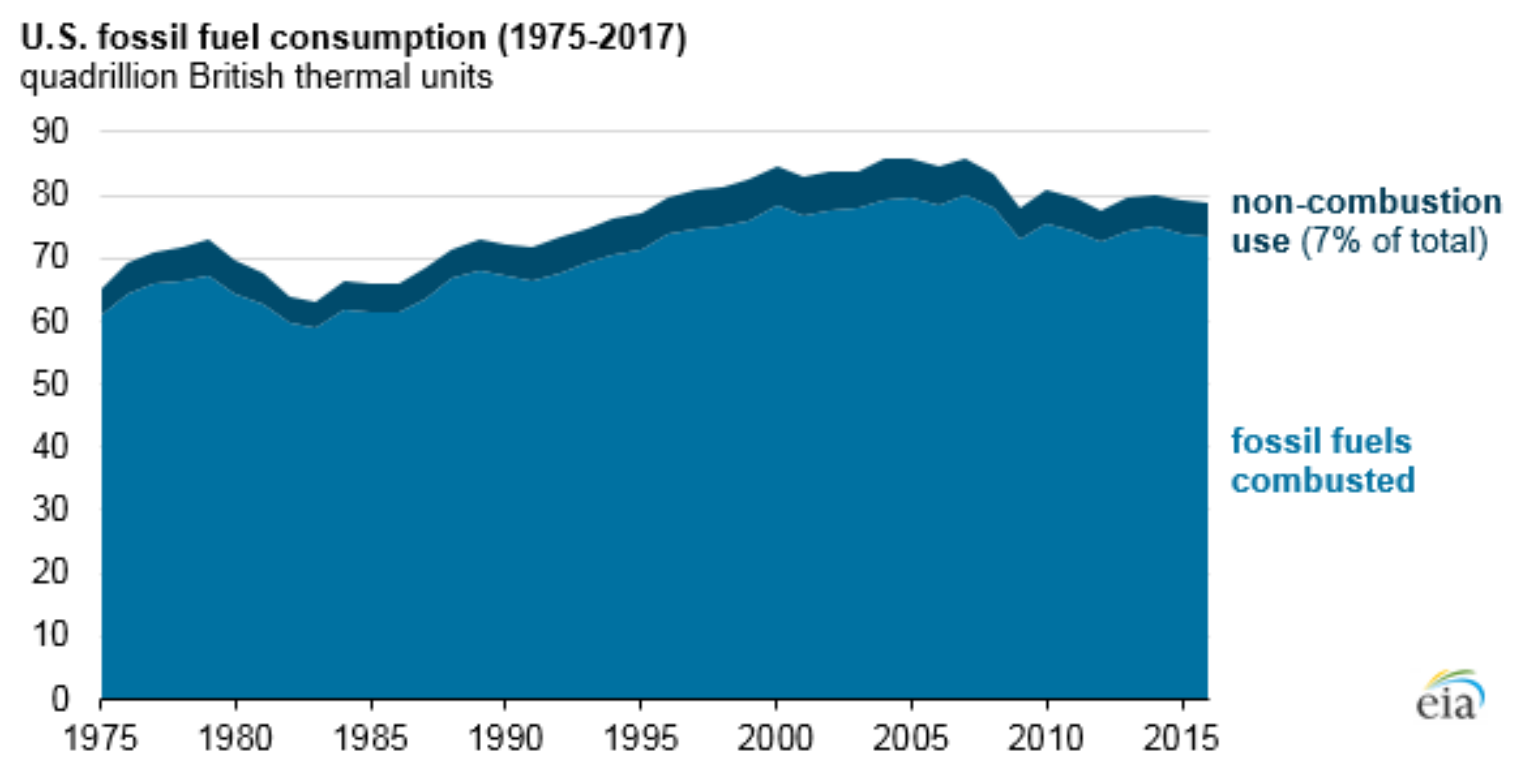

Figure 2.4. Usage pattern of US fossil fuel. Source: U.S. Energy Information Administration, Monthly Energy Review.

Reduction of $\mathrm{CO}_{2}$ to fuel has become the most promising strategy because it helps reduce the amount of $\mathrm{CO}_{2}$ in air and $\mathrm{CO}_{2}$ can work as an energy storage matrix where other energy can be stored and transported. At least six potential $\mathrm{CO}_{2}$ conversion technologies are current topics to 
realize 3E (efficiency, effect and economy) and implement on industrial scale. Some of them are close to commercialization, some are at the benchtop scale, and some have yet to be scientifically proven (Figure 2.5).

\begin{tabular}{|c|c|c|c|c|c|}
\hline \multicolumn{4}{|c|}{5 to 10 years } & \multicolumn{2}{|c|}{$70+$ years } \\
\hline Electrocatalysis & Photocatalysis & Biohybrid & $\begin{array}{l}\text { Nanoporous } \\
\text { Confinement }\end{array}$ & Chain Insertion & $\begin{array}{l}\text { Molecular } \\
\text { Machines }\end{array}$ \\
\hline $\begin{array}{l}\text { Flexible } \\
\text { electricity } \\
\text { source } \\
\text { - Closest to scale } \\
\text { and } \\
\text { commercial } \\
\text { application } \\
\text { - Dependent on } \\
\text { the cost of } \\
\text { electricity }\end{array}$ & $\begin{array}{l}\text { - Direct solar to } \\
\text { fuel conversion } \\
\text { - Portable } \\
\text { - No } \mathrm{CO}_{2} \\
\text { solubility issues } \\
\text { - Efficiencies and } \\
\text { activities are still } \\
\text { low }\end{array}$ & $\begin{array}{l}\text { - Coupling of } \\
\text { enzymes to } \\
\text { inorganic water } \\
\text { splitting } \\
\text { - Microbial } \\
\text { synthesis } \\
\text { - Complicated } \\
\text { molecule } \\
\text { synthesis } \\
\text { - Stability is still } \\
\text { an issue }\end{array}$ & $\begin{array}{l}\text { Catalysis of } \\
\text { hydrocarbons } \\
\text { achieved in } \\
\text { zeolites and } \\
\text { MOFs } \\
\text { - High } \\
\text { temperatures } \\
\text { and pressures } \\
\text { required }\end{array}$ & $\begin{array}{l}\text { - Metal catalysts } \\
\text { for } \\
\text { polymerization } \\
\text { through chain } \\
\text { insertion. } \\
\text { - Currently highly } \\
\text { adopted by } \\
\text { industry } \\
\text { - Have yet to be } \\
\text { demonstrated } \\
\text { with } \mathrm{CO}_{2}\end{array}$ & $\begin{array}{l}\text { - Artificial } \\
\text { enzymes with } \\
\text { dynamic } \\
\text { components } \\
\text { - Potential for } \\
\text { tandem } \\
\text { catalysis with } \\
\text { high selectivity } \\
\text { - Has yet to be } \\
\text { demonstrated }\end{array}$ \\
\hline
\end{tabular}

Figure 2.5. Proposed timeline of $\mathrm{CO}_{2}$ utilization methods [54]. Note: the specific time ranges are based on extrapolation of timeline development of other disruptive technologies such as the advent of 3D printing, solar energy adoption, and electric vehicle development.

Electrocatalytic conversion of $\mathrm{CO}_{2}$ is closest to commercialization [51-53]. Many startup and established companies, such as Opus-12, Mitsui Chemicals, Carbon Recycling International, and Carbon Electrocatalytic Recycling Toronto, are currently at the forefront to monetize the technology [54,55]. With the cost decrease of renewable energy, electrocatalysis will become more and more attractive [56].

However, $\mathrm{CO}_{2}$ is extremely stable due to the strong $\mathrm{C}=\mathrm{O}$ double bond with bonding energy of $750 \mathrm{~kJ} \cdot \mathrm{mol}^{-1}$ which is considerably larger than that of C-C $\left(336 \mathrm{~kJ} \cdot \mathrm{mol}^{-1}\right), \mathrm{C}-\mathrm{O}(327$ $\left.\mathrm{kJ} \cdot \mathrm{mol}^{-1}\right)$, and $\mathrm{C}-\mathrm{H}\left(411 \mathrm{~kJ} \cdot \mathrm{mol}^{-1}\right)$ [57]. Significant energy is required to break the $\mathrm{C}=\mathrm{O}$ bond. Meanwhile, it is very difficult to control the reaction paths and lots of products may be produced during the reduction process, increasing the difficulty in products separation (Table 2.3). 
Table 2.3. Standard electrochemical potentials for $\mathrm{CO}_{2}$ reduction [58].

\begin{tabular}{lc}
\hline Reduction potentials of $\mathrm{CO}_{2}$ & $E^{\circ}[\mathrm{V}]$ vs SHE at pH 7 \\
\hline $\mathrm{CO}_{2}+\mathrm{e}^{-} \rightarrow \mathrm{CO}_{2}^{-}$ & -1.9 \\
$\mathrm{CO}_{2}+2 \mathrm{H}^{+}+2 \mathrm{e}^{-} \rightarrow \mathrm{HCOOH}$ & -0.61 \\
$\mathrm{CO}_{2}+2 \mathrm{H}^{+}+2 \mathrm{e}^{-} \rightarrow \mathrm{CO}+\mathrm{H}_{2} \mathrm{O}$ & -0.52 \\
$2 \mathrm{CO}_{2}+12 \mathrm{H}^{+}+12 \mathrm{e}^{-} \rightarrow \mathrm{C}_{2} \mathrm{H}_{4}+4 \mathrm{H}_{2} \mathrm{O}$ & -0.34 \\
$\mathrm{CO}_{2}+4 \mathrm{H}^{+}+4 \mathrm{e}^{-} \rightarrow \mathrm{HCHO}+\mathrm{H}_{2} \mathrm{O}$ & -0.51 \\
$\mathrm{CO}_{2}+6 \mathrm{H}^{+}+6 \mathrm{e}^{-} \rightarrow \mathrm{CH}_{3} \mathrm{OH}+\mathrm{H}_{2} \mathrm{O}$ & -0.38 \\
$\mathrm{CO}_{2}+8 \mathrm{H}^{+}+8 \mathrm{e}^{-} \rightarrow \mathrm{CH}_{4}+2 \mathrm{H}_{2} \mathrm{O}$ & -0.24 \\
$2 \mathrm{H}^{+}+2 \mathrm{e}^{-} \rightarrow \mathrm{H}_{2}$ & -0.42 \\
\hline
\end{tabular}

The foreground of $\mathrm{CO}_{2}$ reduction for commercial use is dependent on the development of highly efficient and selective catalysts with relatively low energy cost. In recent years, much progress have been made on catalyst to reduce the energy barrier and control reaction pathway $[59,60]$. In the coming chapter, we will focus on the most popular catalysts, $\mathrm{Cu}$-based catalysts, and summarize the factors influencing their performance. 


\section{Reference}

[1] Shahbazi, A., \& Nasab, B. R. (2016). Carbon capture and storage (CCS) and its impacts on climate change and global warming. J. Pet. Environ. Biotechnol, 7, 291.

[2] Fang, C., Wang, S., \& Li, G. (2015). Changing urban forms and carbon dioxide emissions in China: A case study of 30 provincial capital cities. Applied energy, 158, 519-531.

[3] Hunt, A. J., Sin, E. H., Marriott, R., \& Clark, J. H. (2010). Generation, capture, and utilization of industrial carbon dioxide. ChemSusChem: Chemistry \& Sustainability Energy \& Materials, 3(3), 306-322.

[4] Eiler, J. M., \& Schauble, E. (2004). 18013C16O in Earth's atmosphere. Geochimica et Cosmochimica Acta, 68(23), 4767-4777.

[5] Pielke Jr, R. A. (2009). An idealized assessment of the economics of air capture of carbon dioxide in mitigation policy. environmental science \& policy, 12(3), 216-225.

[6] Köne, A. Ç., \& Büke, T. (2010). Forecasting of $\mathrm{CO}_{2}$ emissions from fuel combustion using trend analysis. Renewable and Sustainable Energy Reviews, 14(9), 2906-2915.

[7] Rubin, E. S., Davison, J. E., \& Herzog, H. J. (2015). The cost of $\mathrm{CO}_{2}$ capture and storage. International Journal of Greenhouse Gas Control, 40, 378-400.

[8] Rubin, E., Meyer, L., \& Coninck, H. (2005). Carbon Dioxide Capture and Storage, Technical Summary. IPCC special report, 29.

[9] Change, I. P. O. C. (2014). IPCC. Climate change.

[10] McDonald, T. M., Lee, W. R., Mason, J. A., Wiers, B. M., Hong, C. S., \& Long, J. R. (2012). Capture of carbon dioxide from air and flue gas in the alkylamine-appended metalorganic framework mmen-Mg2 (dobpdc). Journal of the American Chemical Society, 134(16), 7056-7065.

[11] Baker, R. W. (2002). Future directions of membrane gas separation technology. Industrial \& engineering chemistry research, 41(6), 1393-1411.

[12] Bhown, A. S., \& Freeman, B. C. (2011). Analysis and status of post-combustion carbon dioxide capture technologies. Environmental science \& technology, 45(20), 8624-8632.

[13] Jansen, D., Gazzani, M., Manzolini, G., van Dijk, E., \& Carbo, M. (2015). Pre-combustion $\mathrm{CO}_{2}$ capture. International Journal of Greenhouse Gas Control, 40, 167-187.

[14] Wang, Y., Zhao, L., Otto, A., Robinius, M., \& Stolten, D. (2017). A review of postcombustion $\mathrm{CO}_{2}$ capture technologies from coal-fired power plants. Energy Procedia, 114, 650665 .

[15] Shakerian, F., Kim, K. H., Szulejko, J. E., \& Park, J. W. (2015). A comparative review between amines and ammonia as sorptive media for post-combustion $\mathrm{CO}_{2}$ capture. Applied Energy, 148, 10-22.

[16] Wang, M., Joel, A. S., Ramshaw, C., Eimer, D., \& Musa, N. M. (2015). Process intensification for post-combustion $\mathrm{CO}_{2}$ capture with chemical absorption: a critical review. Applied Energy, 158, 275-291. 
[17] Rahman, F. A., Aziz, M. M. A., Saidur, R., Bakar, W. A. W. A., Hainin, M. R., Putrajaya, R., \& Hassan, N. A. (2017). Pollution to solution: Capture and sequestration of carbon dioxide $(\mathrm{CO} 2)$ and its utilization as a renewable energy source for a sustainable future. Renewable and Sustainable Energy Reviews, 71, 112-126.

[18] Llamas, B., Navarrete, B., Vega, F., Rodriguez, E., Mazadiego, L. F., Cámara, Á., \& Otero, P. (2016). Greenhouse Gas Emissions-Carbon Capture, Storage and Utilisation. Greenhouse Gases, 81.

[19] Jansen, D., Gazzani, M., Manzolini, G., van Dijk, E., \& Carbo, M. (2015). Pre-combustion $\mathrm{CO}_{2}$ capture. International Journal of Greenhouse Gas Control, 40, 167-187.

[20] Buhre, B. J., Elliott, L. K., Sheng, C. D., Gupta, R. P., \& Wall, T. F. (2005). Oxy-fuel combustion technology for coal-fired power generation. Progress in energy and combustion science, 31(4), 283-307.

[21] Toftegaard, M. B., Brix, J., Jensen, P. A., Glarborg, P., \& Jensen, A. D. (2010). Oxy-fuel combustion of solid fuels. Progress in energy and combustion science, 36(5), 581-625.

[22] Aaron, D., \& Tsouris, C. (2005). Separation of $\mathrm{CO}_{2}$ from flue gas: a review. Separation Science and Technology, 40(1-3), 321-348.

[23] Yang, H., Xu, Z., Fan, M., Gupta, R., Slimane, R. B., Bland, A. E., \& Wright, I. (2008). Progress in carbon dioxide separation and capture: A review. Journal of environmental sciences, 20(1), 14-27.

[24] Dumée, L., Scholes, C., Stevens, G., \& Kentish, S. (2012). Purification of aqueous amine solvents used in post combustion $\mathrm{CO}_{2}$ capture: A review. International Journal of Greenhouse Gas Control, 10, 443-455.

[25] Meylan, F. D., Moreau, V., \& Erkman, S. (2015). $\mathrm{CO}_{2}$ utilization in the perspective of industrial ecology, an overview. Journal of $\mathrm{CO}_{2}$ Utilization, 12, 101-108.

[26] Keith, D. W., Holmes, G., Angelo, D. S., \& Heidel, K. (2018). A Process for Capturing $\mathrm{CO}_{2}$ from the Atmosphere. Joule, 2(8), 1573-1594.

[27] Lackner, K. S. (2009). Capture of carbon dioxide from ambient air. The European Physical Journal Special Topics, 176(1), 93-106.

[28] Lackner, K. S., Brennan, S., Matter, J. M., Park, A. H. A., Wright, A., \& Van Der Zwaan, B. (2012). The urgency of the development of $\mathrm{CO}_{2}$ capture from ambient air. Proceedings of the National Academy of Sciences, 109(33), 13156-13162.

[29] House, K. Z., Baclig, A. C., Ranjan, M., van Nierop, E. A., Wilcox, J., \& Herzog, H. J. (2011). Economic and energetic analysis of capturing $\mathrm{CO}_{2}$ from ambient air. Proceedings of the National Academy of Sciences, 108(51), 20428-20433.

[30] Randolph, J. B., \& Saar, M. O. (2011). Coupling carbon dioxide sequestration with geothermal energy capture in naturally permeable, porous geologic formations: Implications for $\mathrm{CO}_{2}$ sequestration. Energy Procedia, 4, 2206-2213.

[31] Woodrow, H. (2013, September). Exergy Analysis of Coupled $\mathrm{CO}_{2}$ Sequestration with Geothermal Energy Production. In Second EAGE Sustainable Earth Sciences (SES) Conference and Exhibition. 
[32] uadrelli, E. A., Centi, G., Duplan, J. L., \& Perathoner, S. (2011). Carbon dioxide recycling: emerging large-scale technologies with industrial potential. ChemSusChem, 4(9), 1194-1215.

[33] Pires, J. C. M., Martins, F. G., Alvim-Ferraz, M. C. M., \& Simões, M. (2011). Recent developments on carbon capture and storage: an overview. Chemical engineering research and design, 89(9), 1446-1460.

[34] Leung, D. Y., Caramanna, G., \& Maroto-Valer, M. M. (2014). An overview of current status of carbon dioxide capture and storage technologies. Renewable and Sustainable Energy Reviews, 39, 426-443.

[35] Little, M. G., \& Jackson, R. B. (2010). Potential impacts of leakage from deep $\mathrm{CO}_{2}$ geosequestration on overlying freshwater aquifers. Environmental science \& technology, 44(23), 9225-9232.

[36] Zoback, M. D., \& Gorelick, S. M. (2012). Earthquake triggering and large-scale geologic storage of carbon dioxide. Proceedings of the National Academy of Sciences, 109(26), 1016410168 .

[37] Budzianowski, W. M. (2012). Value-added carbon management technologies for low $\mathrm{CO}_{2}$ intensive carbon-based energy vectors. Energy, 41(1), 280-297.

[38] Yi, Q., Li, W., Feng, J., \& Xie, K. (2015). Carbon cycle in advanced coal chemical engineering. Chemical Society Reviews, 44(15), 5409-5445.

[39] Ciais, P., Bombelli, A., Williams, M., Piao, S. L., Chave, J., Ryan, C. M., ... \& Valentini, R. (2011). The carbon balance of Africa: synthesis of recent research studies. Philosophical transactions of the royal society A: Mathematical, Physical and Engineering Sciences, 369(1943), 2038-2057.

[40] Engström, K., Lindeskog, M., Olin, S., Hassler, J., \& Smith, B. (2017). Impacts of climate mitigation strategies in the energy sector on global land use and carbon balance. Earth System Dynamics, 8(3), 773.

[41] Lim, X. (2015). How to make the most of carbon dioxide. Nature News, 526(7575), 628.

[42] How the $\mathrm{CO}_{2}$ shortage is affecting the food and drink industry.

https://www.ft.com/content/36183d1e-7b73-11e8-bc55-50daf11b720d.

[43] Bui, M., Adjiman, C. S., Bardow, A., Anthony, E. J., Boston, A., Brown, S., ... \& Hallett, J. P. (2018). Carbon capture and storage (CCS): the way forward. Energy \& Environmental Science, 11(5), 1062-1176.

[44] Zheng, Y., Li, F., Hao, L., Shedayi, A. A., Guo, L., Ma, C., ... \& Xu, M. (2018). The optimal $\mathrm{CO}_{2}$ concentrations for the growth of three perennial grass species. BMC plant biology, 18(1), 27.

[45] National Academies of Sciences, Engineering, and Medicine. (2019). Gaseous Carbon Waste Streams Utilization: Status and Research Needs. National Academies Press.

[46] Omae, I. (2012). Recent developments in carbon dioxide utilization for the production of organic chemicals. Coordination Chemistry Reviews, 256(13-14), 1384-1405.

[47] Butler, J. N. (2019). Carbon dioxide equilibria and their applications. Routledge. 
[48] Macartney, A., \& Knops, P. (2019). 11 Mineral carbon sequestration. Fundamentals, 187.

[49] Kim, Y., Hyun, K., Ahn, D., Kim, R., Park, M. H., \& Kim, Y. (2019). Efficient Aluminum Catalysts for the Chemical Conversion of $\mathrm{CO}_{2}$ into Cyclic Carbonates at Room Temperature and Atmospheric $\mathrm{CO}_{2}$ Pressure. ChemSusChem.

[50] Puthiaraj, P., Ravi, S., Yu, K., \& Ahn, W. S. (2019). $\mathrm{CO}_{2}$ adsorption and conversion into cyclic carbonates over a porous $\mathrm{ZnBr}_{2}$-grafted $\mathrm{N}$-heterocyclic carbene-based aromatic polymer. Applied Catalysis B: Environmental, 251, 195-205.

[51] Jiang, Z., Xiao, T., Kuznetsov, V. Á., \& Edwards, P. Á. (2010). Turning carbon dioxide into fuel. Philosophical Transactions of the Royal Society A: Mathematical, Physical and Engineering Sciences, 368(1923), 3343-3364.

[52] Zhang, S., Kang, P., \& Meyer, T. J. (2014). Nanostructured tin catalysts for selective electrochemical reduction of carbon dioxide to formate. Journal of the American Chemical Society, 136(5), 1734-1737.

[53] Creel, E. B., Corson, E. R., Eichhorn, J., Kostecki, R., Urban, J. J., \& McCloskey, B. D. (2019). Directing Selectivity of Electrochemical Carbon Dioxide Reduction Using Plasmonics. ACS Energy Letters, 4(5), 1098-1105.

[54] Bushuyev, O. S., De Luna, P., Dinh, C. T., Tao, L., Saur, G., van de Lagemaat, J., ... \& Sargent, E. H. (2018). What should we make with $\mathrm{CO}_{2}$ and how can we make it?. Joule, 2(5), 825-832.

[55] Initiative, G. C. (2019). Global Roadmap for Implementing $\mathrm{CO}_{2}$ Utilization. Global $\mathrm{CO}_{2}$ Initiative.

[56] 2015 Wind Technologies Market Report. (2016). US Department of Energy.

[57] Wu, J., Huang, Y., Ye, W., \& Li, Y. (2017). $\mathrm{CO}_{2}$ reduction: from the electrochemical to photochemical approach. Advanced Science, 4(11), 1700194.

[58] Leitner, W. (1995). Carbon dioxide as a raw material: the synthesis of formic acid and its derivatives from $\mathrm{CO}_{2}$. Angewandte Chemie International Edition in English, 34(20), 2207-2221.

[59] Kortlever, R., Shen, J., Schouten, K. J. P., Calle-Vallejo, F., \& Koper, M. T. (2015).

Catalysts and reaction pathways for the electrochemical reduction of carbon dioxide. The journal of physical chemistry letters, 6(20), 4073-4082.

[60] Kuhl, K. P., Cave, E. R., Abram, D. N., \& Jaramillo, T. F. (2012). New insights into the electrochemical reduction of carbon dioxide on metallic copper surfaces. Energy \& Environmental Science, 5(5), 7050-7059. 


\section{Chapter 3. Recent advances in $\mathrm{CO}_{2}$ reduction on copper-based electrocatalysts}

\section{Introduction}

Electrocatalysis is one of the most promising approaches for its renewable and environmental friendly properties as well as it has the potential to sustain solar-fuel-based economy. Many valuable products, such as $\mathrm{CO}$, formate, methanol, methane, ethanol and ethylene, can be produced via electrocatalysis, which can be directly or indirectly used in industrial processes. For example, ethanol can be blended in gasoline for auto-engines, and CO can be converted to many chemicals via Fischer-Tropsch synthesis. Although it possesses great potential, the application is seriously held back by its high overpotential, poor selectivity and low faradaic efficiency. Therefore, it is urgent to study the reaction mechanism and develop tailormade electrocatalysts.

The design of electrocatalytic reactor is critical in $\mathrm{CO}_{2}$ reduction. Though many kinds of reactor configurations have been developed to enhance $\mathrm{CO}_{2}$ conversion, the working principle is similar (Scheme 3.1). Typically, there are four main components in a reactor, including anode, cathode, membrane and electrolyte. Specifically, $\mathrm{H}_{2} \mathrm{O}$ is oxidized to $\mathrm{O}_{2}$ spilling at the anode, while $\mathrm{CO}_{2}$ is electrochemically reduced to produce $\mathrm{CO}$ and low carbon organic compounds on the cathode, such as $\mathrm{CH}_{3} \mathrm{OH}, \mathrm{CH}_{3} \mathrm{CH}_{2} \mathrm{OH}, \mathrm{C}_{2} \mathrm{H}_{4}$ and $\mathrm{CH}_{4}$. According to the statistical data, platinum is commonly used as anode, and $\mathrm{KHCO}_{3}$ dominates electrolyte field [3]. Many studies have reported improvement on the performance of membrane. Currently, Nafion produced by Dupont is the most popular one [4,5]. Multitudinous metals and their derivatives, such as $\mathrm{Cu}, \mathrm{Zn}$, 
$\mathrm{Ag}, \mathrm{Au}, \mathrm{Co}, \mathrm{Pd}, \mathrm{Bi}$, etc., are used as cathode. Scheme 3.2 details the structure and components of a electrochemical reactor [2].

In this chapter, we will discuss the progress in $\mathrm{Cu}$-based catalysts because $\mathrm{Cu}$ is the most researched catalyst having the potential to be commercialized.

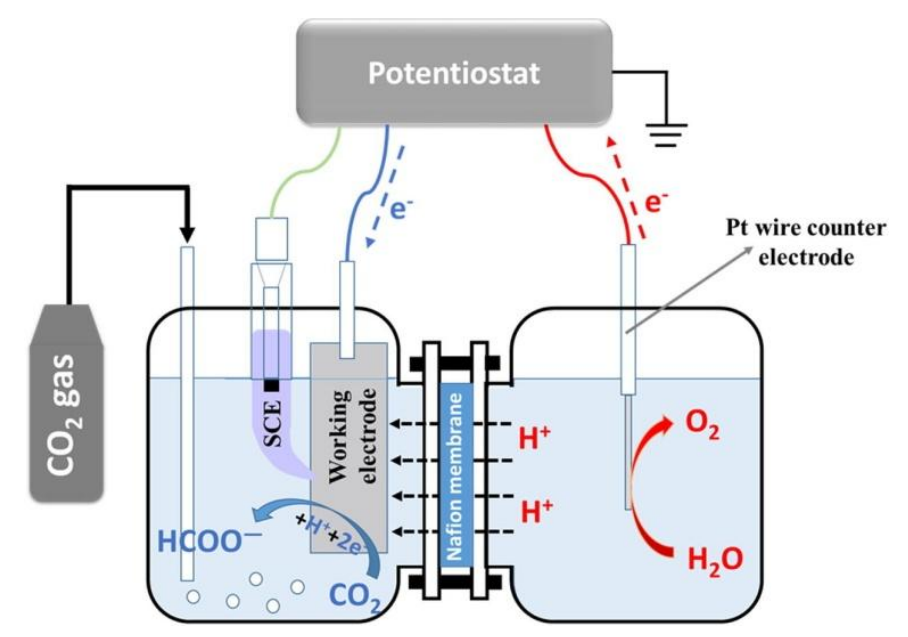

Scheme 3.1. Schematic illustration of electrochemical reduction of $\mathrm{CO}_{2}$ [1].

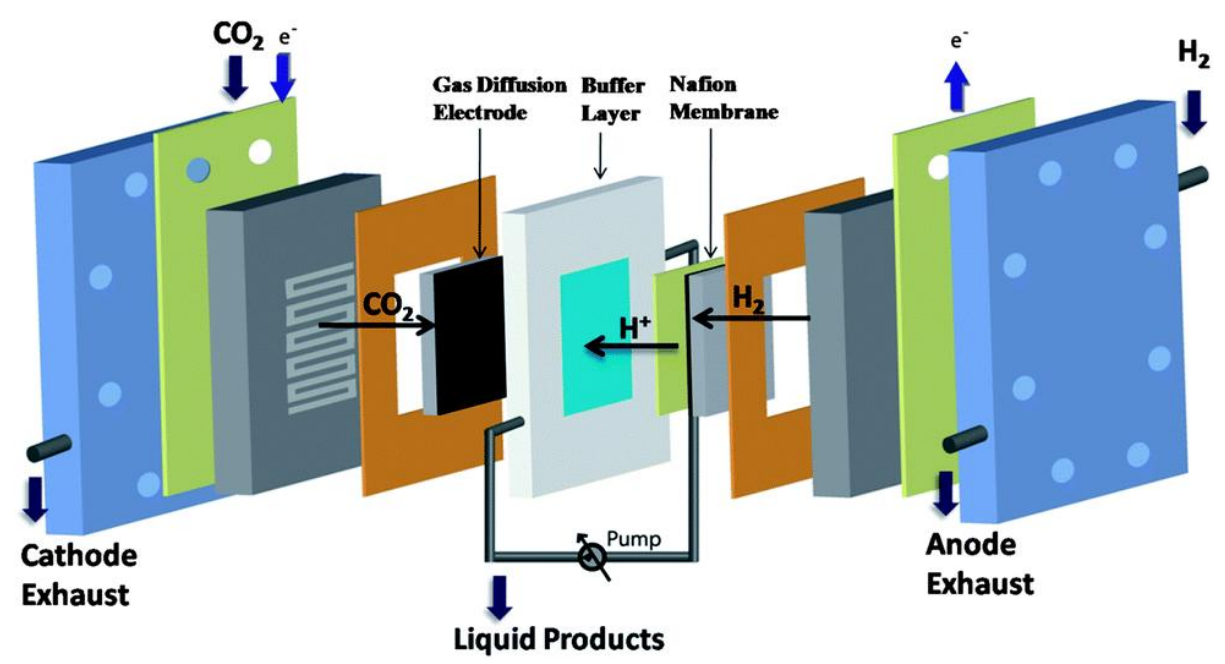

Scheme 3.2. A schematic drawing of the full electrochemical cell including a buffer layer with circulating liquid electrolyte [2]. 
The binding energies of $* \mathrm{CO}$ and $* \mathrm{H}(*$ denotes a surface adsorption site) are used as the descriptors for the correlation between the electrocatalytic performance and the surface property of different metals. It seems weak binding strength of *CO may cause massive $\mathrm{CO}$ formation because it is hard to absorb $\mathrm{CO}$ after it is formed on those metals, such us $\mathrm{Au}, \mathrm{Ag}$ and $\mathrm{Zn}$. While weak binding strength of $* \mathrm{H}$ may cause high proportion of $\mathrm{H}_{2}$ because it is hard to absorb $* \mathrm{H}$ after it is formed on those metals, such as $\mathrm{Ni}$ and Pt. Among those metal catalysts, $\mathrm{Cu}$ possesses the intermediate binding strength to $* \mathrm{CO}$ and does not have hydrogen underpotential deposition $\left(\mathrm{H}_{\text {upd }}\right)$. Those are the reason why copper is the only metal producing various hydrocarbons with relative high efficiency (Figure 3.1 and Table 3.1). Currently, $\mathrm{Cu}$ is the most commonly studied and may be the most suitable for large-scale application due to its cheap price and excellent catalytic property $[3,4]$.

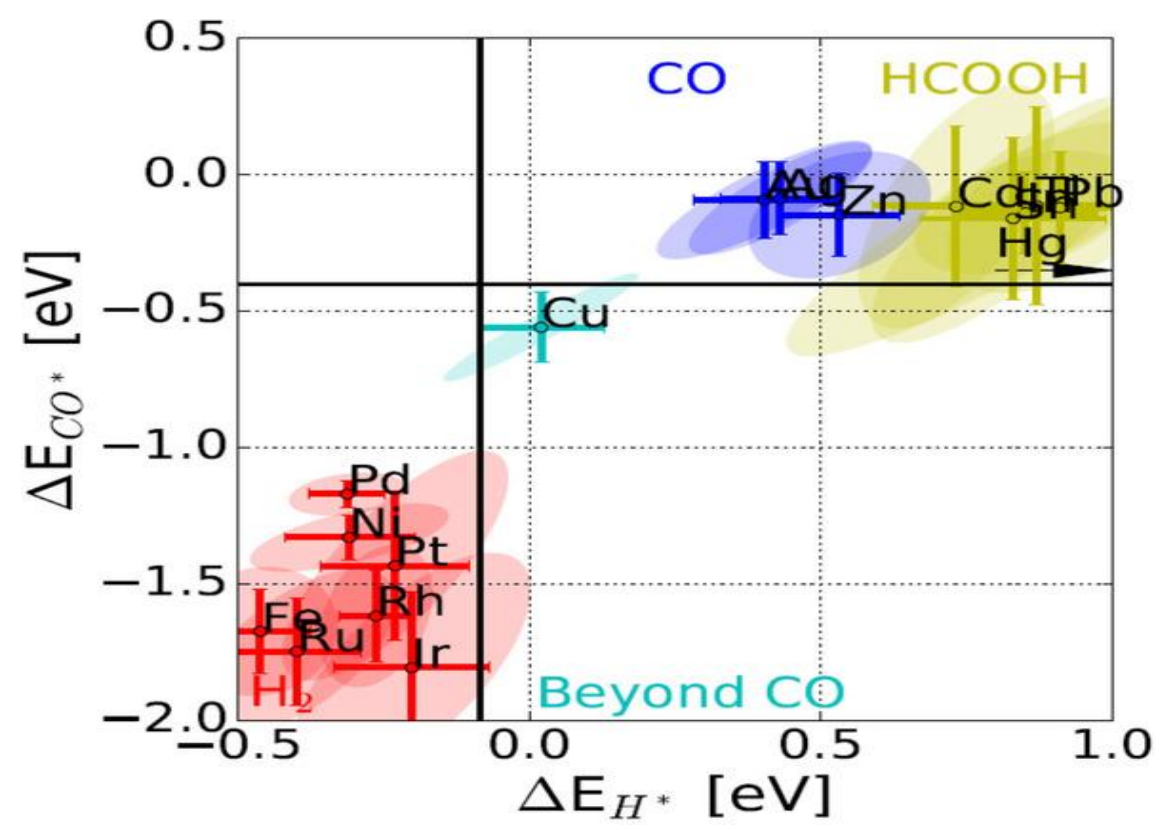

Figure 3.1. The binding energies of the intermediates, $\Delta E_{C O *}$ and $\Delta E_{H^{*}},\left(\mathrm{CO}^{*}={ }^{*} \mathrm{CO}, \mathrm{H}^{*}=* \mathrm{H}\right)$ [3]. 
Table 3.1. Reported faradaic efficiencies of various products measured for the electroreduction of $\mathrm{CO}_{2}$ in $0.1 \mathrm{M} \mathrm{KHCO}_{3}$ [4].

\begin{tabular}{cccccccccccc} 
& & \multirow{8}{c}{$\begin{array}{c}\text { Faradaic efficiency (\%) } \\
\text { Electrode }\end{array}$} & $\begin{array}{c}\text { Potential } \\
\text { (V vs. SHE) }\end{array} \begin{array}{c}\text { Current } \\
\text { density } \\
\left(\mathbf{m A ~} \mathbf{~ c m}^{-2}\right)\end{array}$ & $\mathbf{C H}_{\mathbf{4}}$ & $\mathbf{C}_{2} \mathbf{H}_{\mathbf{4}}$ & $\mathbf{C}_{2} \mathbf{H}_{6} \mathbf{O}^{\mathbf{b}}$ & $\mathbf{C}_{3} \mathbf{H}_{8} \mathbf{O}^{\mathbf{c}}$ & $\mathbf{C O}$ & $\mathbf{H C O O}^{-}$ & $\mathbf{H}_{2}$ & Total \\
\hline $\mathrm{Pb}$ & -1.63 & 5.0 & 0.0 & 0.0 & 0.0 & 0.0 & 0.0 & 97.4 & 5.0 & 102.4 \\
$\mathrm{Hg}$ & -1.51 & 0.5 & 0.0 & 0.0 & 0.0 & 0.0 & 0.0 & 99.5 & 0.0 & 99.5 \\
$\mathrm{Tl}$ & -1.60 & 5.0 & 0.0 & 0.0 & 0.0 & 0.0 & 0.0 & 95.1 & 6.2 & 101.3 \\
$\mathrm{In}$ & -1.55 & 5.0 & 0.0 & 0.0 & 0.0 & 0.0 & 2.1 & 94.9 & 3.3 & 100.3 \\
$\mathrm{Sn}$ & -1.48 & 5.0 & 0.0 & 0.0 & 0.0 & 0.0 & 7.1 & 88.4 & 4.6 & 100.1 \\
$\mathrm{Cd}$ & -1.63 & 5.0 & 1.3 & 0.0 & 0.0 & 0.0 & 13.9 & 78.4 & 9.4 & 103.0 \\
$\mathrm{Bi}$ & -1.56 & 1.2 & - & - & - & - & - & 77 & - & - \\
\hline $\mathrm{Au}$ & -1.14 & 5.0 & 0.0 & 0.0 & 0.0 & 0.0 & 87.1 & 0.7 & 10.2 & 98.0 \\
$\mathrm{Ag}$ & -1.37 & 5.0 & 0.0 & 0.0 & 0.0 & 0.0 & 81.5 & 0.8 & 12.4 & 94.6 \\
$\mathrm{Zn}$ & -1.54 & 5.0 & 0.0 & 0.0 & 0.0 & 0.0 & 79.4 & 6.1 & 9.9 & 95.4 \\
$\mathrm{Pd}$ & -1.2 & 5.0 & 2.9 & 0.0 & 0.0 & 0.0 & 28.3 & 2.8 & 26.2 & 60.2 \\
$\mathrm{Ga}$ & -1.24 & 5.0 & 0 & 0.0 & 0.0 & 0.0 & 23.2 & 0.0 & 79.0 & 102.0 \\
\hline $\mathrm{Cu}$ & -1.44 & 5.0 & 33.3 & 25.5 & 5.7 & 3.0 & 1.3 & 9.4 & 20.5 & 103.5 \\
\hline $\mathrm{Ni}$ & -1.48 & 5.0 & 1.8 & 0.1 & 0.0 & 0.0 & 0.0 & 1.4 & 88.9 & 92.4 \\
$\mathrm{Fe}$ & -0.91 & 5.0 & 0.0 & 0.0 & 0.0 & 0.0 & 0.0 & 0.0 & 0.0 & 94.8 \\
$\mathrm{Pt}$ & -1.07 & 5.0 & 0.0 & 0.0 & 0.0 & 0.0 & 0.0 & 0.1 & 95.7 & 95.8 \\
$\mathrm{Ti}$ & -1.60 & 5.0 & 0.0 & 0.0 & 0.0 & 0.0 & tr. & 0.0 & 99.7 & 99.7 \\
\hline
\end{tabular}

Though $\mathrm{Cu}$ looks like the best metal catalyst for electrocatalytic $\mathrm{CO}_{2}$ reduction, its performance needs to be improved to achieve high efficiency and selectivity. As shown in Figure 3.2, under relative low potential of $-0.75 \mathrm{~V}$ vs. RHE (Reversible Hydrogen Electrode), only $\mathrm{H}_{2}$, $\mathrm{CO}$ and formate are produced [5]. According to previous research, the underlying reasons for high selectivity of $\mathrm{Cu}$ were related to local $\mathrm{pH}$ near electrode, morphology, particle sizes, the presence of atomic-scale defects, surface roughness, strains, and/or residual oxygen atoms in the catalysts, etc [6-9]. Experimental and computational results suggested that the active sites, chemical kinetics and transport effects greatly contributed to high efficiency and electivity. Here, we summarize the factors influencing the performance of $\mathrm{Cu}$-based catalysts. 

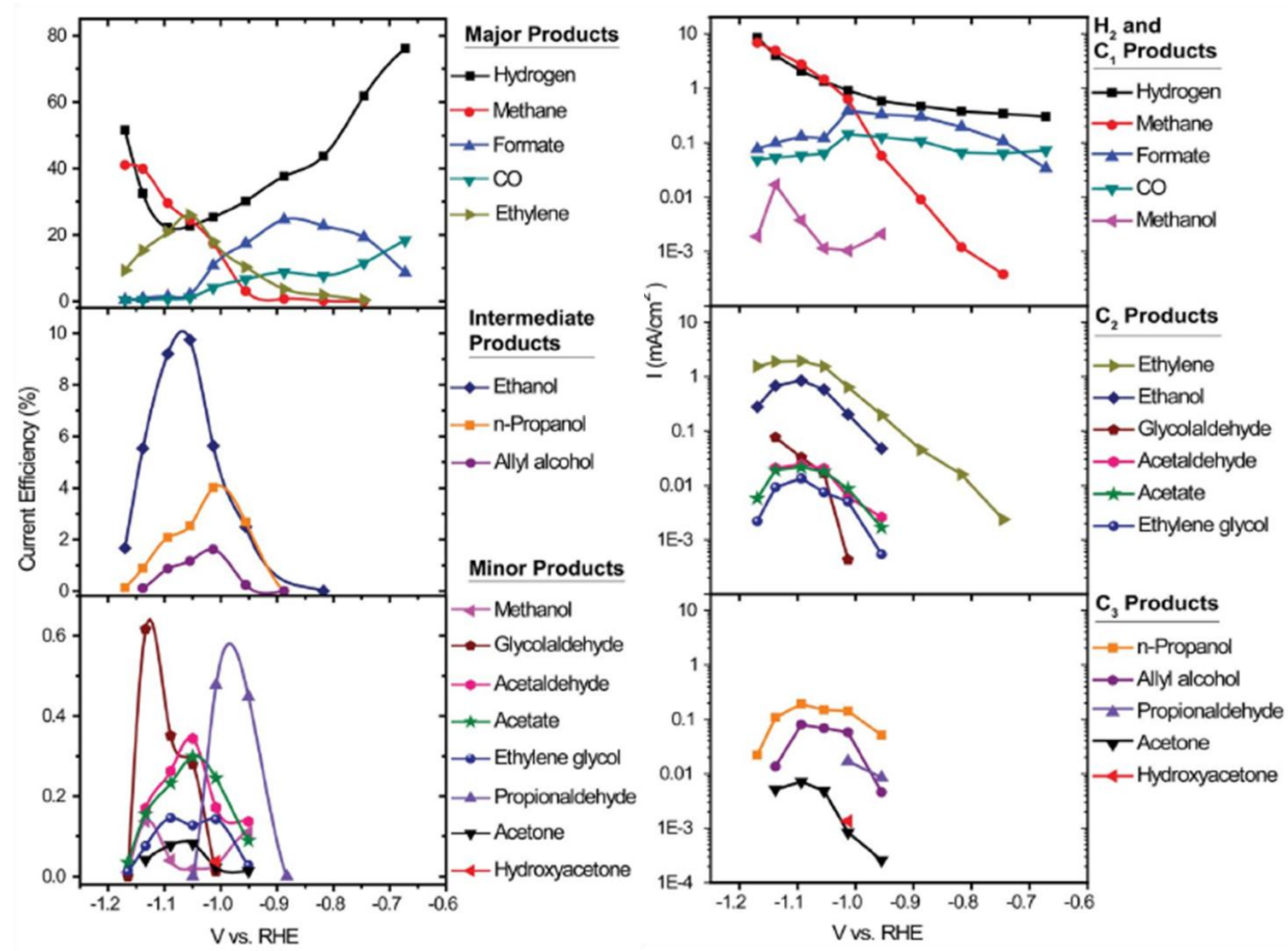

Figure 3.2. Current efficiency for each product as a function of potential (left) and Tafel plot of the partial current going to each product (right), respectively [5].

\subsection{Fabricated $\mathrm{Cu}$ as the only metal for $\mathrm{CO}_{2}$ conversion}

\subsubsection{The effects of current and potential}

In 2018, Dan Ren et al[10] conducted a survey of the current and potential for $\mathrm{CO}_{2}$ conversion, which showed the selectivity of $\mathrm{HCOO}^{-} / \mathrm{CO}, \mathrm{C}_{2} \mathrm{H}_{4}$, and $\mathrm{CH}_{4}$ was greatly affected by current and potential as long as under the mass transport limitation of $\mathrm{CO}_{2}$. Four Cu catalysts (metallic and oxide-derived) with different surface roughness were prepared via electrodeposition, termed as $\mathrm{Cu}-10, \mathrm{CuO}-1, \mathrm{CuO}-10$, and $\mathrm{CuO}-60$ with post-reduced roughness to be $1.4,5,48$, and 186 , respectively. The result showed that total current was positively related to the surface roughness and applied potential, while the maximum current for $\mathrm{CO}_{2}$ reduction 
was around $-20 \mathrm{~mA} \cdot \mathrm{cm}^{-2}$ when the total currents were around $-40 \mathrm{~mA} \cdot \mathrm{cm}^{-2}$ (Figure $\left.3 \mathrm{a}\right)$. When the total current exceeded a particular value, the current density decreased and more $\mathrm{H}_{2}$ was produced due to the low $\mathrm{CO}_{2}$ concentration and buildup of $\mathrm{OH}^{-}$near electrode (Figure $3 \mathrm{~b}$ ). It was proved that different energy barriers were the reason causing $\mathrm{CO}, \mathrm{HCOO}^{-}, \mathrm{C}_{2} \mathrm{H}_{4}, \mathrm{C}_{2} \mathrm{H}_{5} \mathrm{OH}$, and $\mathrm{CH}_{4}$ at different potential windows (Figures 3.3d-e). The morphology of $\mathrm{Cu}$ catalysts affected not only catalytic active sites, but also roughness for lying limiting current density in the suitable potential window for different products $[11,12]$.
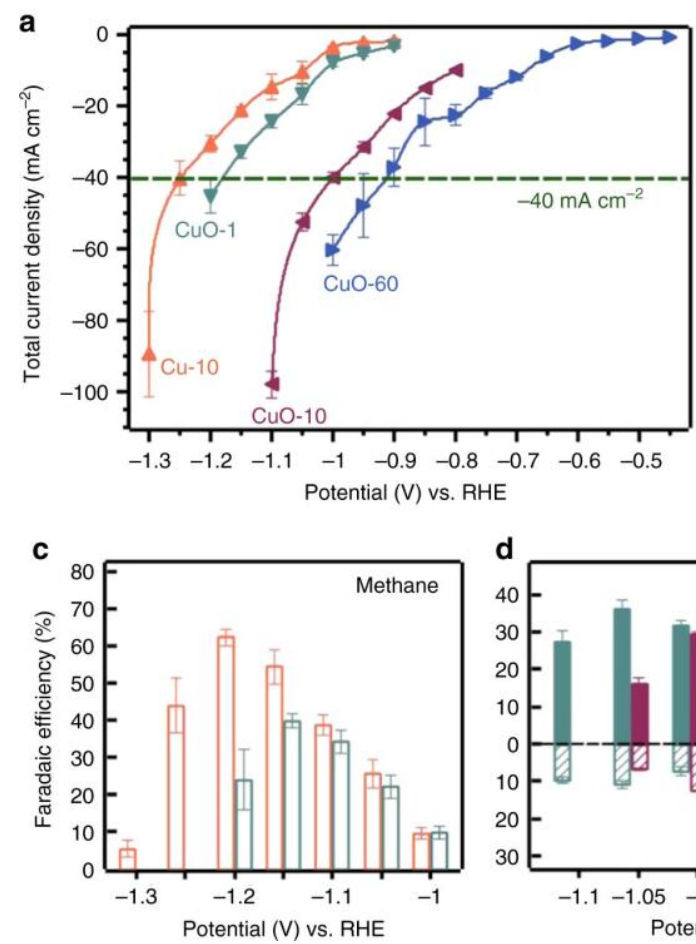
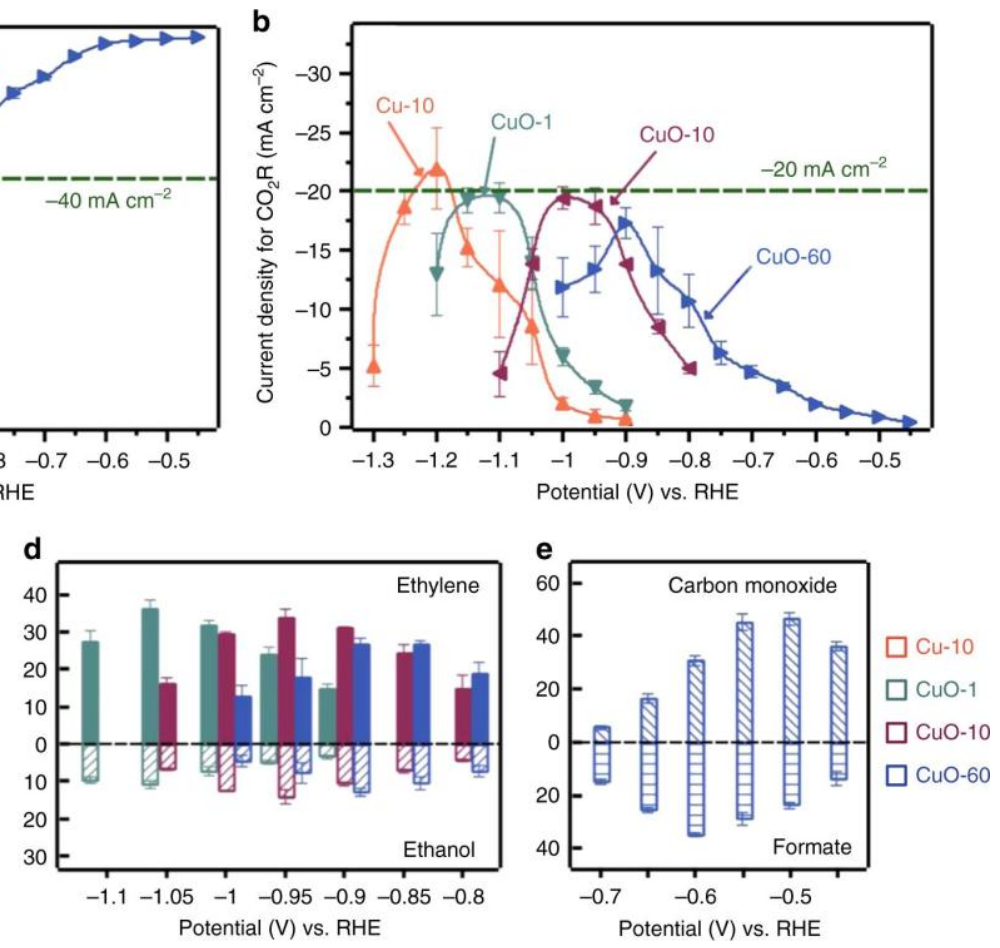

Figure 3.3. a) Total geometric current density; b) current density for $\mathrm{CO}_{2}$ reduction; c) faradaic efficiency of methane on $\mathrm{Cu}-10$ and $\mathrm{CuO}-1$; d) faradaic efficiency of ethylene and ethanol on $\mathrm{CuO}-1, \mathrm{CuO}-10$, and $\mathrm{CuO}-60$ catalysts; and e) faradaic efficiency of carbon monoxide and formate on $\mathrm{CuO}-60$ catalyst [10].

\subsubsection{The effects of catalyst structure}


According to literature reports, noble metals and ionic liquids were competent to selectively reduce $\mathrm{CO}_{2}$ to $\mathrm{CO}$ with high selectivity at low current density [13]. Unfortunately, they were restricted for bulk application due to high cost. Inspired by solid oxide fuel cell and hollow fiber from nickel and stainless steel, Recep Kas et al [14] prepared Cu hollow fibers used for CO production. The Cu hollow fibers could be employed as both gas diffuser and cathode attributed to a defect-rich porous structure as well as extraordinary improvement in mass transport (Figure 3.4). The hydrogen evolution was suppressed while the current density was unprecedentedly high at low potentials. Hence, $\mathrm{CO}_{2}$ was converted with total faradaic efficiencies up to $85 \%$ at overpotentials between 200 and $400 \mathrm{mV}$, and 75\% CO faradaic efficiency was achieved at a potential of $-0.4 \mathrm{~V}$ versus RHE [15], which showed excellent performance compared with other catalysts (Figure 3.5). 

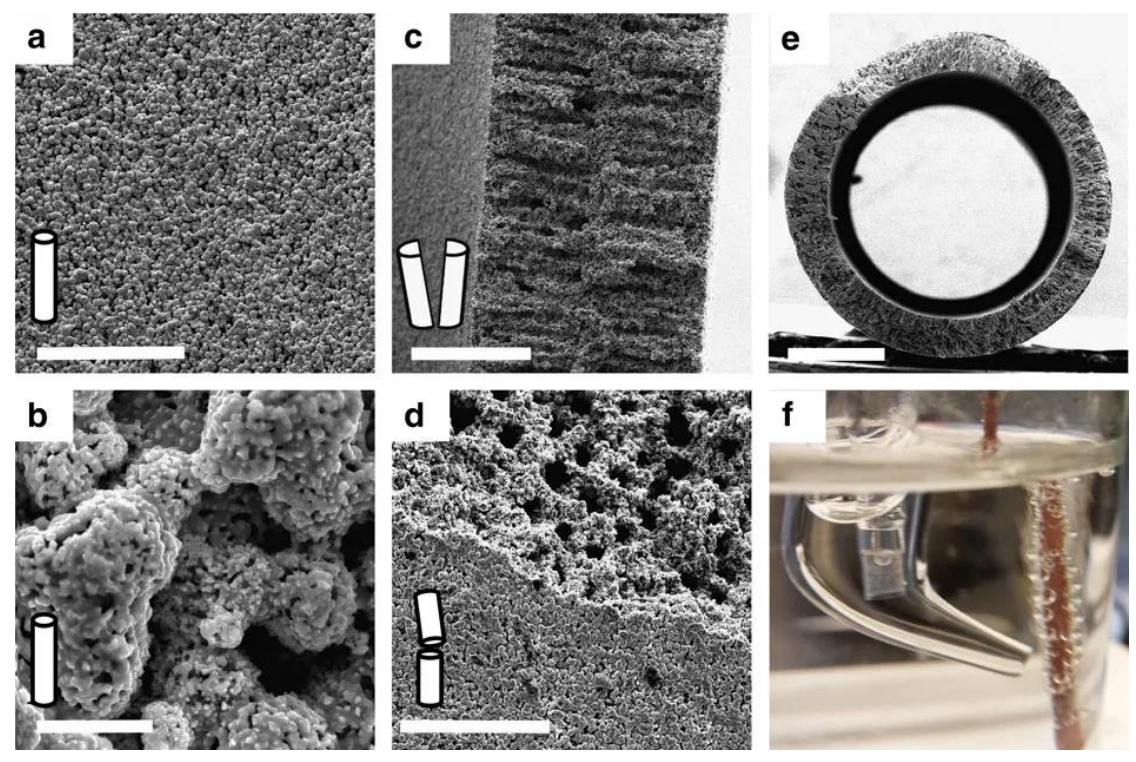

Figure 3.4. SEM images of $\mathrm{Cu}$ hollow fibers: a) outer surface, $50 \mathrm{~mm}$; b) outer surface, $2 \mathrm{~mm}$; c) cross-sectional of a perpendicularly broken, $100 \mathrm{~mm}$; d) outer surface and cross-section in the parallel direction to the length, $50 \mathrm{~mm}$, e) cross-sectional image of the $\mathrm{Cu}$ hollow fiber, $500 \mu \mathrm{m}$; and f) $\mathrm{Cu}$ hollow fiber employed as an electrode at $20 \mathrm{~mL} \cdot \mathrm{min}^{-1}$ gas flow [14].

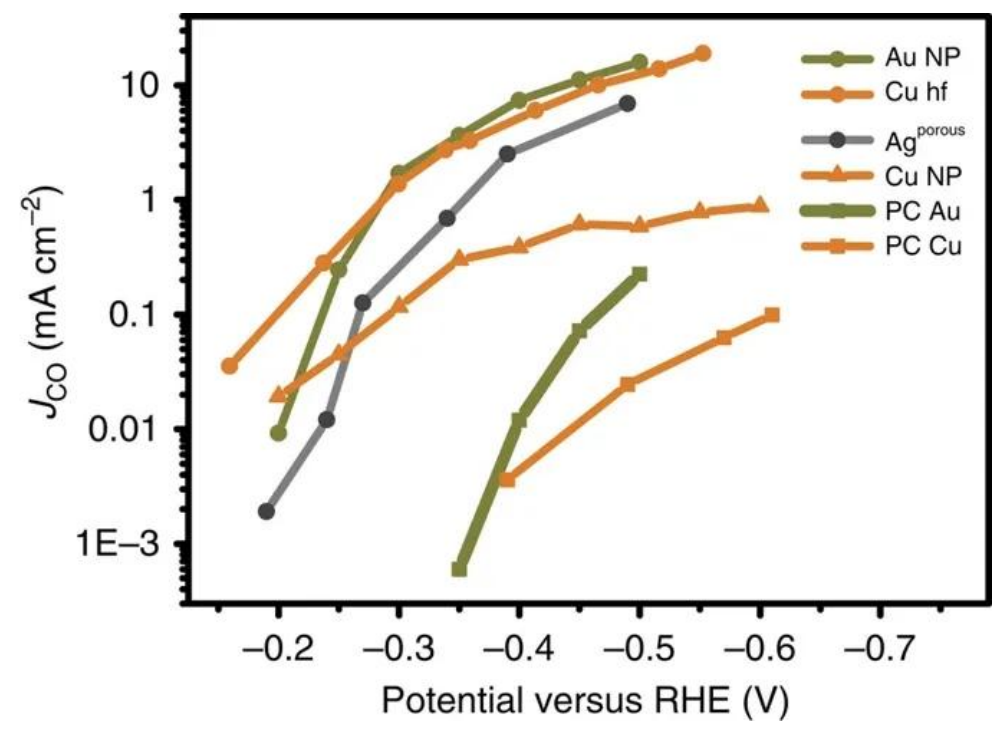

Figure 3.5. Comparison of the performance of different electrodes on the basis of the partial current density with $\mathrm{CO}$ at variable potentials [14]. 


\subsubsection{The effects of $\mathrm{pH}$ value}

The $\mathrm{pH}$ value at the electrode/electrolyte interface is proved to greatly influence the selectivity of final products. High $\mathrm{pH}$ is prone to $\mathrm{CO}$ coupling which further produces $\mathrm{C}_{2} \mathrm{H}_{4}$ [16]. In order to further improve the selectivity of hydrocarbon products affected by $\mathrm{pH}, \mathrm{Cu}$ nanowire was synthesized with different length and density (longer length was corresponding with higher density). Longer $\mathrm{Cu}$ nanowire electrode was always surrounded with higher $\mathrm{pH}$ electrolyte, because the $\mathrm{HCO}_{3}{ }^{-}$in electrolyte was hard to diffuse into the $\mathrm{Cu} \mathrm{NW}$ arrays and the $\mathrm{OH}^{-}$ generated by $\mathrm{CO}_{2}$ reduction was hard to diffuse out the $\mathrm{Cu} \mathrm{NW}$ arrays (Figure 3.6). $\mathrm{C}_{2} \mathrm{H}_{4}$ accompanied with other products (e.g $\mathrm{C}_{2} \mathrm{H}_{6}$ and ethanol) were generated on relatively longer $\mathrm{Cu}$ nanowires [17]. The result was supported by previous conclusion that CO coupling step was favored at a high local $\mathrm{pH}$ near the catalyst surface [18]. It could be an efficient approach to systematically control products on $\mathrm{Cu}$ nanowire by varying $\mathrm{Cu}$ nanowire length and even $\mathrm{pH}$ of electrolyte. 


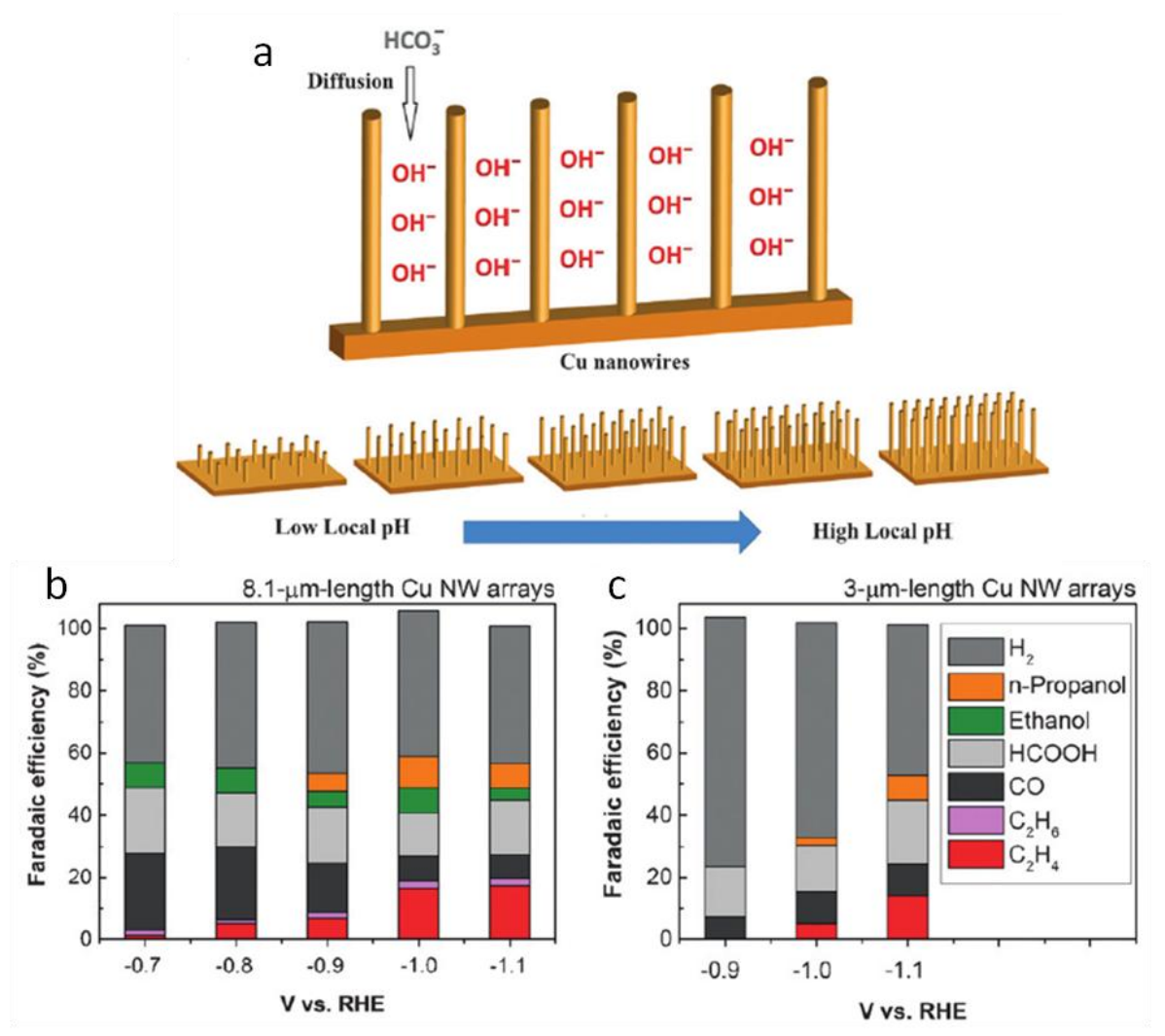

Figure 3.6. a) Schematic illustration of the diffusion of electrolytes into $\mathrm{Cu}$ nanowire arrays; $\mathrm{b}$ and c) faradaic efficiency of various products at 8.1- $\mu$ m-length $\mathrm{Cu} \mathrm{NW}$ arrays and 3- $\mu$ m-length $\mathrm{Cu}$ NW arrays, respectively [17].

\subsubsection{The effects of particle size}

It is well known that varying the size of the catalytically active species is another strategy to tune surface chemisorption and enhance catalytic activities and selectivity in many reactions, such as ammonia synthesis, hydrogenation, electrocatalytic CO oxidation [19,20]. In 2014, Rulle Reske et al [21] investigated the size effects of $\mathrm{Cu}$ nanoparticles (NP) on the $\mathrm{CO}_{2}$ reduction activity and, in particular, on product selectivity. The results showed the particles from 2 to 15 $\mathrm{nm}$ caused unexpected selectivity and activity variation. Generally, $\mathrm{Cu}$ NP exhibited higher current densities as the size decreased, which meant smaller size may cause higher activity, especially when the size was smaller than $5 \mathrm{~nm}$ (Fig 3.7). However, high activity was not 
equivalent to high selectivity. If $\mathrm{CO}$ and $\mathrm{H}_{2}$ were the preferred products to serve as feedstock for gas-to-liquid reaction technologies, the smaller size of $\mathrm{Cu}$ nanoparticles may be the better choice, while size smaller than $5 \mathrm{~nm}$ should be avoided for hydrocarbon products. Here, it was deduced that small $\mathrm{Cu}$ size may cause strong bonding between intermediate reaction species $\left({ }^{*} \mathrm{CO}\right.$ and $\left.* \mathrm{H}\right)$ and catalyst, inhibiting the mobility of $\mathrm{CO}$ and $\mathrm{H}$ to form hydrocarbon.
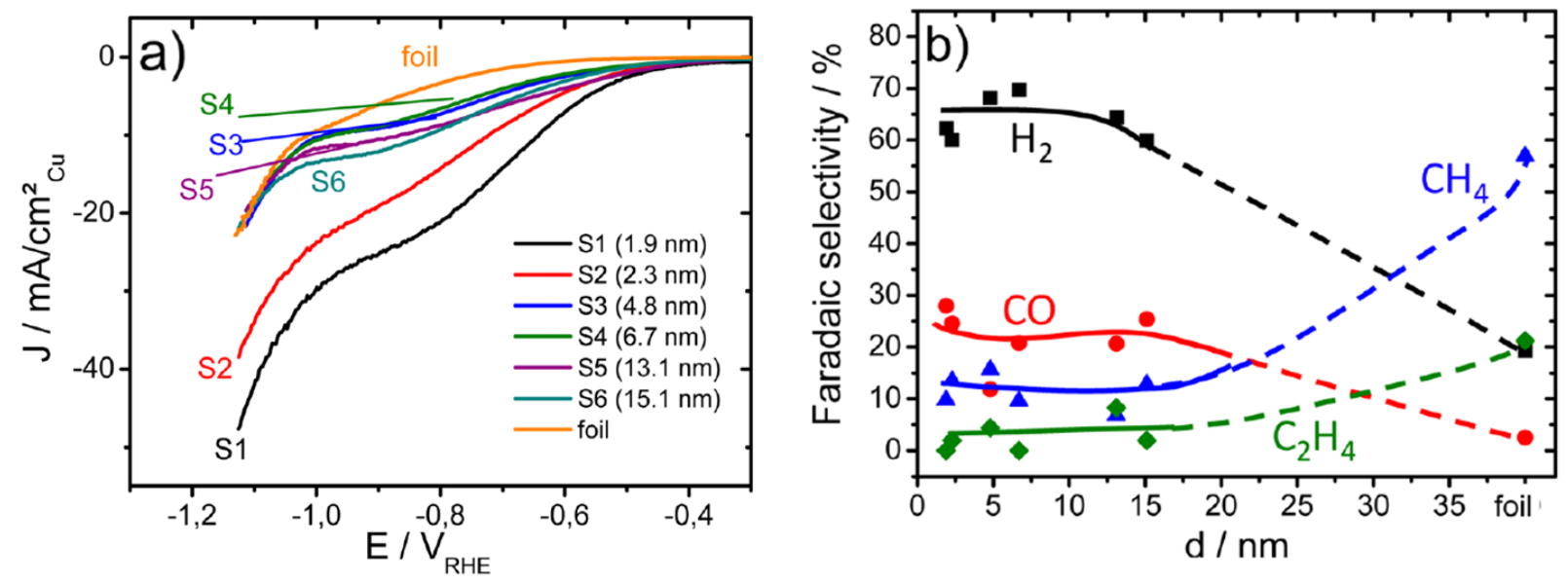

Figure 3.7. a) Linear sweep voltammetry and; b) composition of gaseous products of $\mathrm{CO}_{2}$ reduction on $\mathrm{Cu} \mathrm{NP}$ with different size [21].

\subsubsection{The effects of subsurface oxygen}

It has been reported by many groups that oxide-derived copper showed higher $\mathrm{CO}$ binding energy which changed the products of $\mathrm{CO}_{2}$ reduction [22,23]. However, the mechanism of this phenomenon was not clear until Andre'Eilert et al [24] proved the presence of oxygen and absence of oxide copper based on Ambient Pressure X-ray Photoelectron Spectroscopy (APXPS) and quasi in situ Electron Energy Loss Spectroscopy (EELS). In 2016, Andre'Eilert et al exposed a polycrystalline copper to electrochemical oxidation-reduction cycles to prepare the catalyst.

Results showed the new catalyst improved overall $\mathrm{CO}_{2}$ reduction activity and product yield towards more ethylene versus methane (Fig3.8). It was proposed that residual subsurface oxygen 
formed by oxidation-reduction cycles changed the electronic structure of the catalyst and created sites with higher carbon monoxide binding energy by reducing the $\sigma$-repulsion. Therefore, C-C bond formation was kinetically favored due to higher CO coverage on the catalyst $[25,26]$.
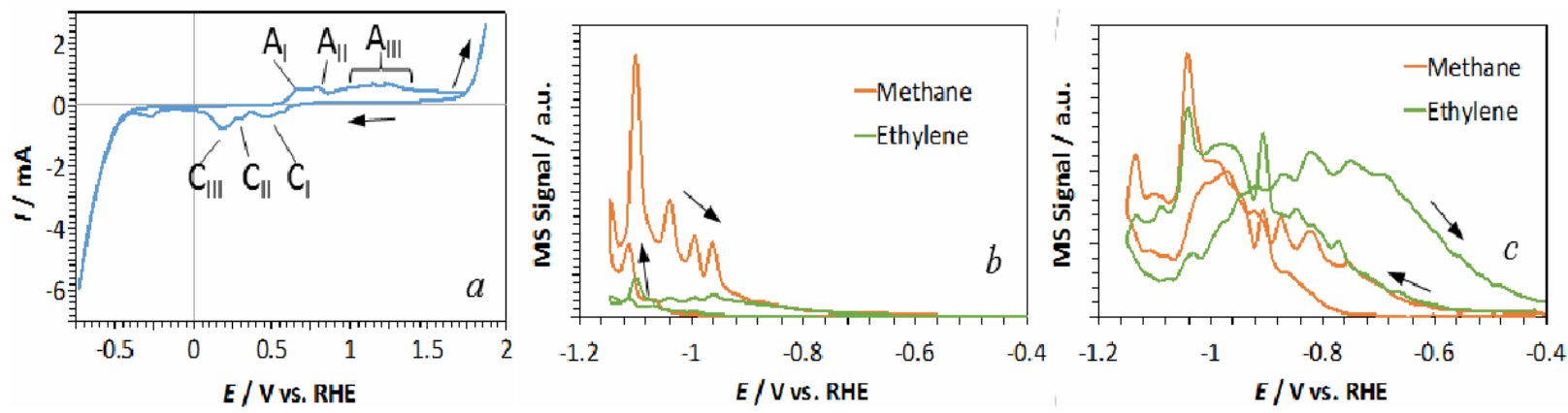

Figure 3.8. a) Cyclic voltammogram of an oxidation-reduction cycle of $\mathrm{Cu}$ in $0.1 \mathrm{M} \mathrm{KHCO}_{3}$ and $4 \mathrm{mM} \mathrm{KCl}$; b and c) online electrochemical mass spectrometry results of $\mathrm{CO}_{2}$ reduction with polycrystalline $\mathrm{Cu}(\mathrm{b})$ and $\mathrm{Cu}$ after an oxidation-reduction cycle (c) [24].

\subsubsection{The effects of sulfur and surface defect}

Atomic vacancy defects influence electrocatalytic performance by adjusting the electronic structure of neighboring atoms and consequently influence the energy barriers of the ratelimiting reaction intermediates $[27,28]$. A core-shell nanoparticles structure catalyst designated as $\mathrm{Cu}_{2} \mathrm{~S}-\mathrm{Cu}-\mathrm{V}$ (where $\mathrm{V}$ denotes vacancy) was synthesized based on the theory that copper sulfide could provide a means to form stable surface defects and control the density of surface vacancies by introducing sulfur into the $\mathrm{Cu}$ structure (Figure 3.9). Due to the synergetic effect of $\mathrm{Cu}_{2} \mathrm{~S}$ core and the surface copper vacancies, the $\mathrm{Cu}_{2} \mathrm{~S}-\mathrm{Cu}-\mathrm{V}$ played an excellent role in suppressing unwanted $\mathrm{C}_{2}$ products and shifted product distribution towards alcohols [29]. 


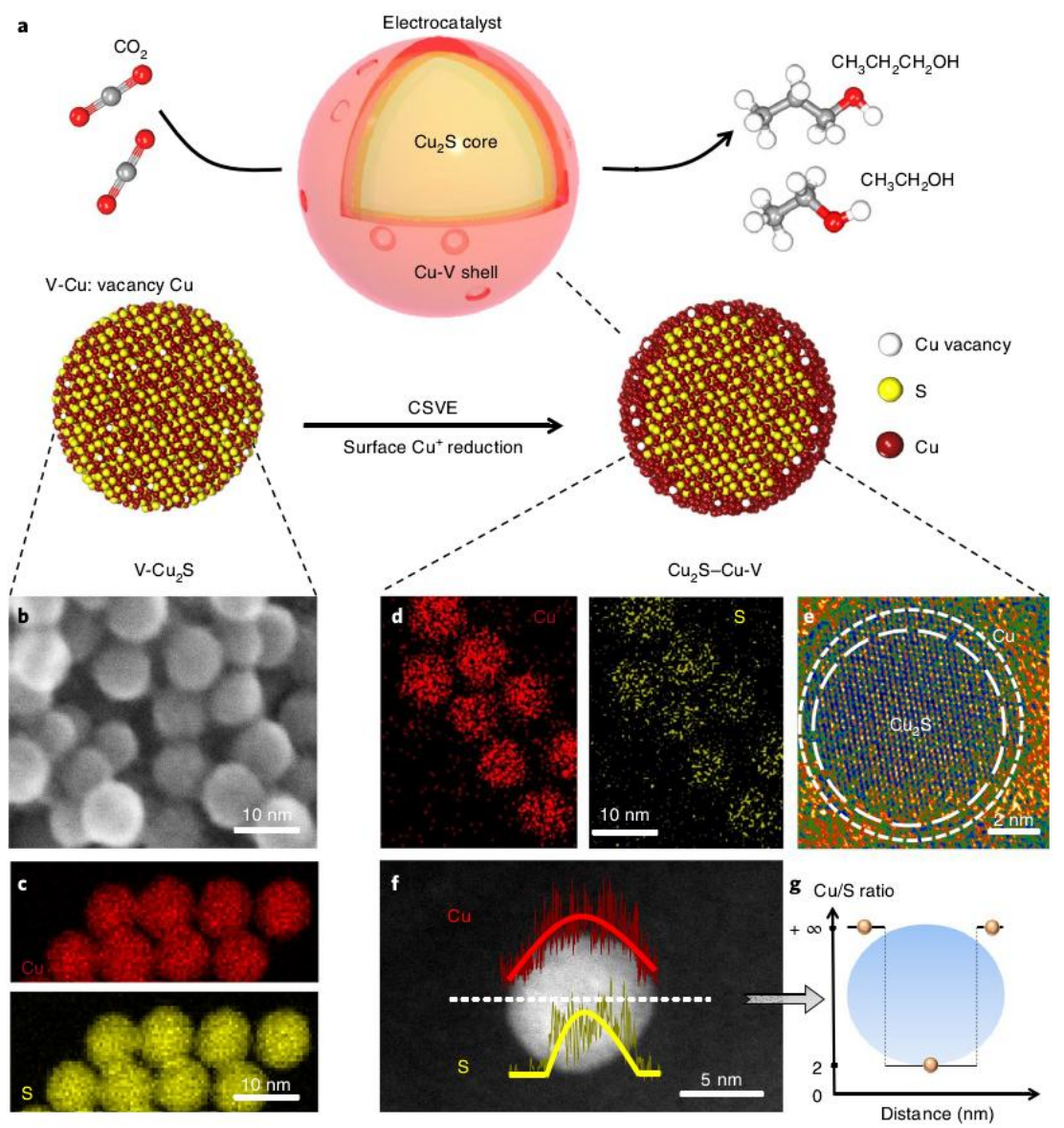

Figure 3.9. Catalyst design and structural characterization. a) Schematic illustration of $\mathrm{Cu}_{2} \mathrm{~S}-\mathrm{Cu}-$ $\mathrm{V}$ electrocatalyst design; b) TEM and c) EDS mapping of the original $\mathrm{V}-\mathrm{Cu}_{2} \mathrm{~S}$ nanoparticles; d) EDS mapping; e) high-resolution TEM; f) EDS line scan and g) the ratio of $\mathrm{Cu} / \mathrm{S}$ concentration of the reduced $\mathrm{Cu}_{2} \mathrm{~S}-\mathrm{Cu}-\mathrm{V}$ nanocatalysts after electrochemical reduction. $\mathrm{V}-\mathrm{Cu}$ indicates $\mathrm{Cu}$ with surface vacancies [29]. 


\subsection{Cu alloy catalysts}

Previous work has demonstrated that electrochemical $\mathrm{CO}_{2}$ reduction with a planar $\mathrm{Cu}$ foil as the catalyst will produce at least 16 different products in varying quantities, which require high energy consumption in product separation. $\mathrm{Cu}$-based bimetallic catalysts have been recognized as another class catalysts for $\mathrm{CO}_{2}$ electroreduction at lower overpotential. It possesses the ability to produce specific products by modulating the adsorption and desorption of key intermediates on the catalyst surface. In the past years, many published research reported to focus on developing bimetallic $\mathrm{Cu}$-based catalysts. Recent research indicated that different pattern and distribution of the bimetallic catalyst impacted not only product distribution, but also the yield [30].

\subsubsection{The selectivity to $\mathrm{CH}_{4}$}

Copper based catalysts are well known for the conversion of $\mathrm{CO}_{2}$ to $\mathrm{CO}$ and other deep reduction products with relatively favorable efficiencies at room temperature. In $2018,4 \% \mathrm{Cu}-$ doped $\mathrm{CeO}_{2}$ nanorods electrocatalyst was used for $\mathrm{CH}_{4}$ production with a faradaic efficiency as high as $58 \%$ at $-1.8 \mathrm{~V}$ [31]. In this type of catalyst, copper was well dispersedly loaded on the $\mathrm{CeO}_{2}$ at the single atomic/ionic level preventing the copper being oxidized and aggregating. There were up to three oxygen vacancies around each $\mathrm{Cu}$ site because of the substitution action of $\mathrm{Cu}$ (Figure 3.10). The synergetic effect of $\mathrm{Cu}, \mathrm{CeO}$ and oxygen vacancy resulted in a highly effective catalytic site for electroreduction. The result also mentioned that the $\mathrm{C}-\mathrm{C}$ banding was substantially prohibited on the catalyst due to atomic dispersion of the electrocatalytic $\mathrm{Cu}$ sites, dramatically enhancing $\mathrm{CH}_{4}$ formation [32,33]. 

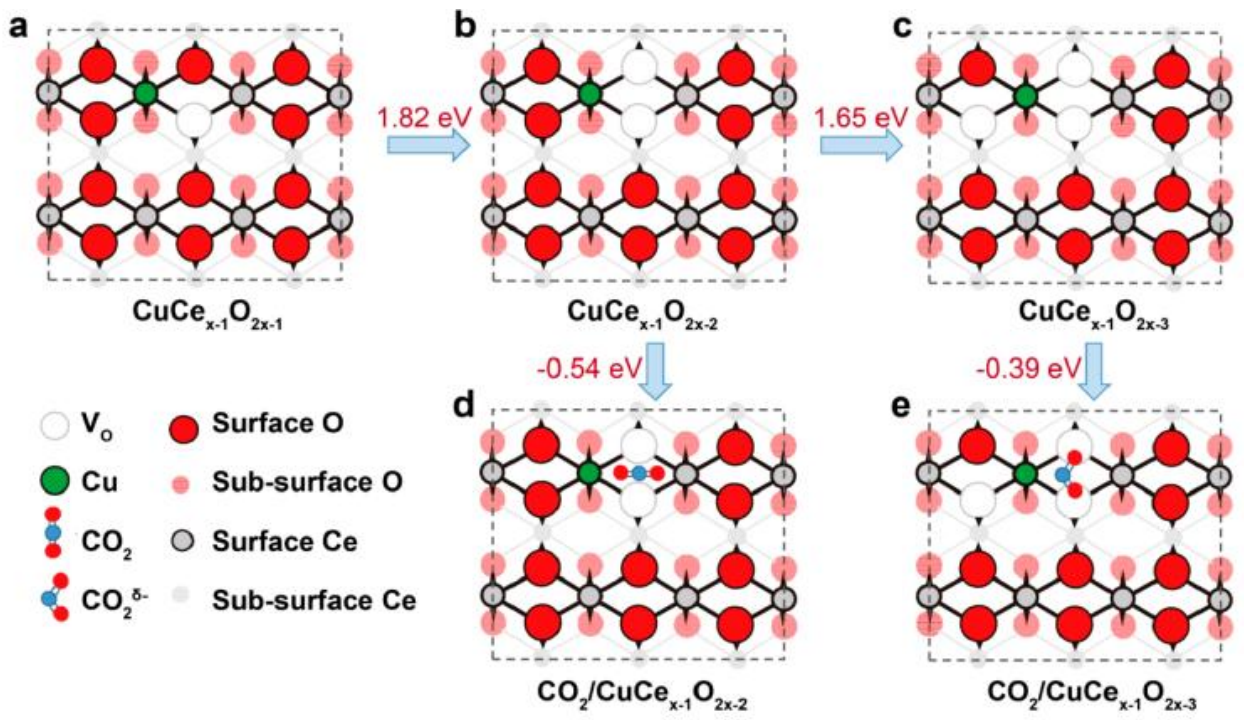

Figure 3.10. Theoretical calculations of the most stable structures of $\mathrm{Cu}$-doped $\mathrm{CeO}_{2}(110)$ and their effects on $\mathrm{CO}_{2}$ activation [31].

\subsubsection{The selectivity for syngas}

Though $\mathrm{Cu}$-based catalysts have excellent performance for $\mathrm{CO}_{2}$ reduction, there are still two problems need to be solved, poor resistance to oxidation and selectivity. To solve the problems, an ultrathin $\mathrm{Cu} / \mathrm{Ni}(\mathrm{OH})_{2}$ nanosheets catalyst was engineered using sodium formate as protector to prevent $\mathrm{Cu}$ being oxidized and $\mathrm{Ni}(\mathrm{OH})_{2}$ as supporter for preventing $\mathrm{Cu}$ nanosheets from being sintered during electrocatalysis (Figure 3.11A-E). Because the redox potential of $\mathrm{HCOO}^{-}$was lower than $\mathrm{Cu}, \mathrm{HCOO}^{-}$suppressed oxidation of $\mathrm{Cu}$ similar to the cathodic protection in galvanized iron pipes. $\mathrm{Cu} / \mathrm{Ni}(\mathrm{OH})_{2}$ exhibited both excellent $\mathrm{CO}_{2}$ adsorption ability and superior charge transport kinetics. It was cost-effective, and the nanosheets provided a current density of $4.3 \mathrm{~mA} \cdot \mathrm{cm}^{-2}$ with a CO Faradaic efficiency of $92 \%$ at a low overpotential of $-0.39 \mathrm{~V}$. Interestingly, syngas was the only products and the ratio of $\mathrm{CO}$ and $\mathrm{H}_{2}$ was tunable by applying different potentials $[34,35]$. The high selectivity may be attributed to the following reasons: 1 ) $\mathrm{Cu} / \mathrm{Ni}(\mathrm{OH})_{2}$ had excellent ability to absorb $\mathrm{CO}_{2}$ while poor ability to absorb $\mathrm{CO} ; 2$ ) $\mathrm{Cu} / \mathrm{Ni}(\mathrm{OH})_{2}$ 
exhibited a superior charge transport kinetics; 3) the existence of $\mathrm{HCOO}^{-}$prevented the $\mathrm{Cu}$ from being oxidized; 4) the $\mathrm{Cu}$ was well dispersed (Figures 3.11 F, G).
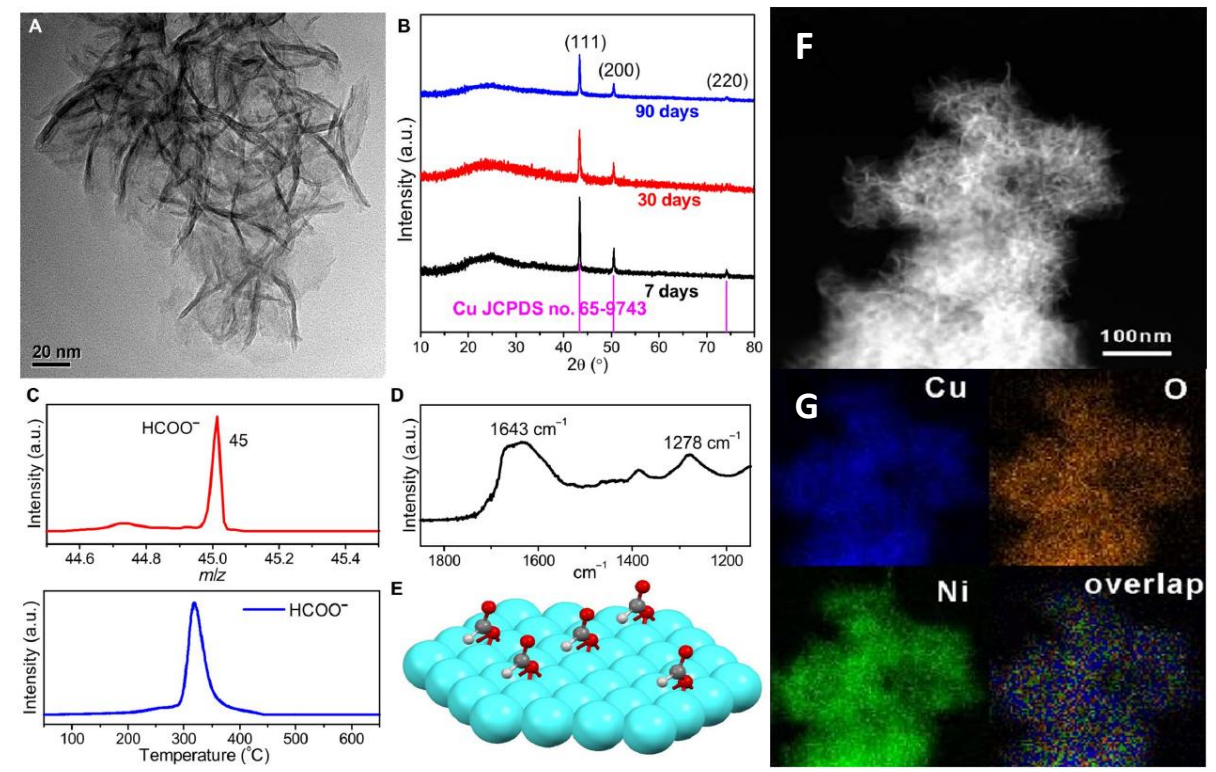

Figure 3.11. A) TEM image of the $\mathrm{Cu} / \mathrm{Ni}(\mathrm{OH})_{2}$ nanosheets after being stored in air at room temperature for 90 days; B) XRD patterns of the nanosheets after storing in air at room temperature for 7 to 90 days; c) TPD-MS profiles of the $\mathrm{Cu} / \mathrm{Ni}(\mathrm{OH})_{2}$ nanosheets heated in vacuum, whereas the bottom shows relative ionization intensities of the main decomposition products at different temperatures, the top displays the accumulative ionization intensity $(\mathrm{m} / \mathrm{z}$, mass/charge ratio); D) FTIR spectrum of the nanosheets and E) adsorption model of formate on $\mathrm{Cu}$ (color codes: cyan, $\mathrm{Cu}$; red, O; gray, C; white, H). F) STEM and G) EDX mapping images of the $\mathrm{Cu} / \mathrm{Ni}(\mathrm{OH})_{2}$ nanosheets [34].

When particle size was between 5 and $15 \mathrm{~nm}, \mathrm{Cu}$ exhibited similar catalytic selectivity in hydrocarbon formation, while the catalytic performance and selectivity unexpectedly increased with decreasing $\mathrm{Cu}$ particle size when its size was below $5 \mathrm{~nm}$. Meanwhile, previous work proved that finely controlled size of Pd displayed high Faradaic efficiency and current density for $\mathrm{CO}$ production. Here, Zhen Yin et al [36] synthesized the Cu-Pd bimetallic alloy with different ratio supported on carbon to produce $\mathrm{CO} . \mathrm{Pd}_{85} \mathrm{Cu}_{15} / \mathrm{C}$ catalyst showed good activity and 
selectivity (Figure 3.12) because the rate-determining steps of $\mathrm{CO}_{2}$ absorption and $\mathrm{CO}$ desorption were improved while the $\mathrm{H}^{+}$combination was inhibited due to synergistic effect of electronic effect and geometric effect.
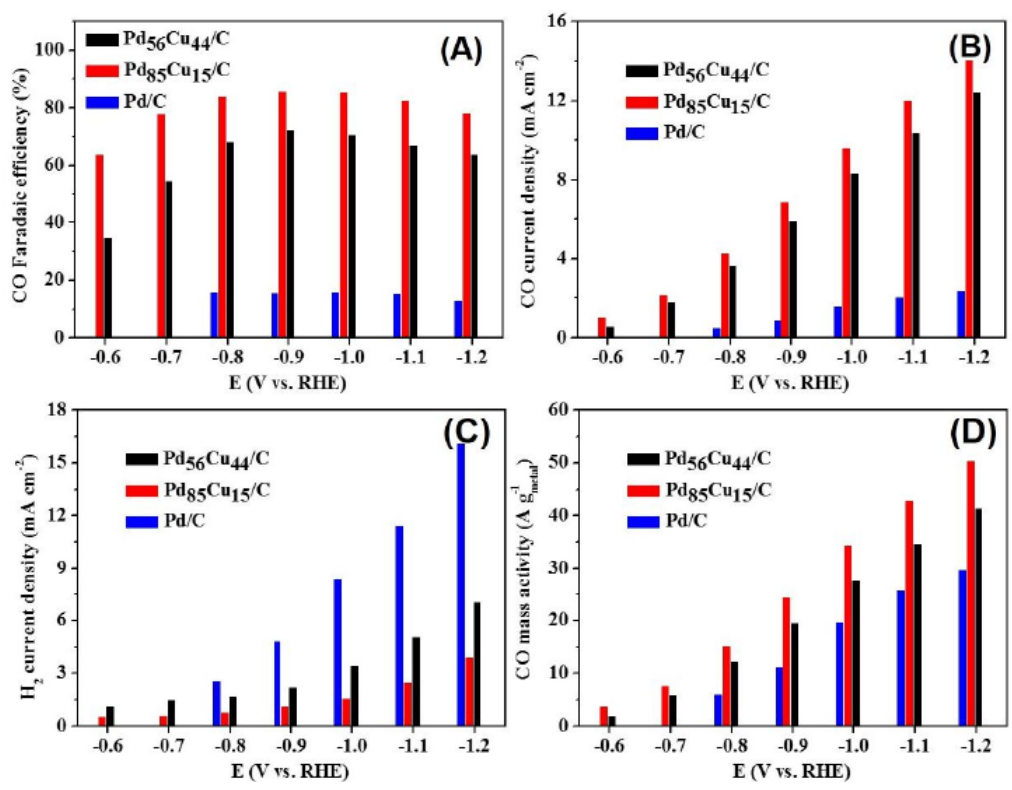

Figure 3.12. $\mathrm{CO}_{2}$ reduction activity over $\mathrm{PdCu} / \mathrm{C}$ and $\mathrm{Pd} / \mathrm{C}$ catalysts in $\mathrm{CO}_{2}$-saturated $0.1 \mathrm{M}$ $\mathrm{KHCO}_{3}$ solution [36].

\subsubsection{The selectivity for multiple-carbon products}

Recently, many alloying catalysts have been synthesized to convert $\mathrm{CO}_{2}$ to multiple-carbon products, especially oxygenated species such as alcohols, because these products are generally more valuable than their hydrocarbon counterparts and they are in liquid form under ambient conditions which simplify the subsequent processing, storage, and distribution [37].

\section{CuPd nanoalloys}

It was another challenge to evaluate the relationship between the atomic arrangements/ ratios (Figure 3.13) and the performance of $\mathrm{CO}_{2}$ reduction. Related studies [38] were conducted to elucidate the mechanism, showing the phase-separated bimetallic catalysts produced $\mathrm{C}_{2}$ 
chemicals while the well-ordered catalysts favored the conversion of $\mathrm{CO}_{2}$ to $\mathrm{CH}_{4}$. For the phaseseparated catalysts, the $\mathrm{Cu}$ atoms structure may allow for favorable molecular distance and small steric hindrance for dimerizing $* \mathrm{CO}$ and $* \mathrm{COH}$ which were further converted to $\mathrm{C}_{2}$ products. While for the ordered structure, Pd stabilized surface ${ }^{*} \mathrm{CHO}$ which were further converted to $\mathrm{CH}_{4}$. It was shown that electronic effect played less important role than geometric/structural effect which determined catalytic selectivity and activity, because $\mathrm{Cu}$ had much higher d-band position than $\mathrm{PdCu}$. It was further proved that $\mathrm{Cu}$ had much better performance to produce $\mathrm{C}_{2}$ than that of Pd (Figure 3.14). Based on a literature report, the orientation of intermediate toward the active sites influenced the reaction, similarly, different ratios of component in the bimetallic catalysts caused various orientations of the intermediate on the surface, therefore led to different selectivity [39].

(a)

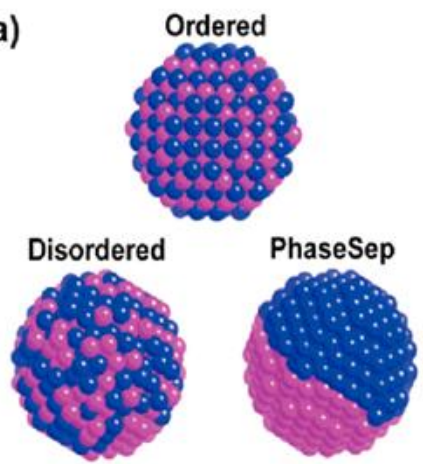

(b)

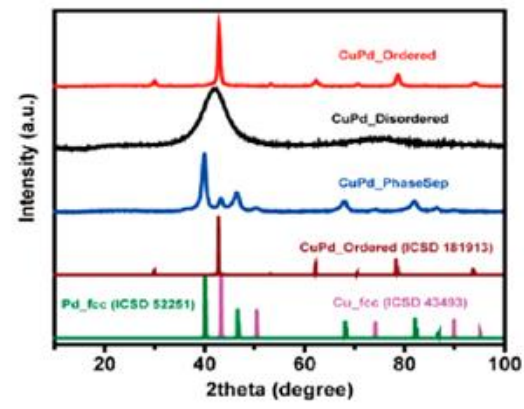

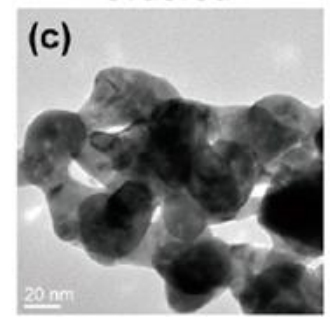

Disordered

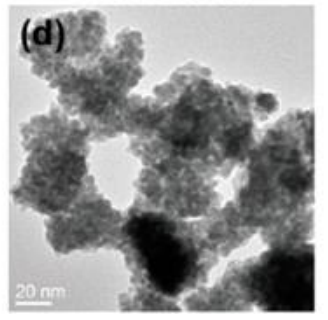

PhaseSep

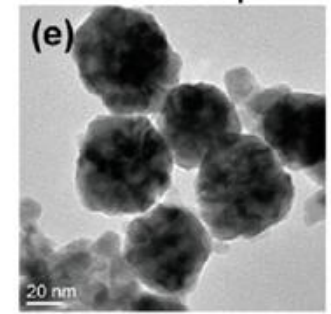

Figure 3.13. a) Illustration of the prepared CuPd nanoalloys with different structures; b) XRD patterns of $\mathrm{CuPd}$ nanoalloys, $\mathrm{Cu}, \mathrm{Pd}$ and $\mathrm{CuPd}$ alloys; c-e) high-resolution TEM images of $\mathrm{Cu}$ (red) and Pd (green) [38]. 

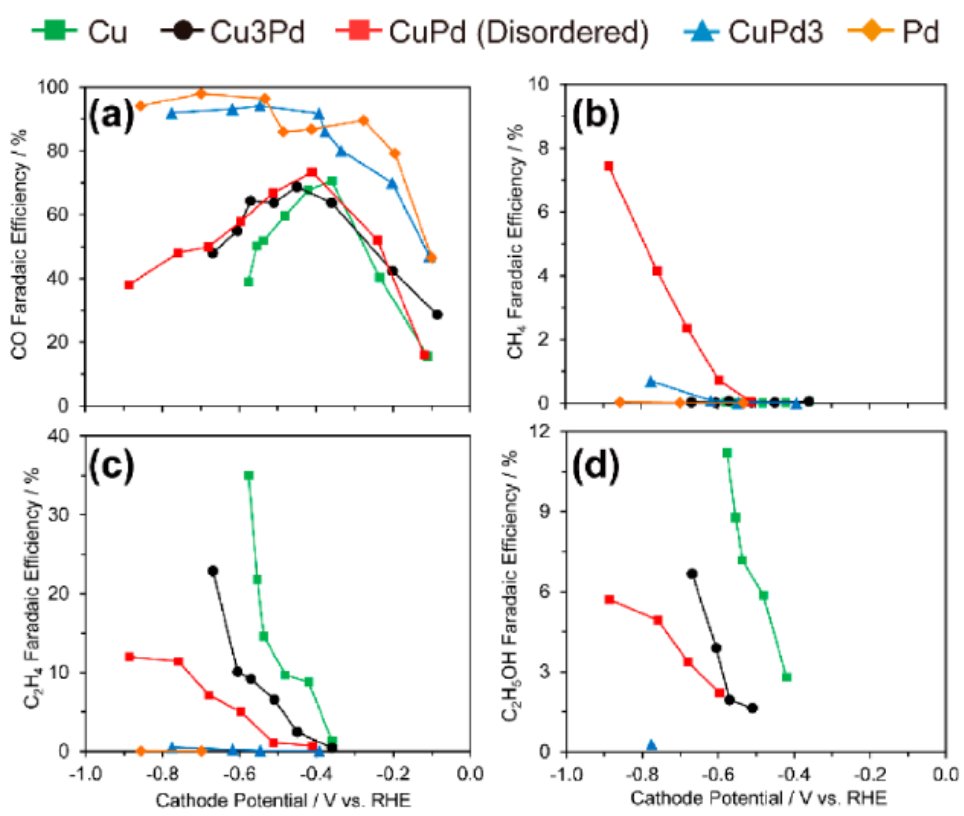

Figure 3.14. Faradaic efficiencies for a) $\mathrm{CO}$; b) $\mathrm{CH}_{4}$; c) $\mathrm{C}_{2} \mathrm{H}_{4}$; d) $\mathrm{C}_{2} \mathrm{H}_{5} \mathrm{OH}$ for catalysts with different $\mathrm{Cu}: \mathrm{Pd}$ ratios: $\mathrm{Cu}, \mathrm{Cu}_{3} \mathrm{Pd}, \mathrm{CuPd}, \mathrm{CuPd}_{3}$, and $\mathrm{Pd}[38]$.

\section{CuZn nanoalloys}

Among all products from the reduction of $\mathrm{CO}_{2}$, ethanol is an attractive liquid fuel. However, due to the barrier of higher energy needed for $\mathrm{C}-\mathrm{C}$ coupling, previously mentioned $\mathrm{Cu}$ nanostructure only produced ethanol with faradaic efficiency generally $<20 \%$ while ethylene as the primary $\mathrm{C}_{2}$ product [40]. Though heteroatoms have been added to $\mathrm{Cu}$ to improve selectivity between ethanol and ethylene, it is hard to realize both high partial current and high selectivity [41]. In order to overcome the shortcoming, $\mathrm{ZnO}$ was used to modify the $\mathrm{CuO}$ nanowires surface using atomic layer deposition (ALD) to improve selectivity. Compared to commonly used methods, such as electrodeposition, annealing or solution processing, ALD was flexible to adjust various bimetallic structures and/or the ratio between different metallic components. As a result, $48.6 \%$ faradaic efficiency and $97 \mathrm{~mA} \cdot \mathrm{cm}^{-2}$ partial current density for $\mathrm{C}_{2}$ liquids was achieved at $-0.68 \mathrm{~V} .32 \%$ faradaic efficiency of ethanol was formed at $-1.15 \mathrm{~V}$ and the partial current density increased from $7.5 \mathrm{~mA} \cdot \mathrm{cm}^{-2}$ on $\mathrm{Cu}$ to $10.5 \mathrm{~mA} \cdot \mathrm{cm}^{-2}$ on $\mathrm{CuZn}$. According to the 
systematic analysis of the electrocatalytic behavior, it was believed that the presence of $\mathrm{Zn}$ modified the binding energy of $\mathrm{CO}$ on $\mathrm{Cu}$, which was combined with $* \mathrm{CH}_{3}$ to form $* \mathrm{COCH}_{3}$, a precursor of ethanol [42].

Scientists also propose to alloy $\mathrm{Ag}$ with $\mathrm{Cu}$ to bring their superiority into full play, because $\mathrm{Ag}$ is a highly selective catalyst for $\mathrm{CO}$ production while $\mathrm{Cu}$ possesses the capability to further reduce $\mathrm{CO}$ to more valued products $[43,44]$. CuAg nanoporous structure catalyst was synthesized using 3,5-diamino-1,2,4-triazole (DAT) as an inhibitor (Figure 3.15). Because of the existence of $\mathrm{DAT}$, the nucleation of $\mathrm{Cu}$ or $\mathrm{Ag}$ was inhibited, and $\mathrm{Cu}$ and $\mathrm{Ag}$ were homogeneously mixed via electrodeposition. The catalyst exhibited excellent efficiency with about $60 \% \mathrm{C}_{2} \mathrm{H}_{4}$ and $25 \%$ $\mathrm{C}_{2} \mathrm{H}_{5} \mathrm{OH}$ at a relatively low applied potential (-0.7 V vs. RHE) and a high current density (300 $\mathrm{mA} \cdot \mathrm{cm}^{-2}$ ) [45]. According to previous research results [46], $\mathrm{Cu}_{2} \mathrm{O}$ was mainly responsible for high yield of $\mathrm{CH}_{3} \mathrm{OH}$. It was deduced here that high selectivity towards $\mathrm{C}_{2} \mathrm{H}_{4}$ and $\mathrm{C}_{2} \mathrm{H}_{5} \mathrm{OH}$ was because the incorporation of $\mathrm{Ag}$ into the alloy. In one aspect, $\mathrm{Ag}$ oxide could be reduced by $\mathrm{Cu}$ due to the formation enthalpies of $\mathrm{Cu}_{2} \mathrm{O}\left(-169 \mathrm{~kJ} \cdot \mathrm{mol}^{-1}\right)$ and $\mathrm{Ag}_{2} \mathrm{O}\left(-31.1 \mathrm{~kJ} \cdot \mathrm{mol}^{-1}\right)$; In another aspect, $\mathrm{Cu}$ was more likely to be oxygenated to $\mathrm{Cu}_{2} \mathrm{O}$ because $\mathrm{Cu}$ atoms in the $\mathrm{CuAg}$ samples tended to carry a slightly positive charge. In 2018, Drew Higgins [47] prepared CuAg thin films with nonequilibrium $\mathrm{Cu} / \mathrm{Ag}$ alloying for $\mathrm{CO}_{2}$ reduction, further explaining why $\mathrm{Ag}$ could improve the selectivity to $\mathrm{C}_{2}$ products. The results indicated that though the overall reduction activity decreased for $\mathrm{CuAg}$ versus $\mathrm{Cu}, \mathrm{Ag}$ miscibility into $\mathrm{Cu}$ increased the activity and selectivity toward liquid carbonyl products likely due to the decreased surface binding energies of oxygen-containing intermediate species. Meanwhile, it was observed that the competing products of hydrocarbons and $\mathrm{H}_{2}$ were significantly suppressed. Density functional theory (DFT) simulation suggested that $\mathrm{Ag}$ doped in $\mathrm{Cu}$ weakened the binding energy of $* \mathrm{H}$ species, causing 
the steadily decrease in activity and selectivity toward hydrocarbons and the $\mathrm{H}_{2}$ when the ratio of $\mathrm{Ag} / \mathrm{Cu}$ increased. The better understanding of the underlying mechanisms may further improve selectivity toward liquid carbonyl products.
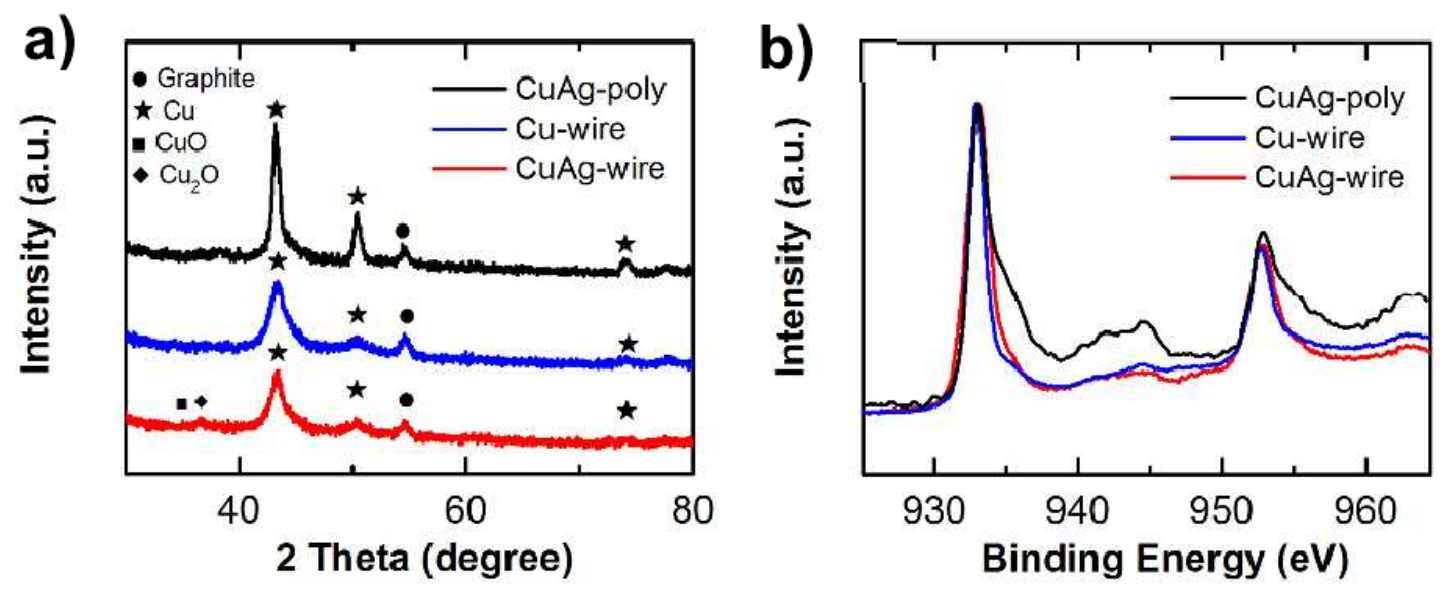

Figure 3.15. a) XRD and b) XPS patterns of CuAg-poly (6\% Ag) electrodeposited without DAT, $\mathrm{Cu}$-wire (0\% Ag) electrodeposited with DAT, and CuAg-wire (6\% Ag) electrodeposited with DAT [45].

\subsection{Organic $\mathrm{Cu}$}

It was reported that the hydrophobicity of electrode was regarded as an determinant on the selectivity of $\mathrm{CO}_{2}$ reduction, because its submerged hydrophobic surfaces trapped appreciable amounts of gas at the nanoscale which facilitates $\mathrm{CO}_{2}$ accumulation at the $\mathrm{Cu}$-solution interface $[48,49]$. Inspired by the plastrons of diving bell spider composed of hydrophobic hairs that trapped air and thereby allowed the spider to respire under water, a hierarchically structured $\mathrm{Cu}$ dendrites electrode was synthesized with super hydrophobic surface generated by 1octadecanethiol treatment (Figure 3.16). As a result, $\mathrm{H}_{2}$ evolution was substantially suppressed from $71 \%$ faradaic efficiency to $10 \%$, while $\mathrm{CO}_{2}$ reduction was increased from $24 \%$ to $86 \%$, of which $\mathrm{C}_{2}$ products comprised $74 \% \mathrm{FE}[50]$. 

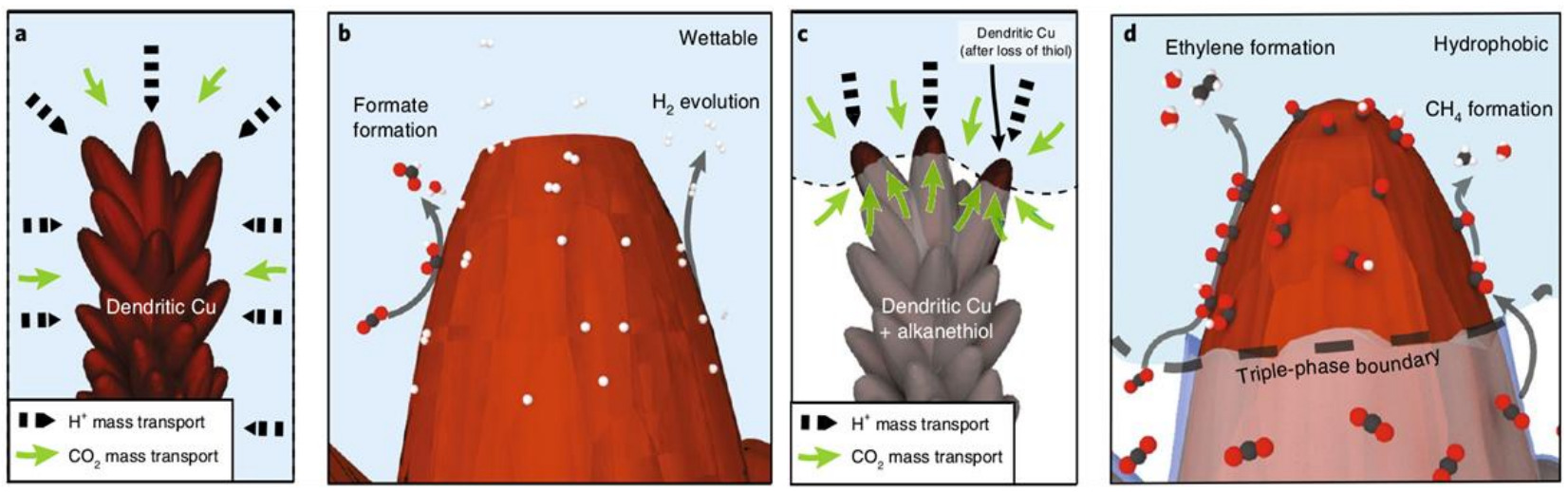

Figure 3.16. The illustration of a-b) wettable dendrite electrode and c-d) hydrophobic dendrite electrode for electroreduction [50].

Zhe Weng et al [51] synthesized a Cu centered organic catalyst in 2016, copper-porphyrin complex (copper(II)-5,10,15,20-tetrakis-(2,6-dihydroxyphenyl) porphyrin), called PorCu (Figure 3.17). It was used as a heterogeneous electrocatalyst for reducing $\mathrm{CO}_{2}$ to hydrocarbons in aqueous media. At the point of $-0.976 \mathrm{~V}$, the partial current densities of $\mathrm{CH}_{4}$ and $\mathrm{C}_{2} \mathrm{H}_{4}$ were 13.2 and $8.4 \mathrm{~mA} \cdot \mathrm{cm}^{-2}$, while the corresponding turnover frequencies were 4.3 and 1.8 molecules $\cdot$ site $^{-}$ ${ }^{1} \cdot \mathrm{s}^{-1}$, respectively. The catalytic reaction rates for hydrocarbon products were higher than other reported molecular metal complex catalyst and most $\mathrm{Cu}$ based electrocatalysts at around $\sim-1 \mathrm{~V}$. It was considered the $\mathrm{Cu}$ center and $\mathrm{OH}$ groups in the porphyrin structure played indispensable role for the high conversion $[52,53]$. Especially, the PorCu molecular structure with the $\mathrm{Cu}$ center in the +1 oxidation state worked as the active catalyst for electrochemically converting $\mathrm{CO}_{2}$ to $\mathrm{CH}_{4}$ and $\mathrm{C}_{2} \mathrm{H}_{4}$, and the $\mathrm{OH}$ groups may help bind certain reaction intermediates or provide an intra molecular source of protons. 


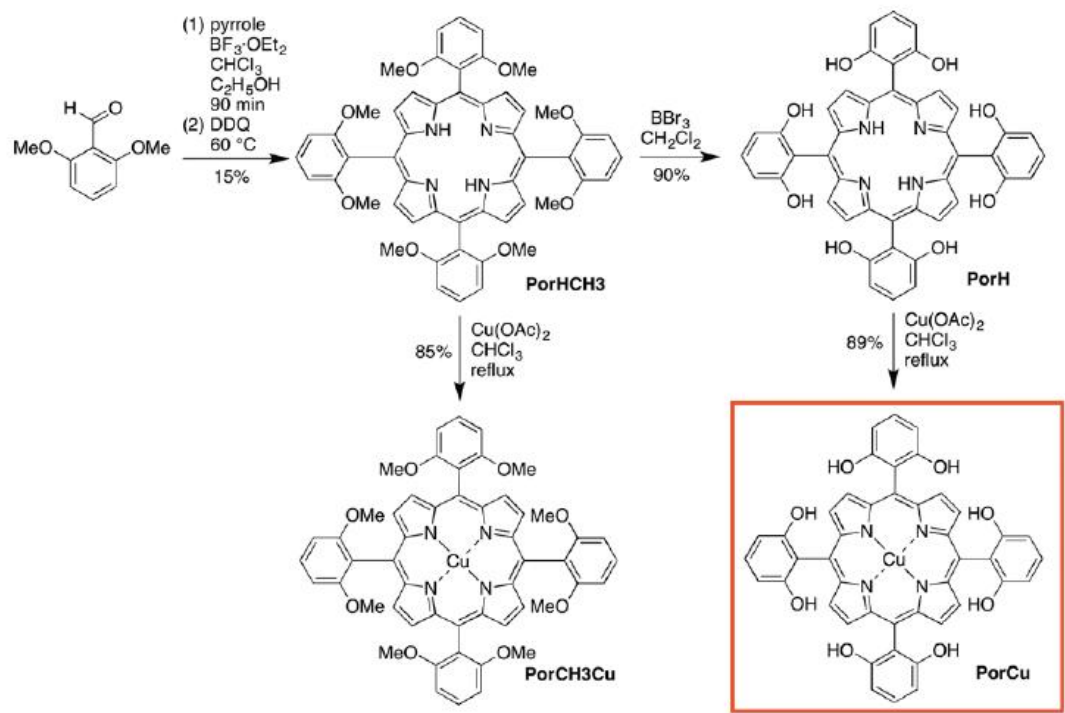

Figure 3.17. Synthetic routes for copper-porphyrin molecular catalysts [51]. 


\subsection{Conclusion}

In this chapter, we discuss why $\mathrm{Cu}$ is the most popular metal and briefly introduce the electrochemical cell used for $\mathrm{CO}_{2}$ electroreduction. Furthermore, referring to recent representative $\mathrm{Cu}$-based catalysts, we illustrate factors influencing the performance of catalysts and primarily explain how those factors impact the activity and selectivity of $\mathrm{CO}_{2}$ conversion. Those factors are $\mathrm{pH}$ value, morphology, particle sizes, the presence of atomic-scale defects, surface roughness, and/or residual oxygen atoms, and so on. In summary, these factors can benefit selectivity and yield by optimizing binding capability of $\mathrm{CO}_{2}$ and intermediates, suppressing hydrogen formation and improving electron transportation. There are many methods that are introduced to optimize the performance of $\mathrm{Cu}$-based catalyst. For example, doping $\mathrm{Cu}$ with other metal proves to be an effective and feasible option. Doping may help change both the inner structure and outer structure simultaneously, further optimizing the binding energy, improving electron transportation and suppressing hydrogen formation. This chapter can guide us to produce more ideal catalysts, in addition, the information presented in this chapter can be a foundation to summarize the property and mechanism in next chapter.

Nevertheless, it is very difficult to fairly and objectively compare current results used for analyzing the catalytic performance of different catalysts due to a lack of standardized methods for measuring and reporting activity data [54]. The conversion rate of $\mathrm{CO}_{2}$ is influenced by catalyst type, electrolyte, hydrodynamics of the electrochemical cell, etc. Hence, the recommended measurements should evaluate the data in the absence of a convolution of intrinsic kinetics and mass transport effects and will not introduce artifacts from impurities, either from the electrolyte or counter electrode. In addition, electrochemical reactions rates should be 
normalized to both the geometric electrode area and the electrochemically active surface area to facilitate the comparison of reported catalysts $[55,56]$. 


\section{Reference}

[1] Zhao, C., \& Wang, J. (2016). Electrochemical reduction of $\mathrm{CO}_{2}$ to formate in aqueous solution using electro-deposited Sn catalysts. Chemical Engineering Journal, 293, 161-170.

[2] Wu, J., Risalvato, F. G., Ma, S., \& Zhou, X. D. (2014). Electrochemical reduction of carbon dioxide III. The role of oxide layer thickness on the performance of Sn electrode in a full electrochemical cell. Journal of Materials Chemistry A, 2(6), 1647-1651.

[3] Bagger, A., Ju, W., Varela, A. S., Strasser, P., \& Rossmeisl, J. (2017). Electrochemical CO 2 reduction: a classification problem. ChemPhysChem, 18(22), 3266-3273.

[4] Hori, Y., Wakebe, H., Tsukamoto, T., \& Koga, O. (1994). Electrocatalytic process of CO selectivity in electrochemical reduction of $\mathrm{CO}_{2}$ at metal electrodes in aqueous media. Electrochimica Acta, 39(11-12), 1833-1839.

[5] Kuhl, K. P., Cave, E. R., Abram, D. N., \& Jaramillo, T. F. (2012). New insights into the electrochemical reduction of carbon dioxide on metallic copper surfaces. Energy \& Environmental Science, 5(5), 7050-7059.

[6] De Luna, P., Quintero-Bermudez, R., Dinh, C. T., Ross, M. B., Bushuyev, O. S., Todorović, P., ... \& Sargent, E. H. (2018). Catalyst electro-redeposition controls morphology and oxidation state for selective carbon dioxide reduction. Nature Catalysis, 1(2), 103-110.

[7] Reske, R., Mistry, H., Behafarid, F., Roldan Cuenya, B., \& Strasser, P. (2014). Particle size effects in the catalytic electroreduction of $\mathrm{CO}_{2}$ on $\mathrm{Cu}$ nanoparticles. Journal of the American Chemical Society, 136(19), 6978-6986.

[8] Li, C. W., Ciston, J., \& Kanan, M. W. (2014). Electroreduction of carbon monoxide to liquid fuel on oxide-derived nanocrystalline copper. Nature, 508(7497), 504.

[9] Handoko, A. D., Ong, C. W., Huang, Y., Lee, Z. G., Lin, L., Panetti, G. B., \& Yeo, B. S. (2016). Mechanistic insights into the selective electroreduction of carbon dioxide to ethylene on $\mathrm{Cu}_{2} \mathrm{O}$-derived copper catalysts. The Journal of Physical Chemistry C, 120(36), 20058-20067.

[10] Ren, D., Fong, J., \& Yeo, B. S. (2018). The effects of currents and potentials on the selectivities of copper toward carbon dioxide electroreduction. Nature communications, $9(1)$, 925.

[11] Singh, M. R., Kwon, Y., Lum, Y., Ager III, J. W., \& Bell, A. T. (2016). Hydrolysis of electrolyte cations enhances the electrochemical reduction of $\mathrm{CO}_{2}$ over $\mathrm{Ag}$ and $\mathrm{Cu}$. Journal of the American Chemical Society, 138(39), 13006-13012.

[12] Lum, Y., Yue, B., Lobaccaro, P., Bell, A. T., \& Ager, J. W. (2017). Optimizing C-C coupling on oxide-derived copper catalysts for electrochemical $\mathrm{CO}_{2}$ reduction. The Journal of Physical Chemistry C, 121(26), 14191-14203.

[13] Lu, Q., Rosen, J., Zhou, Y., Hutchings, G. S., Kimmel, Y. C., Chen, J. G., \& Jiao, F. (2014). A selective and efficient electrocatalyst for carbon dioxide reduction. Nature communications, 5, 3242 .

[14] Kas, R., Hummadi, K. K., Kortlever, R., De Wit, P., Milbrat, A., Luiten-Olieman, M. W., ... \& Mul, G. (2016). Three-dimensional porous hollow fibre copper electrodes for efficient and high-rate electrochemical carbon dioxide reduction. Nature communications, 7, 10748. 
[15] Ma, M., Trześniewski, B. J., Xie, J., \& Smith, W. A. (2016). Selective and efficient reduction of carbon dioxide to carbon monoxide on oxide-derived nanostructured silver electrocatalysts. Angewandte Chemie, 128(33), 9900-9904.

[16] Schouten, K. J. P., Qin, Z., Pérez Gallent, E., \& Koper, M. T. (2012). Two pathways for the formation of ethylene in $\mathrm{CO}$ reduction on single-crystal copper electrodes. Journal of the American Chemical Society, 134(24), 9864-9867.

[17] Ma, M., Djanashvili, K., \& Smith, W. A. (2016). Controllable hydrocarbon formation from the electrochemical reduction of $\mathrm{CO}_{2}$ over $\mathrm{Cu}$ nanowire arrays. Angewandte Chemie International Edition, 55(23), 6680-6684.

[18] Kas, R., Kortlever, R., Y1lmaz, H., Koper, M. T., \& Mul, G. (2015). Manipulating the hydrocarbon selectivity of copper nanoparticles in $\mathrm{CO}_{2}$ electroreduction by process conditions. ChemElectroChem, 2(3), 354-358.

[19] Gasteiger, H. A., Kocha, S. S., Sompalli, B., \& Wagner, F. T. (2005). Activity benchmarks and requirements for Pt, Pt-alloy, and non-Pt oxygen reduction catalysts for PEMFCs. Applied Catalysis B: Environmental, 56(1-2), 9-35.

[20] Merte, L. R., Behafarid, F., Miller, D. J., Friebel, D., Cho, S., Mbuga, F., ... \& Nilsson, A. (2012). Electrochemical oxidation of size-selected Pt nanoparticles studied using in situ highenergy-resolution X-ray absorption spectroscopy. ACS Catalysis, 2(11), 2371-2376.

[21] Reske, R., Mistry, H., Behafarid, F., Roldan Cuenya, B., \& Strasser, P. (2014). Particle size effects in the catalytic electroreduction of $\mathrm{CO}_{2}$ on $\mathrm{Cu}$ nanoparticles. Journal of the American Chemical Society, 136(19), 6978-6986.

[22] Lee, S., Kim, D., \& Lee, J. (2015). Electrocatalytic production of C3-C4 compounds by conversion of $\mathrm{CO}_{2}$ on a chloride-induced bi-phasic $\mathrm{Cu}_{2} \mathrm{O}-\mathrm{Cu}$ catalyst. Angewandte Chemie International Edition, 54(49), 14701-14705.

[23] Kuhl, K. P., Hatsukade, T., Cave, E. R., Abram, D. N., Kibsgaard, J., \& Jaramillo, T. F. (2014). Electrocatalytic conversion of carbon dioxide to methane and methanol on transition metal surfaces. Journal of the American Chemical Society, 136(40), 14107-14113.

[24] Eilert, A., Cavalca, F., Roberts, F. S., Osterwalder, J., Liu, C., Favaro, M., ... \& Nilsson, A. (2016). Subsurface oxygen in oxide-derived copper electrocatalysts for carbon dioxide reduction. The journal of physical chemistry letters, 8(1), 285-290.

[25] Liu, C., Lourenço, M. P., Hedström, S., Cavalca, F., Diaz-Morales, O., Duarte, H. A., ... \& Pettersson, L. G. (2017). Stability and effects of subsurface oxygen in oxide-derived Cu catalyst for $\mathrm{CO}_{2}$ reduction. The Journal of Physical Chemistry C, 121(45), 25010-25017.

[26] Cavalca, F., Ferragut, R., Aghion, S., Eilert, A., Diaz-Morales, O., Liu, C., ... \& Nilsson, A. (2017). Nature and distribution of stable subsurface oxygen in copper electrodes during electrochemical $\mathrm{CO}_{2}$ reduction. The Journal of Physical Chemistry C, 121(45), 25003-25009.

[27] Liu, X., Wang, X., Zhou, B., Law, W. C., Cartwright, A. N., \& Swihart, M. T. (2013). Sizecontrolled synthesis of $\mathrm{Cu}_{2-\mathrm{x}} \mathrm{E}(\mathrm{E}=\mathrm{S}, \mathrm{Se})$ nanocrystals with strong tunable near-infrared localized surface plasmon resonance and high conductivity in thin films. Advanced Functional Materials, 23(10), 1256-1264. 
[28] Luther, J. M., Jain, P. K., Ewers, T., \& Alivisatos, A. P. (2011). Localized surface plasmon resonances arising from free carriers in doped quantum dots. Nature materials, 10(5), 361.

[29] Zhuang, T. T., Liang, Z. Q., Seifitokaldani, A., Li, Y., De Luna, P., Burdyny, T., ... \& Dinh, C. T. (2018). Steering post-C-C coupling selectivity enables high efficiency electroreduction of carbon dioxide to multi-carbon alcohols. Nature Catalysis, 1(6), 421.

[30] Peterson, A. A., \& Nørskov, J. K. (2012). Activity descriptors for $\mathrm{CO}_{2}$ electroreduction to methane on transition-metal catalysts. The Journal of Physical Chemistry Letters, 3(2), 251-258.

[31] Wang, Y., Chen, Z., Han, P., Du, Y., Gu, Z., Xu, X., \& Zheng, G. (2018). Single-atomic Cu with multiple oxygen vacancies on ceria for electrocatalytic $\mathrm{CO}_{2}$ reduction to $\mathrm{CH}_{4}$. ACS Catalysis, 8(8), 7113-7119.

[32] Manthiram, K., Beberwyck, B. J., \& Alivisatos, A. P. (2014). Enhanced electrochemical methanation of carbon dioxide with a dispersible nanoscale copper catalyst. Journal of the American Chemical Society, 136(38), 13319-13325.

[33] Li, Y., Cui, F., Ross, M. B., Kim, D., Sun, Y., \& Yang, P. (2017). Structure-sensitive $\mathrm{CO}_{2}$ electroreduction to hydrocarbons on ultrathin 5-fold twinned copper nanowires. Nano letters, 17(2), 1312-1317.

[34]Dai, L., Qin, Q., Wang, P., Zhao, X., Hu, C., Liu, P., ... \& Mo, S. (2017). Ultrastable atomic copper nanosheets for selective electrochemical reduction of carbon dioxide. Science advances, 3(9), e1701069.

[35] Jin, M., He, G., Zhang, H., Zeng, J., Xie, Z., \& Xia, Y. (2011). Shape-controlled synthesis of copper nanocrystals in an aqueous solution with glucose as a reducing agent and hexadecylamine as a capping agent. Angewandte Chemie International Edition, 50(45), 1056010564.

[36] Yin, Z., Gao, D., Yao, S., Zhao, B., Cai, F., Lin, L., ... \& Bao, X. (2016). Highly selective palladium-copper bimetallic electrocatalysts for the electrochemical reduction of $\mathrm{CO}_{2}$ to CO. Nano Energy, 27, 35-43.

[37] Shaner, M. R., Atwater, H. A., Lewis, N. S., \& McFarland, E. W. (2016). A comparative technoeconomic analysis of renewable hydrogen production using solar energy. Energy \& Environmental Science, 9(7), 2354-2371.

[38] Ma, S., Sadakiyo, M., Heima, M., Luo, R., Haasch, R. T., Gold, J. I., ... \& Kenis, P. J. (2016). Electroreduction of carbon dioxide to hydrocarbons using bimetallic $\mathrm{Cu}-\mathrm{Pd}$ catalysts with different mixing patterns. Journal of the American Chemical Society, 139(1), 47-50.

[39] Schouten, K. J. P., Kwon, Y., Van der Ham, C. J. M., Qin, Z., \& Koper, M. T. M. (2011). A new mechanism for the selectivity to $\mathrm{C}_{1}$ and $\mathrm{C}_{2}$ species in the electrochemical reduction of carbon dioxide on copper electrodes. Chemical Science, 2(10), 1902-1909.

[40] Pander III, J. E., Ren, D., Huang, Y., Loo, N. W. X., Hong, S. H. L., \& Yeo, B. S. (2018). Understanding the Heterogeneous Electrocatalytic Reduction of Carbon Dioxide on OxideDerived Catalysts. ChemElectroChem, 5(2), 219-237.

[41] Lee, S., Park, G., \& Lee, J. (2017). Importance of Ag-Cu biphasic boundaries for selective electrochemical reduction of $\mathrm{CO}_{2}$ to ethanol. ACS Catalysis, 7(12), 8594-8604. 
[42] Ren, D., Gao, J., Pan, L., Wang, Z., Luo, J., Zakeeruddin, S. M., ... \& Grätzel, M. (2019). Atomic Layer Deposition of $\mathrm{ZnO}$ on $\mathrm{CuO}$ Enables Selective and Efficient Electroreduction of Carbon Dioxide to Liquid Fuels. Angewandte Chemie International Edition, 58(42), 1503615040 .

[43] Hatsukade, T., Kuhl, K. P., Cave, E. R., Abram, D. N., \& Jaramillo, T. F. (2014). Insights into the electrocatalytic reduction of $\mathrm{CO}_{2}$ on metallic silver surfaces. Physical Chemistry Chemical Physics, 16(27), 13814-13819.

[44] Hatsukade, T., Kuhl, K. P., Cave, E. R., Abram, D. N., Feaster, J. T., Jongerius, A. L., ... \& Jaramillo, T. F. (2017). Carbon Dioxide Electroreduction using a Silver-Zinc Alloy. Energy Technology, 5(6), 955-961.

[45] Hoang, T. T., Verma, S., Ma, S., Fister, T. T., Timoshenko, J., Frenkel, A. I., ... \& Gewirth, A. A. (2018). Nanoporous copper-silver alloys by additive-controlled electrodeposition for the selective electroreduction of $\mathrm{CO}_{2}$ to ethylene and ethanol. Journal of the American Chemical Society, 140(17), 5791-5797.

[46] Le, M., Ren, M., Zhang, Z., Sprunger, P. T., Kurtz, R. L., \& Flake, J. C. (2011). Electrochemical reduction of $\mathrm{CO}_{2}$ to $\mathrm{CH}_{3} \mathrm{OH}$ at copper oxide surfaces. Journal of the Electrochemical Society, 158(5), E45-E49.

[47] Higgins, D., Landers, A. T., Ji, Y., Nitopi, S., Morales-Guio, C. G., Wang, L., ... \& Jaramillo, T. F. (2018). Guiding electrochemical carbon dioxide reduction toward carbonyls using copper silver thin films with interphase miscibility. ACS Energy Letters, 3(12), 2947-2955.

[48] Melnichenko, Y. B., Lavrik, N. V., Popov, E., Bahadur, J., He, L., Kravchenko, I. I., ... \& Szekely, N. K. (2014). Cavitation on deterministically nanostructured surfaces in contact with an aqueous phase: A small-angle neutron scattering study. Langmuir, 30(33), 9985-9990.

[49] Raciti, D., \& Wang, C. (2018). Recent advances in $\mathrm{CO}_{2}$ reduction electrocatalysis on copper. ACS Energy Letters, 3(7), 1545-1556.

[50] Wakerley, D., Lamaison, S., Ozanam, F., Menguy, N., Mercier, D., Marcus, P., ... \& Mougel, V. (2019). Bio-inspired hydrophobicity promotes $\mathrm{CO}_{2}$ reduction on a $\mathrm{Cu}$ surface. Nature materials, 1-6.

[51]Weng, Z., Jiang, J., Wu, Y., Wu, Z., Guo, X., Materna, K. L., ... \& Wang, H. (2016). Electrochemical $\mathrm{CO}_{2}$ reduction to hydrocarbons on a heterogeneous molecular $\mathrm{Cu}$ catalyst in aqueous solution. Journal of the American Chemical Society, 138(26), 8076-8079.

[52] Savéant, J. M. (2008). Molecular catalysis of electrochemical reactions. Mechanistic aspects. Chemical Reviews, 108(7), 2348-2378.

[53]Lin, S., Diercks, C. S., Zhang, Y. B., Kornienko, N., Nichols, E. M., Zhao, Y., ... \& Chang, C. J. (2015). Covalent organic frameworks comprising cobalt porphyrins for catalytic $\mathrm{CO}_{2}$ reduction in water. Science, 349(6253), 1208-1213.

[54] Voiry, D., Chhowalla, M., Gogotsi, Y., Kotov, N. A., Li, Y., Penner, R. M., ... \& Weiss, P. S. (2018). Best practices for reporting electrocatalytic performance of nanomaterials. 
[55] Clark, E. L., Resasco, J., Landers, A., Lin, J., Chung, L. T., Walton, A., ... \& Bell, A. T. (2018). Standards and protocols for data acquisition and reporting for studies of the electrochemical reduction of carbon dioxide. ACS Catalysis, 8(7), 6560-6570.

[56] Buriak, J. M., Jones, C. W., Kamat, P. V., Schanze, K. S., Schatz, G. C., Scholes, G. D., \& Weiss, P. S. (2016). Virtual Issue on Best Practices for Reporting the Properties of Materials and Devices: Record Well, Repeat Often, Report Correctly. 


\section{Chapter 4 Performance and mechanism of $\mathrm{Cu}$-based catalysts}

\section{Introduction}

Electrochemistry has been becoming more and more important because of renewable energy consumption and storage. Progresses in controllable synthesis approaches and characterization of catalyst have significant benefit in understanding fundamental mechanism and developing highly efficient catalysts. Meanwhile, numerical models have being supplemented the experimental results to simulate the reaction path and calculate the energy cost. In this chapter, we will summarize and discuss the catalytic property and mechanism.

\subsection{Catalytic performance}

Cu-based catalysts are the most promising to realize commercial utilization for valued chemicals production, such as methane, ethanol and ethylene. Various types of $\mathrm{Cu}$-based catalysts (pure $\mathrm{Cu}, \mathrm{Cu}$ bimetallic, organic $\mathrm{Cu}$, etc.) have been developed to achieve this goal [1]. Table 4.1 summarizes the cu-based catalysts and their performance for different chemical products in recent years. 
Table 4.1. Summary of electrocatalytic reduction toward carbon products performance on different catalysts [1].

\begin{tabular}{|c|c|c|c|c|c|c|c|c|}
\hline \multirow{2}{*}{ Catalyst } & \multirow[t]{2}{*}{$\mathrm{E} / \mathrm{V}$} & \multicolumn{6}{|c|}{ Faradaic efficiency $/ \%$} & \multirow{2}{*}{$\begin{array}{c}\mathrm{J}_{\mathrm{C} 2+} \\
\left(\mathrm{mA} \cdot \mathrm{cm}^{-2}\right)\end{array}$} \\
\hline & & $\mathrm{CO}$ & $\mathrm{CH}_{4}$ & $\mathrm{C}_{2} \mathrm{H}_{4}$ & $\mathrm{C}_{2} \mathrm{H}_{5} \mathrm{OH}$ & propanol & $\mathrm{C}_{2+}$ & \\
\hline Phase-separated $\mathrm{CuPd}{ }^{\text {a) }}$ & -0.74 & & & 48 & 15 & & & \\
\hline $\mathrm{Cu} \mathrm{NCs} / \mathrm{Cu}$ foils ${ }^{\text {a) }}$ & -0.96 & & & 32 & & & 60.5 & 41 \\
\hline Ag-Cu core-shell ${ }^{\text {b) }}$ & -1.06 & & 18 & 25 & & & & \\
\hline $\mathrm{Cu}_{2} \mathrm{O}$ derived $\mathrm{Cu} \mathrm{NP}^{\mathrm{b}}$ ) & -1.1 & & & 19 & & & & \\
\hline $\mathrm{Cu}$ mesocrystal ${ }^{\text {b) }}$ & -0.99 & & 1.47 & 27.2 & & & & \\
\hline $\mathrm{Cu}$ nanowire array ${ }^{\mathrm{b})}$ & -1.1 & & & 17.4 & & 8 & & \\
\hline Prism $\mathrm{Cu}^{\text {b) }}$ & -1.1 & & & & & & 35 & 10 \\
\hline $\mathrm{Cu}$ NPs covered $\mathrm{Cu}$ foil ${ }^{\mathrm{b})}$ & -1.1 & & 1 & & & & 36 & N.A. \\
\hline Electropolished $\mathrm{Cu}$ foil ${ }^{\mathrm{b})}$ & -1.05 & & & & & & 40.6 & 2.8 \\
\hline 44-nm Cu cubic NPs b) & -1.1 & & & 41 & & & 46.4 & 1.4 \\
\hline $\mathrm{Cu}$ NPs ensembles ${ }^{\mathrm{b})}$ & -0.75 & & & & & & $\sim 50$ & \\
\hline 3.6-um $\mathrm{Cu}_{2} \mathrm{O}$ film ${ }^{\mathrm{b})}$ & -0.99 & & & 34.26 & 16.37 & & 50.8 & 17.8 \\
\hline $\mathrm{OD}-\mathrm{Cu}_{4} \mathrm{Zn}{ }^{\mathrm{b})}$ & -1.05 & & & & & & 51 & 15 \\
\hline $\mathrm{Cu}_{28} \mathrm{Ag}_{72}{ }^{\mathrm{b})}$ & Pulse & & & 12.8 & 17.3 & & 54.2 & \\
\hline $\mathrm{Cu}(100)$ single electrode ${ }^{\mathrm{b})}$ & -1 & & 30.4 & 40.4 & 9.7 & 1.5 & 57.8 & 2.9 \\
\hline $18-\mathrm{nm} \mathrm{Cu}^{\mathrm{b})}$ & -1.03 & & & 42.6 & 11.8 & 5.4 & 59.8 & 18.7 \\
\hline $\mathrm{Cu}(100)^{\mathrm{b})}$ & -0.97 & & & & & & 60 & 2 \\
\hline $\mathrm{Pd}_{85} \mathrm{Cu}_{15} / \mathrm{C}^{\mathrm{b})}$ & -0.89 & 86 & & & & & & \\
\hline Plasma Oxidized $\mathrm{Cu}^{\text {b) }}$ & -0.9 & & & 60 & & & 60 & 12 \\
\hline $\mathrm{CuOx}-\mathrm{Vo}^{\mathrm{b})}$ & -1.4 & & & 63 & & & 63 & \\
\hline $\mathrm{Ag}-\mathrm{Cu}_{2} \mathrm{O} P S^{\mathrm{c})}$ & -1.2 & & 1.7 & 7.8 & 20.1 & & & \\
\hline
\end{tabular}




\begin{tabular}{|c|c|c|c|c|c|c|c|}
\hline Mesoporous $\mathrm{Cu}$ film ${ }^{\mathrm{d})}$ & -0.8 & & & & & 57 & 7 \\
\hline $\mathrm{N}$-doped graphene dots ${ }^{\mathrm{d})}$ & -0.75 & & 31 & & & 67 & 40 \\
\hline Cu DAT wire ${ }^{\text {d) }}$ & -0.69 & & & & & 68.9 & 124 \\
\hline $\mathrm{Au}_{3} \mathrm{Cu}^{\mathrm{d})}$ & -0.38 & 90.2 & & & & & \\
\hline Ultrathin $\mathrm{Cu} / \mathrm{Ni}(\mathrm{OH})_{2} \mathrm{NS}^{\mathrm{d})}$ & -0.39 & 92 & & & & & \\
\hline Nanoporous $\mathrm{Cu}^{\mathrm{e})}$ & -0.67 & & 38.6 & 16.6 & 4.5 & 62 & 411 \\
\hline $\mathrm{ZnO} / \mathrm{CuO}^{\mathrm{e})}$ & -0.68 & & 18.1 & 41.4 & 5.5 & 66.7 & \\
\hline CuAg wire ${ }^{e}$ & -0.68 & & 60 & 25 & & 85 & 265 \\
\hline Surface Reconstructed $\mathrm{Cu}^{\mathrm{f}}$ & -2.6 & & 56 & & 5 & 73 & 17 \\
\hline Abrupt $\mathrm{Cu}$ interface ${ }^{\mathrm{g})}$ & -0.67 & & & & & 81 & 608 \\
\hline $\begin{array}{l}\text { 3D porous hollow fibre } \\
\text { copper }\end{array}$ & -0.4 & 72 & & & & & \\
\hline
\end{tabular}

As can been seen in the Table 4.1, there are many factors influencing the selectivity and productivity, such us type of metal, surface structure, shape. Basically, to make products with high value, high energy will be required. For example, $\mathrm{CO}$ can be produced at a current of $0.4 \mathrm{~V}$ with high production, while approximately $-0.7 \mathrm{~V}$ will be required to produce more valuable carbon chemicals. Though it is very hard to do quantitative analysis due to too many uncertain/various factors, qualitative analysis can be done to further guide experimental or computational study to design and synthesize more reliable $\mathrm{Cu}$-based catalysts. According to the basic knowledge of electrochemistry and the published catalysts in Table 4.1, we may obtain the following summarization.

First, currently, $\mathrm{Cu}$ is the most important metal for $\mathrm{CO}_{2}$ conversion. Scientists studied the shape and the particle size of $\mathrm{Cu}$-based catalysts to produce more efficient catalysts. From the 
macro scene, catalysts with high specific surface area are more efficient because they provide more adsorption sites for $\mathrm{CO}_{2}$ and intermediates, which have been partially proved by the evidences listed in the above table that the abrupt $\mathrm{Cu}$ interface has very high current for $\mathrm{CO}_{2}$ conversion at low potential and most $\mathrm{Cu}$ are produced to nanoscale size. At the micro level, it cannot be guaranteed that higher productivity of target product will be achieved when the particle size because smaller. Because too small particle size may result in the shortage of multisites to produce products with more than one carbon. This deduction may be supported by Rulle Reske's experiment, showing that the main product will be $\mathrm{CO}$ and $\mathrm{H}_{2}$ when the particle size of the catalyst is smaller than $2 \mathrm{~nm}$.

Second, the doped metal in $\mathrm{Cu}$ is significant to determine the final product. Different metal doped in $\mathrm{Cu}$ may cause different product preference and the ratio of metals doped in the $\mathrm{Cu}$ also influence the product distribution. For one thing, specific metal may increase the current. For another thing, it can improve the adsorption site to avoid the steric hindrance. Basically, $\mathrm{Au}, \mathrm{Pd}$, $\mathrm{Zn}$ and Ag catalysts favor the formation of $\mathrm{CO}$, which means it is hard to produce products with more value when they are used alone. However, when $\mathrm{Au}$ and $\mathrm{Ag}$ is doped in $\mathrm{Cu}$, they can reduce the energy cost to produce more valuable products. For example, $\mathrm{CuAg}$ wire and $\mathrm{ZnO} / \mathrm{CuO}$ are excellent catalysts to produce $\mathrm{C}_{2+}$ products with high efficiency at relatively low potential, and faradaic efficiency are 85 and 66.7 at $-6.8 \mathrm{~V}$, respectively. However, when Pd and $\mathrm{Au}$ are doped in $\mathrm{Cu}$, the effect to increase organic carbon chemicals is limited or even counterproductive. The possible reason is that there is competition in the alloy which means $\mathrm{Cu}$ may be stronger to absorb $\mathrm{CO}_{2}$ than $\mathrm{Zn}$ and $\mathrm{Au}$, while it is weaker to absorb $\mathrm{CO}_{2}$ than $\mathrm{Pd}$ and $\mathrm{Au}$. Another possible reason is that the atomic radius of doped atom ( Pd:169 pm, Au:174 pm, 
Ag:165 pm, Zn:142 pm, Cu:145 pm) may not match the bond length of C-C, resulting in blocking C-C formation.

\subsection{Mechanism and pathways for $\mathrm{CO}_{2}$ conversion to $\mathrm{C}_{2}$ products}

Understanding electrocatalytic mechanism and the relationship between catalyst's structure and performance on molecular level will further provide sights and thoughts to design and improve catalysts to enhance $\mathrm{CO}_{2}$ reduction ability and produce more high-value products. However, proposing a conclusive mechanism for the reduction of $\mathrm{CO}_{2}$ is challenging, as more than ten chemicals are produced from $\mathrm{CO}_{2}$. Besides, these chemicals include a broad mix of aldehydes, ketones, carboxylic acids, and alcohols, out of which 12 are $\mathrm{C}_{2}$ or $\mathrm{C}_{3}$ species, showing the complexity of this reaction. Therefore, a lot of work have been done to improve the efficiency and selectivity. Though the relationships between catalytic performances and various factors ( $\mathrm{pH}$, defect, size, shape, chemical bond, etc.) have been experimentally investigated, most publications have not systematically discussed the reaction pathway and mechanism. As we know, the electron transfer to adsorbate is thought to have low kinetic barrier. The step for achieving $\mathrm{C}-\mathrm{C}$ coupling determines the rate and selectivity of $\mathrm{C}_{2}$ products, because it needs to overcome the barrier of $\mathrm{C}-\mathrm{C}$ bond formation which consumes much energy.

There is nearly no debate that $\mathrm{CO}_{2}$ will be converted to $\mathrm{HCOOH}$ and $\mathrm{CO}$ first. $\mathrm{HCOOH}$ can not be converted to other chemicals further. Normally, $\mathrm{CO}$ is ideal product because it is the intermediate to electrocatalytically produce organic carbon chemicals, such as $\mathrm{CH}_{4}, \mathrm{C}_{2} \mathrm{H}_{4}$, and $\mathrm{CH}_{3} \mathrm{CH}_{2} \mathrm{OH}$. Experiments also reveal that the product distribution of $\mathrm{CO}$ reduction is as same as that of $\mathrm{CO}_{2}$ reduction. Those are why many researches focus on $\mathrm{CO}$ conversion when they study the mechanism of $\mathrm{CO}_{2}$ conversion. 
To obtain more valuable organic carbon chemicals, the first step is to prohibit the formation of $\mathrm{HCOOH}$ and the desorption of $\mathrm{CO}$. Since $\mathrm{CO}$ and formate products involve very different reaction mechanism, formate formation can be suppressed by controlling $\mathrm{pH}$, designing new nanoscale catalysts and modifying the properties of the electrolyte, to obtain high concentration of CO. Meanwhile, it is found that $\mathrm{Cu}(100)$ only leads to $\mathrm{CO}$ formation without $\mathrm{HCOO}^{-}$. Ruud Kortlever et al [2] proposed the reaction pathways in Figure 4.1. They pointed out that when the applied potential was $-0.8 \mathrm{~V}$, the reaction occurred on the $\mathrm{Cu}(111)$ facet and the products tended to be $\mathrm{C}_{1}$ and $\mathrm{CH}_{4}$ was dominant when ${ }^{*} \mathrm{CHO}$ and ${ }^{*} \mathrm{COH}$ were the intermediates. When the applied potential was low, reaction occurred on $\mathrm{Cu}(100)$ and $* \mathrm{CO}$ dimerization occurred on $\mathrm{Cu}(100)$ facet to produce $\mathrm{C}_{2}$ products which was dominated by $\mathrm{C}_{2} \mathrm{H}_{4}$. Ming Ma et al [3] proposed that there were two pathways to produce $\mathrm{C}_{2}$ products (Figure 4.2) and $\mathrm{C}_{2} \mathrm{H}_{4}$ could be produced from both $* \mathrm{CO} \rightarrow * \mathrm{COH} \rightarrow \mathrm{C}_{2} \mathrm{H}_{4}$ and $* \mathrm{CO}+* \mathrm{CO} \rightarrow * \mathrm{COCO}$ paths. However, both research only focused on thermodynamic level, ignoring the influence of reaction barriers. For example, though direct dimerization of $* \mathrm{CO}$ is thermally available under low potential, it is obvious that the barrier of dimerization of adsorbed $* \mathrm{CO}$ is still very high under an electric field and it is unfavorable from kinetic perspective [4]. 


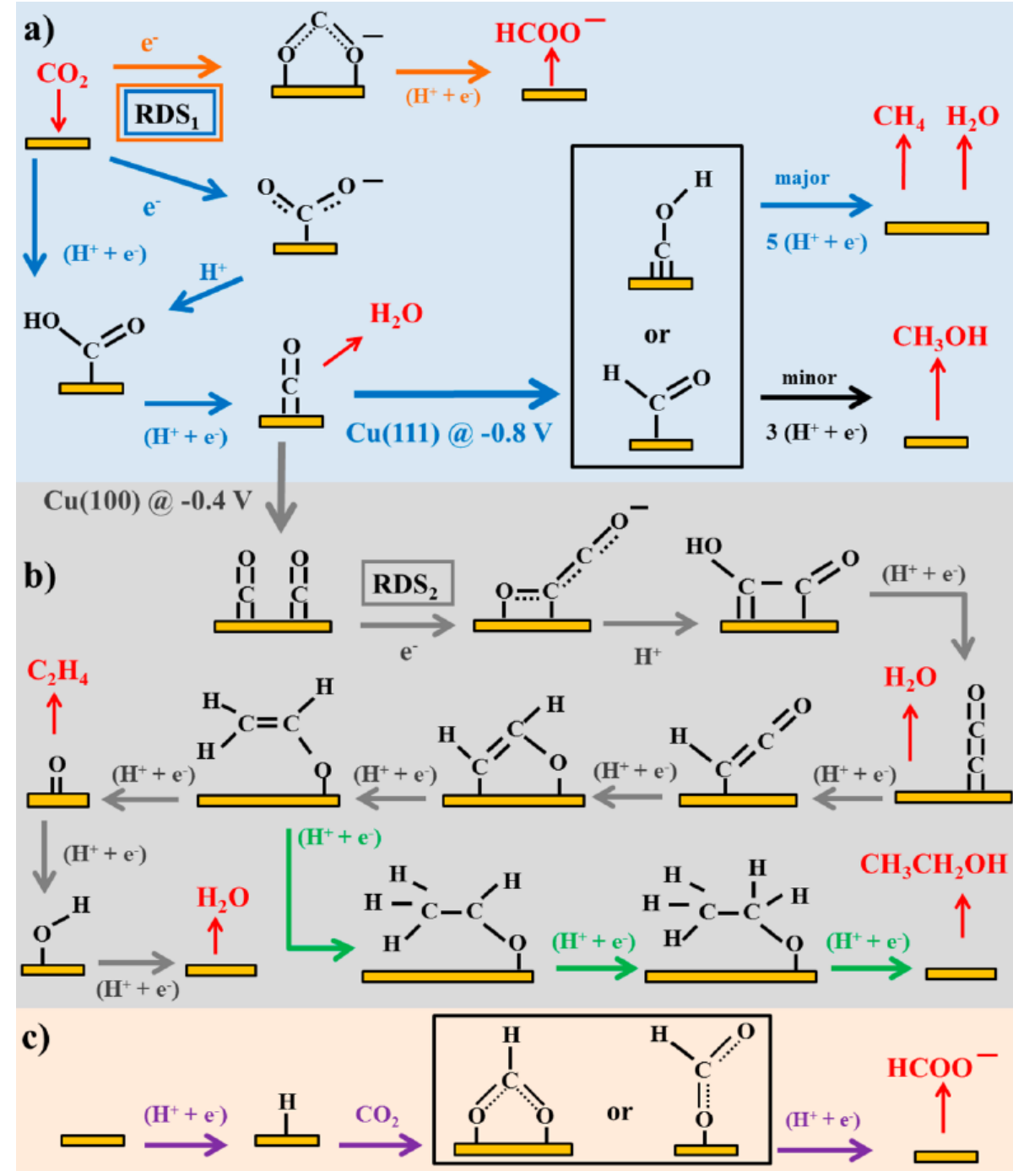

Figure 4.1. Possible reaction pathways for the electrocatalytic reduction of $\mathrm{CO}_{2}$ to products on transition metals and molecular catalysts [2]. 


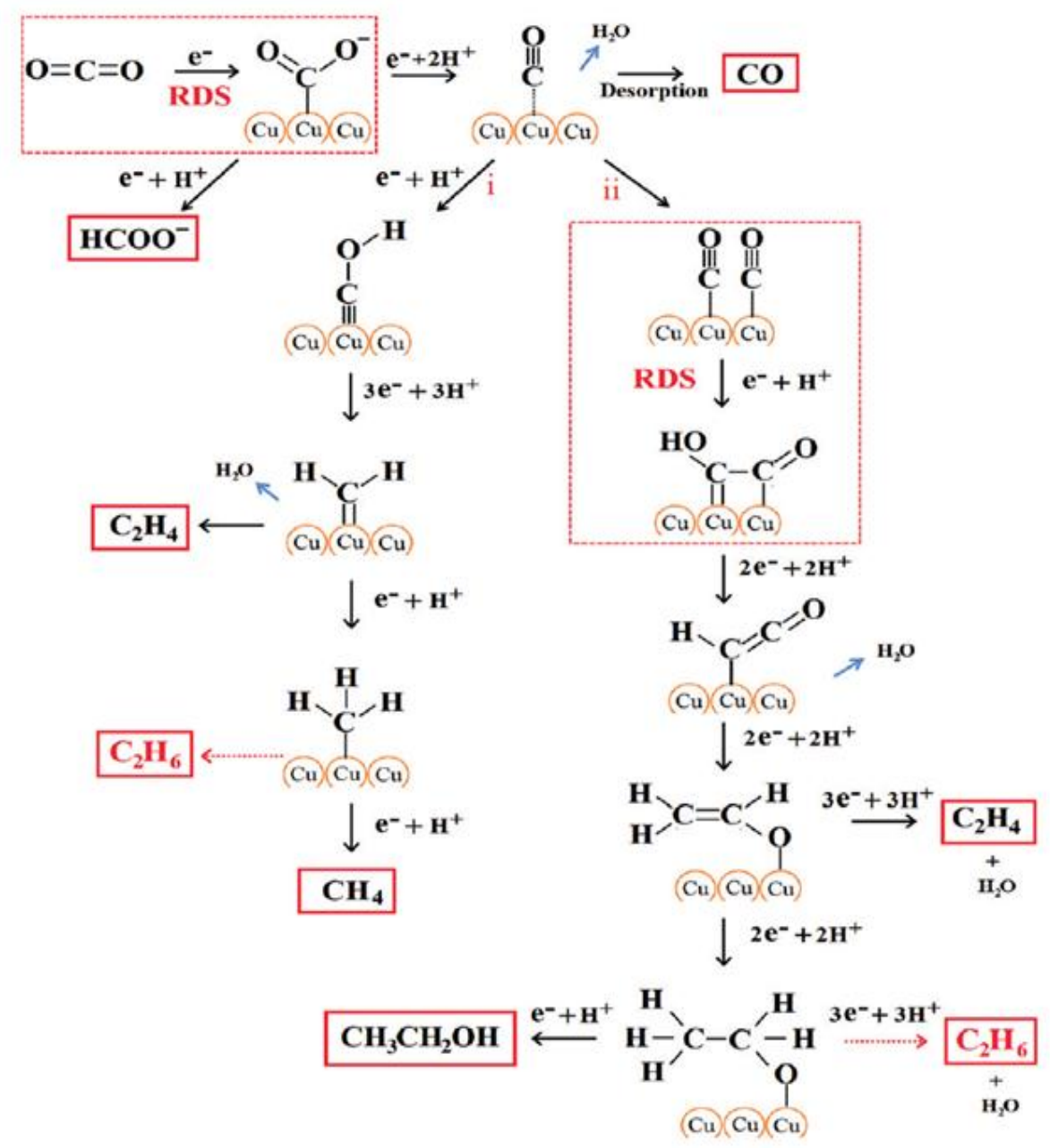

Figure 4.2. Proposed reaction paths for electrocatalytic reduction of $\mathrm{CO}_{2}$ on $\mathrm{Cu}$ nanowire arrays [3].

In 2013, electron-ion transfer reactions were taken into account to study reaction kinetics of elementary steps. The results indicated that the reduction of $\mathrm{CO}$ was the key selectivitydetermining step on $\mathrm{Cu}(111)$ and ${ }^{*} \mathrm{COH}$ played a critical role in forming methane/ethylene. $\mathrm{C}_{2} \mathrm{H}_{4}$ was produced through nonelectrochemical $* \mathrm{CH}_{2}$ dimerization as shown in Figure 4.3. Moreover, it was further proved that reaction environment and potential were essential for determining intermediates content and the formation of methane/ethylene [5]. 


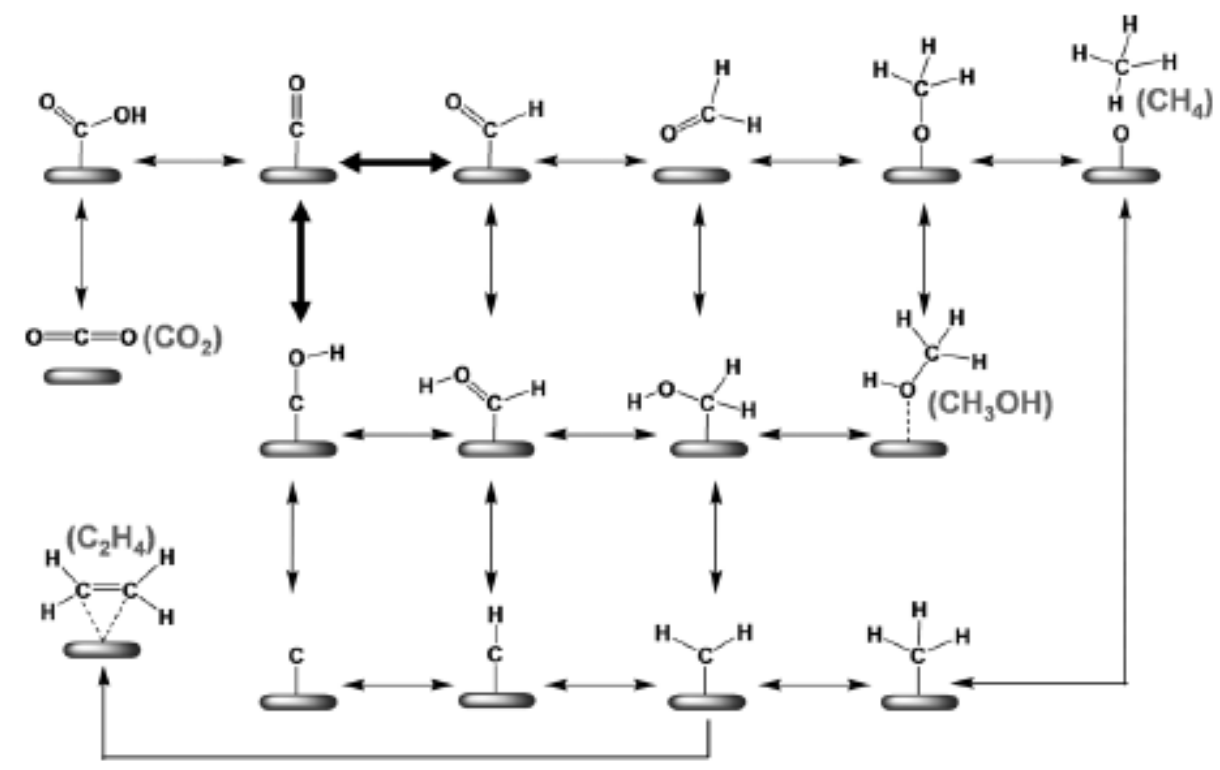

Figure 4.3. Proposed reaction paths for $\mathrm{CO}_{2}$ electroreduction on $\mathrm{Cu}(111)$ [5].

In 2016, Xiao et al [6] predicted the atomistic mechanisms for the pathways of products during $\mathrm{CO}$ reduction at different $\mathrm{pH}$ conditions on $\mathrm{Cu}(111)$ facet. Free energies for $\mathrm{CO}$ reduction (Figure 4.4) indicated that $\mathrm{C}_{1}$ products were relatively easy to be produced at acidic atmosphere while $\mathrm{C}_{2}$ chemicals preferred $* \mathrm{CO}+* \mathrm{COH} / * \mathrm{CHO}$ pathway at neutral $\mathrm{pH}$ or $* \mathrm{CO}+* \mathrm{CO} \rightarrow$ *COCO pathway at alkaline atmosphere. At low $\mathrm{pH}=1$ with potential of $-0.80 \mathrm{~V}$, multi-carbon production was kinetically suppressed, $\mathrm{C}_{1}$ products were mainly produced through $* \mathrm{COH}$ pathway. At neutral $\mathrm{pH}$ value with potential of $-1.17 \mathrm{~V}$, though both $* \mathrm{CO}+{ }^{*} \mathrm{CO} \rightarrow * \mathrm{COCO}$ and $* \mathrm{CO}+{ }^{*} \mathrm{COH} /{ }^{*} \mathrm{CHO}$ pathways might be accessible, $* \mathrm{COH}$ reduction was dominant and $\mathrm{C}_{1}$ was the man product. At high $\mathrm{pH}=12, \mathrm{C}_{1}$ pathway was kinetically blocked and $* \mathrm{CO}+{ }^{*} \mathrm{CO} \rightarrow$ *COCO pathway was predominant. However, we must point out that ${ }^{*} \mathrm{COCO}$ is highly unstable on the $\mathrm{Cu}(111)$ surface. Compared to $* \mathrm{CHO},{ }^{*} \mathrm{COH}$ was favored due to their activation barriers of $* \mathrm{COH}(0.21 \mathrm{eV})$ and $* \mathrm{CHO}(0.39 \mathrm{eV})$ calculated by DFT at $-1.15 \mathrm{~V}$ on $\mathrm{Cu}(111)$ facet [2]. 


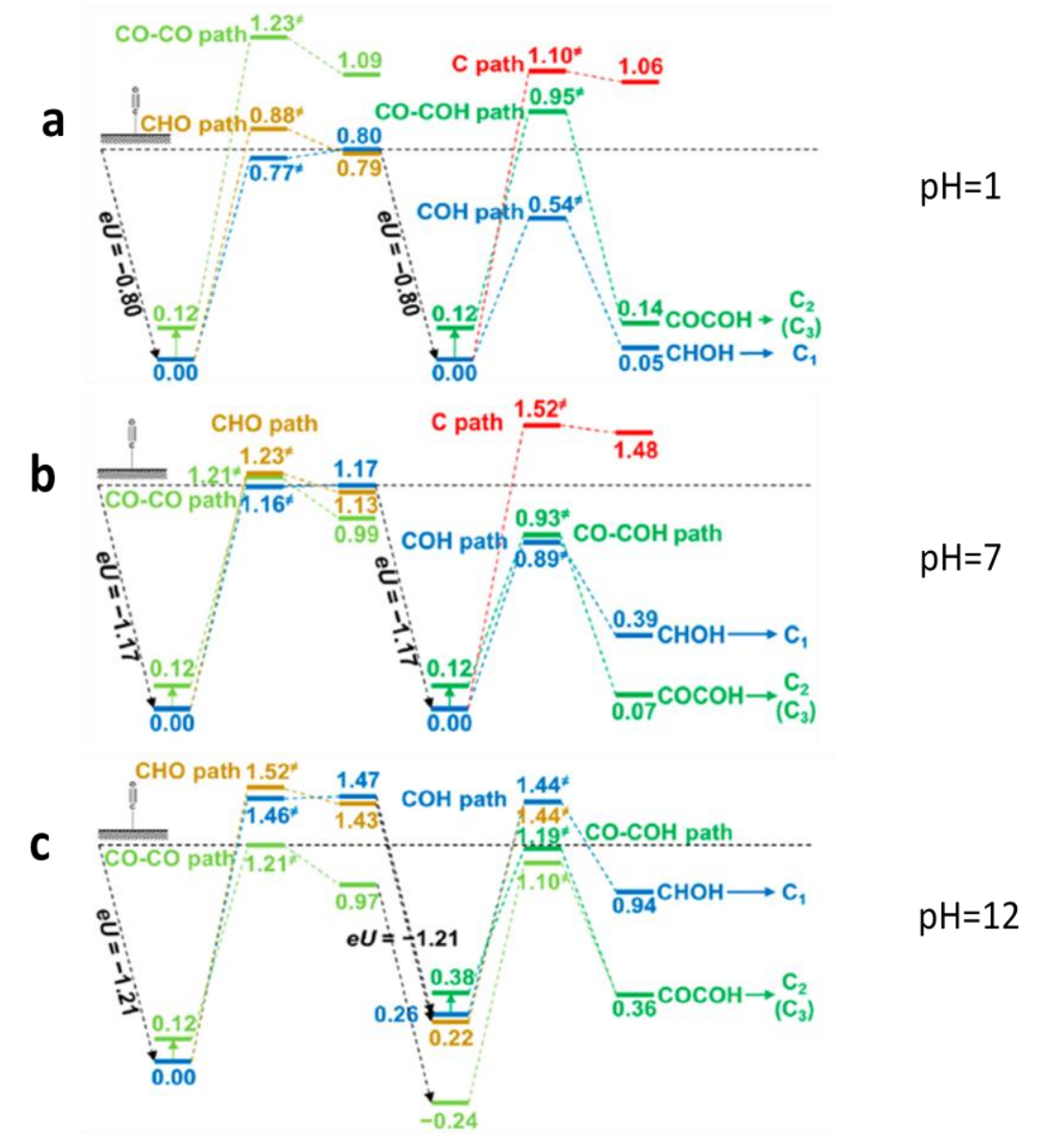

Figure 4.4. Free energy of $\mathrm{CO}$ electrochemical reduction on $\mathrm{Cu}(111)$ at $\mathrm{pH}=1,7$ and 12 , respectively [6].

Though $\mathrm{Cu}(111)$ facet can be utilized to produce $\mathrm{C}_{1}$ products and $\mathrm{C}_{2}$ products, $\mathrm{C}_{1}$ is preferential. Dimerization of the intermediates $* \mathrm{CHO}$ or $* \mathrm{COH}$ toward ethylene is believed to be the pathway that produces ethylene once current density reaches $10 \mathrm{~mA} \cdot \mathrm{cm}^{-2}$ and takes place on both $\mathrm{Cu}(100)$ and $\mathrm{Cu}(111)$ facet. However, $\mathrm{Cu}(100)$ is a more active surface than $\mathrm{Cu}(111)$, leading to lower overpotentials for both $\mathrm{C}_{1}$ and $\mathrm{C}_{2}$ products. Earlier work showed $\mathrm{C}_{1}$ was preferentially formed on $\mathrm{Cu}(111)$, while $\mathrm{C}_{2} \mathrm{H}_{4}$ was the main product on $\mathrm{Cu}(100)$ [9]. In addition, $\mathrm{pH}$ value was a significant factor for the product selectivity. At $\mathrm{pH}=1$ (acidic), $\mathrm{CH}_{4}$ was observed without $\mathrm{C}_{2} \mathrm{H}_{4}$ or other $\mathrm{C}_{2}$ products on both $\mathrm{Cu}(100)$ and $\mathrm{Cu}(111)$ [7]. In contrast, $\mathrm{C}_{2} \mathrm{H}_{4}$ 
production was comparable with $\mathrm{CH}_{4}$ production in the presence of neutral and basic solutions. As $\mathrm{C}_{2}$ products was more valuable, reaction on $\mathrm{Cu}(100)$ was desirable for its higher performance than $\mathrm{Cu}(111)$ to produce $\mathrm{C}_{2}$ products. Meanwhile, recent experiments showed that under standard electrochemical conditions, $\mathrm{Cu}(100)$ may be more stable. In 2015, Tao Cheng et al [8] reported $* \mathrm{CHO}$ was the main intermediate for $\mathrm{C}_{1}$ products on $\mathrm{Cu}(100)$, rather than $* \mathrm{COH}$. In 2018, Alejandro Garza et al [10] proposed another reaction pathway for the reduction of CO to $\mathrm{C}_{2}$ products at high potentials on $\mathrm{Cu}(100)$. It showed $* \mathrm{CO}+* \mathrm{CHO} \rightarrow * \mathrm{COCHO}$ occurred first, and then $* \mathrm{COCHO}$ was converted to $\mathrm{C}_{2} \mathrm{H}_{4}$ or $\mathrm{CH}_{3} \mathrm{CH}_{2} \mathrm{OH}$ (Figure 4.5), meaning $* \mathrm{CHO}$ was the main intermediate when reaction occurred on $\mathrm{Cu}(100)$. Based on the previous research, we try to summarize the possible pathways for $\mathrm{CO}_{2}$ conversion to $\mathrm{C}_{2}$ products. Basically, there are four pathways for $\mathrm{C}_{2}$ formation, which are $* \mathrm{CO}+{ }^{*} \mathrm{CO} \rightarrow{ }^{*} \mathrm{C}_{2},{ }^{*} \mathrm{CO}+{ }^{*} \mathrm{COH} \rightarrow \mathrm{C}_{2},{ }^{*} \mathrm{CO}+{ }^{*} \mathrm{CHO}$ $\rightarrow \mathrm{C}_{2}$ and $* \mathrm{COH} \rightarrow * \mathrm{CH}_{2} \rightarrow \mathrm{C}_{2}$. When the potential is small $(\sim-0.4 \mathrm{~V})$, though the reaction thermally follows $* \mathrm{CO}+* \mathrm{CO} \rightarrow * \mathrm{COCO}$ pathway on $\mathrm{Cu}(100)$, it is hard to react due to kinetics barrier [9]. When the potential is high, the reaction mainly follows the path $* \mathrm{CO}+* \mathrm{COH} \rightarrow$ $\mathrm{C}_{2} \mathrm{H}_{4}$ or ${ }^{*} \mathrm{COH} \rightarrow{ }^{*} \mathrm{CH}_{2} \rightarrow \mathrm{C}_{2}$ on $\mathrm{Cu}(111)$. On $\mathrm{Cu}(100)$ surface at high potentials, $* \mathrm{CO}+{ }^{*} \mathrm{CHO}$ $\rightarrow \mathrm{C}_{2}$ is supposed as the main way to produce $\mathrm{C}_{2}$. Different reaction pathways for $\mathrm{C}_{2}$ products are summarized in Figure 4.5. 

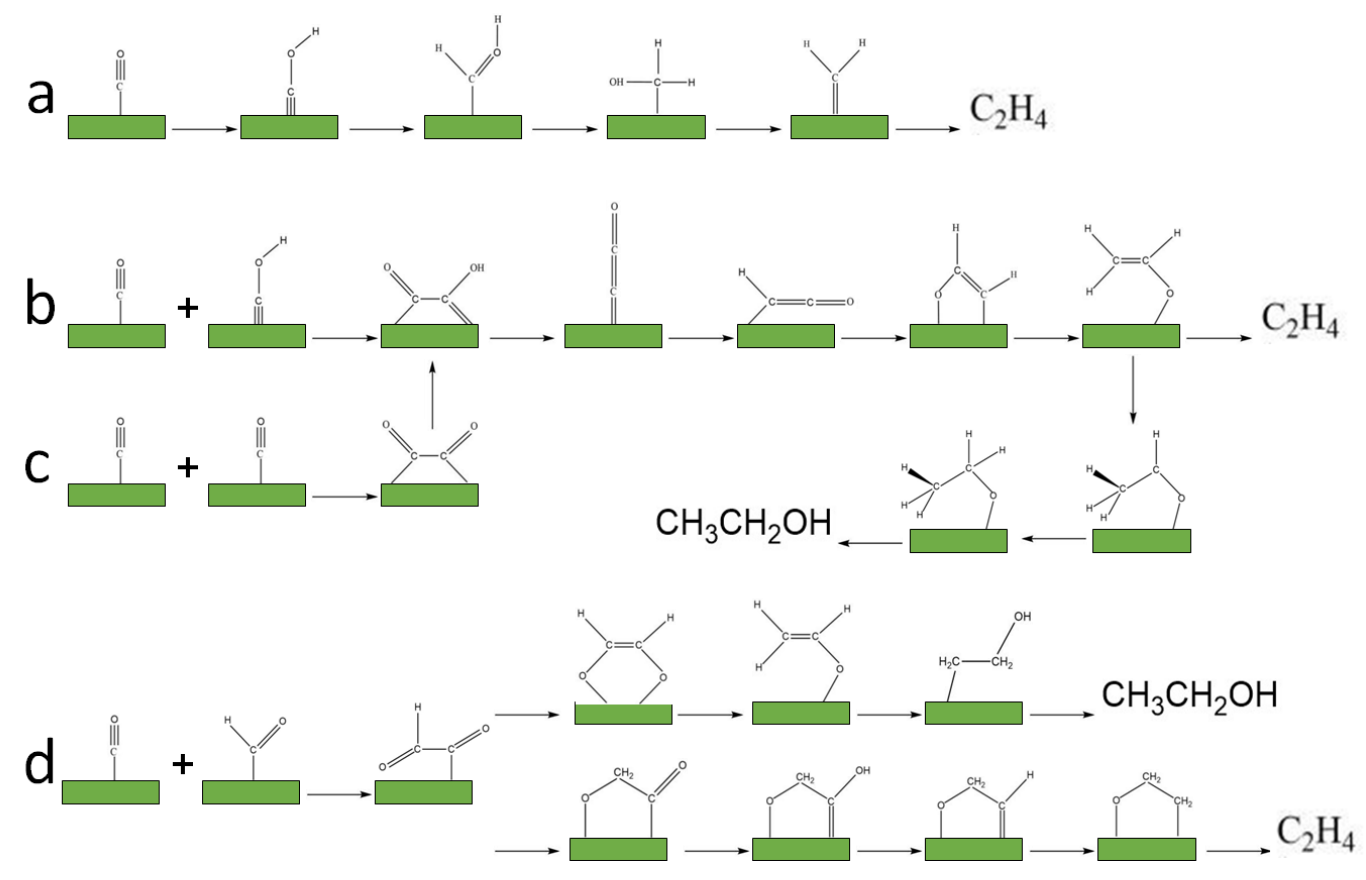

Figure 4.5. Summarized mechanisms for the reduction of $\mathrm{CO}$ to $\mathrm{C}_{2}$ products $[1,10]$.

After we elucidate the reaction mechanism, we can design the effective catalyst to obtain the aimed product. For example, ${ }^{*} \mathrm{C}_{2} \mathrm{H}_{3} \mathrm{O}$ is the common reaction intermediate for both ethylene and ethanol formation (Figure 4.5. b, c), therefore, it is possible to modify the catalyst's structure to suppress ethylene production while promote the hydrogenation of the intermediate and finally enhance the selectivity towards alcohols $[11,12]$. 


\subsection{Conclusion}

High overpotential of the reaction and low activity of currently known catalysts still hamper this process from commercialization. Cu-based catalysts are known to electrochemically convert $\mathrm{CO}_{2}$ to hydrocarbons and/or oxygenates at considerably high faradaic efficiency, however, other products such as $\mathrm{CO}, \mathrm{HCOO}-$, and $\mathrm{H}_{2}$ are also produced at fairly high faradaic efficiencies. The existing catalysts are hard to satisfy the industrial usage ( $\mathrm{FE} \gg>50 \%$ for $\mathrm{C}_{2}$ products, current density $\left\langle<-200 \mathrm{~mA} \cdot \mathrm{cm}^{-2}\right.$ while applied potentials $\gg>-1.0 \mathrm{~V}$ vs. RHE [8]. In addition, to satisfy the industrial requirements, the catalysts should be durable, however, few research results related to catalyst's lifetime have been reported.

$\mathrm{CO}_{2}$ can be directly converted to valuable products in the presence of catalyst in one step or two steps which reduced $\mathrm{CO}_{2}$ to $\mathrm{CO}$ first and then converted to fuels with higher energy. This technology can satisfy long-distance and heavy freight transportation requirements. Although $\mathrm{CO}_{2}$ can be catalytically converted to fuels, it requires high energy. In particular, the reduction of $\mathrm{H}_{2} \mathrm{O}$ to $\mathrm{H}_{2}$ considerably compete with synthesis to fuel at low potential. There is a debate that two steps may be more attractive for lower energy cost and higher selectivity and controllability, because $\mathrm{CO}$ reduction activity may be obscured in the presence of a large excess of $\mathrm{CO}_{2}$ [13]. According to our study, the two step reaction may have more advantages compared with one step reaction [14-17]. On one hand, $\mathrm{CO}$ is the intermediate to convert $\mathrm{CO}_{2}$ to chemical products. Though $\mathrm{Cu}$ may be the best catalyst to directly convert $\mathrm{CO}_{2}$ to organic products, it does not mean it is the best candidate to convert $\mathrm{CO}_{2}$ to $\mathrm{CO}$. Actually, there are many metals used to produce $\mathrm{CO}$, such as $\mathrm{Ag}, \mathrm{Au}$, and $\mathrm{Co}$, most of which achieve the FE more than $90 \%$ under relative low potential. On the other hand, the adsorption energy and mechanism of $\mathrm{CO}$ on the catalyst surface is significantly different with that of $\mathrm{CO}_{2}$. The adsorption atom is $\mathrm{C}$ for $\mathrm{CO}$ adsorption on the 
catalyst while $\mathrm{O}$ become the adsorption atom for $\mathrm{CO}_{2}$ adsorption. Compared to $\mathrm{CO}_{2}, \mathrm{CO}$ can be easier adsorbed due to its structure. Hence, recently, more and more research are focused on CO conversion.

Current mechanism achievement of converting $\mathrm{CO}_{2}$ to value-added products are not enough and the debates of reaction pathways are still existing. Because many factors influence the catalyst's performance and it is very hard to build the models to precisely reflect the real situation [18-20]. Though more computational and experimental work need to be done to further elucidate the mechanism of producing $\mathrm{C}_{2}$ products, the following summaries may be universally accepted.

i) The applied potential is a determining factor influencing the reaction. Though low potential is beneficial, it is impossible to fulfill our goals under certain value. For example, direct dimerization of $* \mathrm{CO}$ is thermally available under low potential, it is obvious that the barrier of dimerization of adsorbed $* \mathrm{CO}$ is still very high under an electric field and it is kinetically unfavorable. Theoretically, no matter what reaction situation we create, the kinetic barrier exist. At current situation, the range from -0.65 to $-1.0 \mathrm{~V}$ may be reasonable and acceptable.

ii) Facet is an important factor when we consider the selectivity of $\mathrm{CO}_{2}$ conversion. Normally, $\mathrm{Cu}(111)$ facet prefers to produce $\mathrm{C}_{1}$ products while $\mathrm{Cu}(100)$ facet prefers to convert $\mathrm{CO}_{2}$ to $\mathrm{C}_{2}$ products. That is why much research focus on $\mathrm{Cu}(100)$ now.

iii) The reaction to produce $\mathrm{C}_{2}$ products is $\mathrm{pH}$ sensitive. $\mathrm{C}_{2}$ products can be produced with high yield under higher $\mathrm{pH}$ value. The situation is corresponding with our former finding that longer nanowire may lead to higher $\mathrm{C}_{2}$ yield. 
iv) It is useful to dope suitable atoms into $\mathrm{Cu}$-based catalysts to change its electrical structure or space structure to further improve the efficiency and selectivity of the catalysts.

v) In reality, making a single proton-electron pair transfer to * $\mathrm{CO}$ intermediates to form $* \mathrm{CHO} / * \mathrm{COH}$ could promote the occurrence probability of coupling to other $* \mathrm{CO}$ derived intermediates. 


\section{Reference}

[1] Yang, Y., Zhang, Y., Hu, J. S., \& Wan, L. J. Progress in the Mechanisms and Materials for $\mathrm{CO}_{2}$ Electroreduction toward $\mathrm{C}_{2+}$ Products. Acta Phys.-Chim. Sin. 2020, 36 (1):1-13.

[2] Kortlever, R., Shen, J., Schouten, K. J. P., Calle-Vallejo, F., \& Koper, M. T. (2015). Catalysts and reaction pathways for the electrochemical reduction of carbon dioxide. The journal of physical chemistry letters, 6(20), 4073-4082.

[3] Ma, M., Djanashvili, K., \& Smith, W. A. (2016). Controllable hydrocarbon formation from the electrochemical reduction of $\mathrm{CO}_{2}$ over $\mathrm{Cu}$ nanowire arrays. Angewandte chemie international edition, 55(23), 6680-6684.

[4] Montoya, J. H., Peterson, A. A., \& Nørskov, J. K. (2013). Insights into C-C Coupling in $\mathrm{CO}_{2}$ Electroreduction on Copper Electrodes. ChemCatChem, 5(3), 737-742.

[5] Nie, X., Esopi, M. R., Janik, M. J., \& Asthagiri, A. (2013). Selectivity of $\mathrm{CO}_{2}$ reduction on copper electrodes: the role of the kinetics of elementary steps. Angewandte Chemie International Edition, 52(9), 2459-2462.

[6] Xiao, H., Cheng, T., Goddard III, W. A., \& Sundararaman, R. (2016). Mechanistic explanation of the $\mathrm{pH}$ dependence and onset potentials for hydrocarbon products from electrochemical reduction of $\mathrm{CO}$ on $\mathrm{Cu}(111)$. Journal of the American Chemical Society, 138(2), 483-486.

[7] Liu, X., Schlexer, P., Xiao, J., Ji, Y., Wang, L., Sandberg, R. B., ... \& Hahn, C. (2019). pH effects on the electrochemical reduction of $\mathrm{CO}_{(2)}$ towards $\mathrm{C}_{2}$ products on stepped copper. Nature communications, 10(1), 1-10.

[8] Cheng, T., Xiao, H., \& Goddard III, W. A. (2015). Free-energy barriers and reaction mechanisms for the electrochemical reduction of $\mathrm{CO}$ on the $\mathrm{Cu}(100)$ surface, including multiple layers of explicit solvent at pH 0. The journal of physical chemistry letters, 6(23), 4767-4773.

[9] Zheng, Y., Vasileff, A., Zhou, X., Jiao, Y., Jaroniec, M., \& Qiao, S. Z. (2019). Understanding the roadmap for electrochemical reduction of $\mathrm{CO}_{2}$ to multi-carbon oxygenates and hydrocarbons on copper-based catalysts. Journal of the American Chemical Society, 141(19), 7646-7659.

[10] Garza, A. J., Bell, A. T., \& Head-Gordon, M. (2018). Mechanism of $\mathrm{CO}_{2}$ reduction at copper surfaces: Pathways to $\mathrm{C}_{2}$ products. Acs Catalysis, 8(2), 1490-1499.

[11] Mistry, H., Varela, A. S., Bonifacio, C. S., Zegkinoglou, I., Sinev, I., Choi, Y. W., ... \& Cuenya, B. R. (2016). Highly selective plasma-activated copper catalysts for carbon dioxide reduction to ethylene. Nature communications, 7, 12123.

[12] Vasileff, A., Xu, C., Jiao, Y., Zheng, Y., \& Qiao, S. Z. (2018). Surface and interface engineering in copper-based bimetallic materials for selective $\mathrm{CO}_{2}$ electroreduction. $\mathrm{Chem}, 4(8)$, 1809-1831.

[13] Li, C. W., Ciston, J., \& Kanan, M. W. (2014). Electroreduction of carbon monoxide to liquid fuel on oxide-derived nanocrystalline copper. Nature, 508(7497), 504.

[14]Weng, Z., Jiang, J., Wu, Y., Wu, Z., Guo, X., Materna, K. L., ... \& Wang, H. (2016). Electrochemical $\mathrm{CO}_{2}$ reduction to hydrocarbons on a heterogeneous molecular $\mathrm{Cu}$ catalyst in aqueous solution. Journal of the American Chemical Society, 138(26), 8076-8079. 
[15] Peterson, A. A., Abild-Pedersen, F., Studt, F., Rossmeisl, J., \& Nørskov, J. K. (2010). How copper catalyzes the electroreduction of carbon dioxide into hydrocarbon fuels. Energy \& Environmental Science, 3(9), 1311-1315.

[16]Schneider, J., Jia, H., Muckerman, J. T., \& Fujita, E. (2012). Thermodynamics and kinetics of $\mathrm{CO}_{2}, \mathrm{CO}$, and $\mathrm{H}^{+}$binding to the metal centre of $\mathrm{CO}_{2}$ reduction catalysts. Chemical Society Reviews, 41(6), 2036-2051.

[17] Savéant, J. M. (2008). Molecular catalysis of electrochemical reactions. Mechanistic aspects. Chemical Reviews, 108(7), 2348-2378.

[18] Lin, S., Diercks, C. S., Zhang, Y. B., Kornienko, N., Nichols, E. M., Zhao, Y., ... \& Chang, C. J. (2015). Covalent organic frameworks comprising cobalt porphyrins for catalytic $\mathrm{CO}_{2}$ reduction in water. Science, 349(6253), 1208-1213.

[19] Montoya, J. H., Peterson, A. A., \& Nørskov, J. K. (2013). Insights into C-C Coupling in $\mathrm{CO}_{2}$ Electroreduction on Copper Electrodes. ChemCatChem, 5(3), 737-742.

[20] Zhu, W., Zhang, L., Yang, P., Hu, C., Dong, H., Zhao, Z. J., ... \& Gong, J. (2018).

Formation of Enriched Vacancies for Enhanced $\mathrm{CO}_{2}$ Electrocatalytic Reduction over $\mathrm{AuCu}$ Alloys. ACS Energy Letters, 3(9), 2144-2149. 